\title{
Cardiovascular adjustments to gravitational stress
}

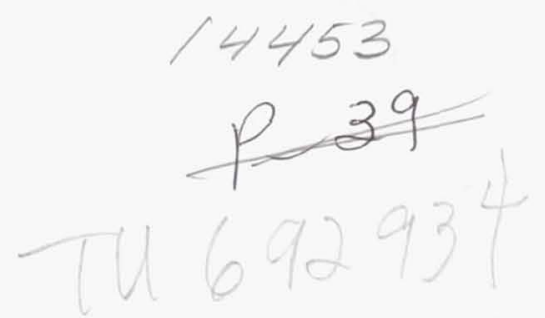

\section{GUNNAR BLOMQVIST}

H. L OWELL STONE
Departments of Internal Medicine (Cardiology) and Physiology, Weinberger Laboratory for Cardiopulmonary Research, Southwestern Medical School, University of Texas Health Science Center, Dallas, Texas

Department of Physiology and Biophysics, University of Oklahoma Health Science Center, Oklahoma City, Oklahoma

\section{CHAPTER CONTENTS}

Hydrostatic Pressure

Models

Hydrostatic indifference point

Transmural pressure and tissue filtration

Immediate Cardiovascular Responses to Posture Changes and Blood Volume Redistribution

Experimental conditions

Lower-body negative pressure

Passive tilt

Immersion

G-suit devices

Lower-body positive pressure

Blood volume and distribution

Intravascular and intracardiac pressures

Cardiac dimensions and pump performance

Cardiac output

Regional flow

Brain

Myocardium

Skin and muscle

Splanchnic region

Kidneys

Postural effects on hemodynamic responses to exercise

Dynamic responses to posture changes

Regulatory mechanisms

Systemic responses

Cardiovascular Adaptation to Prolonged Bed Rest, Zero Gravity, and Related Conditions

Experimental conditions

Bed rest

Head-down tilt

Immersion

Zero gravity

Body composition

Blood volume

Cardiovascular function

Maximal oxygen uptake

Cardiac dimensions and performance

Systemic hemodynamics

Orthostatic intolerance

Dynamic responses

Hypergravic Conditions

Experimental conditions

Fluid shifts
Cardiac dimensions and performance

Cardiac output and regional flow

Pulmonary blood flow

Brain

Splanchnic and muscle blood flow

Dynamic responses and reflex adjustments

THE EFFECTS OF GRAVITY on the cardiovascular system must be taken into account whenever a hemodynamic assessment is made. All intravascular pressures have a gravity-dependent hydrostatic component. The interaction between the gravitational field, the position of the body, and the functional characteristics of the blood vessels determines the distribution of intravascular volume. In turn this distribution largely determines cardiac pump function.

Multiple control mechanisms are activated to preserve optimal tissue perfusion when the magnitude of the gravitational field or its direction relative to the body changes. Humans are particularly sensitive to such changes because of the combination of their normally erect posture and the large body mass and blood volume below the level of the heart. Current aerospace technology also exposes human subjects to extreme variations in the gravitational forces that range from zero during space travel to as much as nine-times normal during operation of high-performance military aircraft. This chapter therefore emphasizes human physiology.

\section{HYDROSTATIC PRESSURE}

\section{Models}

Hydrostatic pressure is a force acting in a fluid system as a result of a gravitational field. The hydrostatic pressure is a static pressure in both open and closed fluid systems and is added to other forces generated in the system. In the cardiovascular system 
the action of the heart generates a dynamic pressure. The elastic properties and the pressure-volume characteristics of the peripheral vascular compartment modify both the dynamic and the static pressure components.

The various pressure components and their interactions are considered in a series of models of increasing complexity, starting with a simple, rigid, open cylinder. Such a cylinder of height $h$, filled with fluid of density $\rho$, has forces acting in various directions unless the fluid is completely at rest. At rest the major force acting on the fluid is a static pressure force generated by the gravitational field and directed perpendicularly to the earth's surface. The difference between the pressure at $h$ and that at the surface of the fluid is directly proportional to $h$. This result can be derived by considering the balance of forces acting on some horizontal plane in the fluid (55). This force at rest is strictly vertical, implying that the horizontal components of the pressure force balance. The vertical pressure is therefore independent of the horizontal position in the cylinder. The weight of an element in the fluid at $h$ must be balanced by an upward pressure force at the bottom of the plane. This force is greater than the downward pressure force at the top. If $A$ is the cross-sectional area of the horizontal plane and if $\mathrm{P}_{1}$ and $\mathrm{P}_{2}$ are the pressures acting on the bottom and top, respectively (Fig. 1), then the net upward force on the horizontal plane is $\left(\mathrm{P}_{1}-\mathrm{P}_{2}\right) A$. This pressure force equals the downward-acting weight of the fluid above the horizontal plane. The downward-acting force of the fluid equals the product of $\rho$, the volume $\left(A h^{\prime}\right)$, and the force of gravity $(g)$. Thus

$$
\begin{gathered}
\left(\mathrm{P}_{1}-\mathrm{P}_{2}\right) A=\rho g A h^{\prime} \\
\mathrm{P}_{1}-\mathrm{P}_{2}=\rho g h^{\prime}
\end{gathered}
$$

If $\mathrm{P}_{2}$ is atmospheric $\left(\mathrm{P}_{\mathrm{A}}\right)$, the surface of the tank is at $h=0$, and in the fluid $h$ is negative, the pressure anywhere in the tank $(\mathrm{P})$ is

$$
\mathrm{P}=\mathrm{P}_{\mathrm{A}}-\rho g h
$$

As the depth below the surface of the tank increases, the pressure force increases. The pressure in Equation 2 is the hydrostatic pressure for a fluid at rest in a rigid tank (55).

When the same cylinder is closed rigidly at both ends and filled with fluid until all air is excluded, the pressure at the top of the cylinder is negative and approximately one-half of the pressure in the cylinder shown in Figure $1 A$. The pressure at the bottom is equally large but of the opposite sign (Fig. $1 B$ ) and $\mathrm{P}$ $=0$ at $0.5 h$. The elastic properties of the circulatory system are disregarded by this model. Replacing both rigid ends of the closed cylinder with elastic membranes of identical properties results in a set of circumstances similar to those in the rigid, closed model (Fig. $1 C)$. When one end of the cylinder is closed with an elastic material more rigid than that at the opposite end, however, the point in the fluid at which the

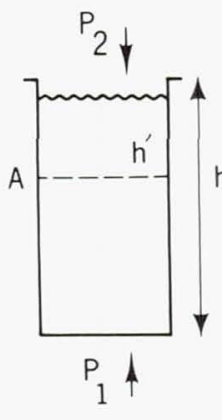

A

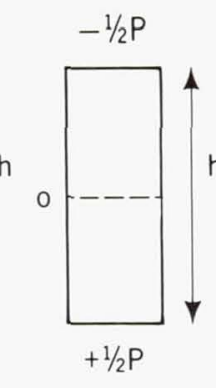

B

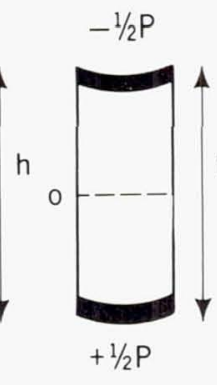

C

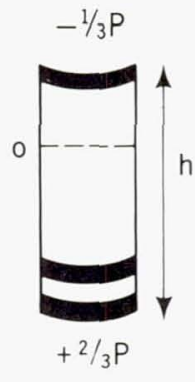

D
FIG. 1. Hydrostatic pressures (P) in simple fluid-filled systems of height h. Relationship of hydrostatic pressure and zero in cylinder open to atmosphere $(A)$ and cylinders closed at both ends with rigid membranes $(B)$, with membranes of equal elasticity at both ends $(C)$, and with membrane more elastic at upper end $(D)$.

hydrostatic pressure is zero moves toward the less rigid end. The magnitude of the shift in the zero point depends on the elastic properties of the ends of the cylinder (62). Including a pump in the system (e.g., heart in circulatory tree) does not change the location of the zero hydrostatic pressure point in the system but adds an additional pressure component (dynamic pressure). Thus the pressure at the top of the cylinder in Figure $1 D$ equals the sum of $-1 / 3 \mathrm{P}$ and the pressure generated by the pump.

When the cylinder is closed at both ends (Fig. 1C, $D$ ), the hydrostatic pressure at the bottom differs from that expected in an open-ended cylinder. The pressure difference between the top and the bottom corresponds to the full effective hydrostatic pressure of the open system given in Figure $1 A$, but part of the column in the closed system in Figure $1 C$ is suspended from the top of the cylinder and exerts a negative pressure there. Only a portion of the total pressure difference between top and bottom is positive at the bottom of the cylinder.

In summary, three components contribute to a pressure measured anywhere within a closed fluid system, e.g., the cardiovascular system. The first component is the hydrostatic pressure, which in a stable body position is static. The complex second component reflects overall and regional elastic properties of the blood vessels, particularly the pressure-volume relationships of the veins. In general it is a static pressure but changes when the characteristics of the system are altered. The third component is the dynamic pressure that the heart generates.

\section{Hydrostatic Indifference Point}

One would assume from these considerations that during postural changes intravascular pressures in dependent regions would rise, intravascular pressures in superior regions would fall, and pressure at some intermediate point would remain constant. Pressure measurements have been made in dead and in anesthetized animals during changes from the horizontal 
to the head-up and head-down positions (61, 83, 135, 225,308 ). Clark et al. (61) measured intravenous pressure at several sites in dead animals. When the animals were tilted from the horizontal position either head up or head down, the equilibrium pressure equaled the sum of the hydrostatic pressure generated by the new position and the static pressure measured in the horizontal position. When the catheter tip was $\sim 6 \mathrm{~cm}$ below the heart, the hydrostatic pressure was independent of body position. This point has been referred to as the hydrostatic indifference point (HIP) for the measurement of venous pressure. Anesthetized dogs produced similar results, but the HIP was $12 \mathrm{~cm}$ below the heart. This implies that the autonomic nervous system and changes in venous tone can influence the anatomical location of the HIP. In either case headup tilt decreased and head-down tilt increased intracardiac pressures. However, changing the position of the HIP changes the magnitude of the pressure change at any intravascular site as a result of postural change. Guyton and Greganti (135) repeated the studies of Clark et al. (61). They placed a catheter in the right atrium and then changed the position of the tip until changes in body position produced no changes in pressure. The apparatus they used allowed them to define the position of the HIP relative to the three major axes of the body. The HIP was located within the right ventricle (Fig. 2) immediately below the level of the tricuspid valve. Interventions like reduction of blood volume, epinephrine infusion, and destruction of the spinal cord did not alter the anatomic location of the HIP for venous pressures but affected the position of the HIP for the arterial system (308). Guyton and Greganti (135) postulated that the venous HIP was located within the heart to maintain stable ventricular filling pressure and cardiac output during changes in body position. Stroke volume, however, decreases by about $30 \%$ in humans tilted from the horizontal to the head-up position $(224,260,345)$ mainly because of changes in ventricular filling pressures. Thus a species difference in the response to postural changes exists. Direct measurements suggest that the anatomical location of the HIP in humans is outside the heart. Gauer and Thron (110) defined, by measurements in the horizontal position and during

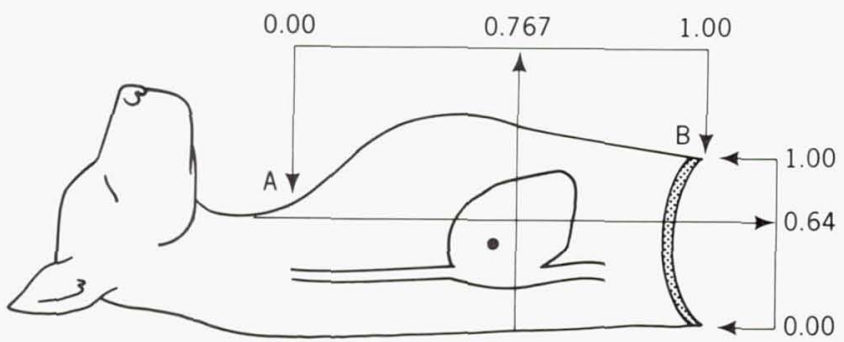

FIG. 2. Hydrostatic indifference point (HIP) in anesthetized dog is in right ventricle. $A$ : sternal notch; $B$ : xiphoid process. Distance between reference points is 1.00; coordinates of HIP are fractions. [Adapted from Guyton and Greganti (135).] head-up tilt, a venous HIP site a few centimeters below the diaphragm. Progressive head-down tilt initially caused the expected increase in cardiac filling pressures, but later it caused a paradoxical fall, implying a shift in HIP from a position below the heart to a position above the atria.

Factors such as the compliance, volume, and size of the components of the venous system determine the anatomical position of the HIP. Any change from basal conditions that affects one or more of these factors is likely to alter the position of the HIP. The pressure-volume curves of isolated veins are nonlinear and shift in response to physiological stimuli (109, 118, 185), whereas the effective systemic vascular pressurevolume relationship (as defined by volume infusion and withdrawal in intact subjects) approaches linearity (80). The pressure-volume characteristics, either through a pure volume change or through a change in the characteristics of the vessel wall (compliance), may change to a different extent in different regions. The position of the HIP theoretically should shift away from the region with a decrease in compliance. However, Guyton and Greganti (135) found that neither hemorrhagic volume depletion nor denervation by spinal ablation affected the position of the HIP in anesthetized dogs. The results are difficult to explain unless there were offsetting compliance changes caused by a combination of alterations in volume and in neural and myogenic control.

\section{Transmural Pressure and Tissue Filtration}

The three components of the pressure measured anywhere in the vascular system may be restated as 1) the hydrostatic pressure caused by the force of gravity, 2) the static filling pressure of the resting circulation $(61,134,140)$, and 3 ) the dynamic pressure from the relationship between blood flow and resistance (229). The properties of the tissues surrounding the blood vessels and their effects on the relationship between intravascular and transmural pressures in the various portions of the vascular system should also be considered. This particularly applies to the low-pressure portions of the vascular system. The transmural pressure $\left(\mathrm{P}_{\mathrm{T}}\right)$ is

$$
\mathrm{P}_{\mathrm{T}}=\mathrm{P}_{\mathrm{i}}-\mathrm{P}_{\mathrm{e}}
$$

where $\mathrm{P}_{\mathrm{i}}$ is the intravascular pressure and $\mathrm{P}_{\mathrm{e}}$ is the extravascular pressure. In Hydrostatic Indifference Point, p. 1026, the change in intravascular pressure with changes in body position is discussed in reference to the HIP. The effect of the gravitational field on the pressure forces outside of the vascular compartment, however, must also be taken into account. Changes in these forces may dramatically alter the effect of changes in the intravascular hydrostatic pressure component.

The tissues surrounding most of the blood vessels in the mammal are composed of $70 \%$ water, which has a specific gravity of 1 . Because the outer covering of 
the body has elastic properties, it may serve as a pressure garment under many conditions. In addition many of the blood vessels pass through cavities that do not connect directly with the outside environment. Because the body is mostly water, these cavities may be expected to behave like fluid-filled systems. Changes in body position within a gravitational field would be expected to alter the pressure in these tissues in direct proportion to the vertical height of the fluid columns. From Equation 2 the expected gradient in hydrostatic pressure composed mostly of water equals $1 \mathrm{cmH}_{2} \mathrm{O} / \mathrm{cm}$ of vertical height above or below the reference level.

Extravascular pressure changes with varying body position have been measured in the cerebrospinal fluid compartment $(139,216,217)$ and the abdominal cavity (284). The extravascular pressure in these systems also changes with gravitational force and modifies the effective vascular pressure, i.e., the transmural pressure. In the cerebrospinal fluid system the HIP in normal subjects is located between $\mathrm{C}_{7}$ and $\mathrm{T}_{5}$ in the spinal column. This location, which is similar to that of the venous HIP, tends to minimize postural changes in effective transmural vascular pressures within the central nervous system. Pressure has been measured in the pleural and pericardial cavities in conjunction with simultaneous measurements of vascular pressures in experimental animals $(9-11,68)$. The intravascular pressures in the right and left atrium decreased in the head-up and head-down positions more than in the supine position (Fig. 3). This would indicate that cardiac filling pressure decreased in both the head-up and head-down position because of the hydrostatic column of blood. Pressures in the pleural and pericardial cavity, however, responded similarly, and transmural cardiac pressures did not change significantly.

Changes in body position would greatly affect capillary fluid filtration if changes of similar magnitude in the extravascular pressures did not counteract the changes in intravascular hydrostatic pressure. In addition regulatory mechanisms at the microvascular level control the tissue filtration rate. The important

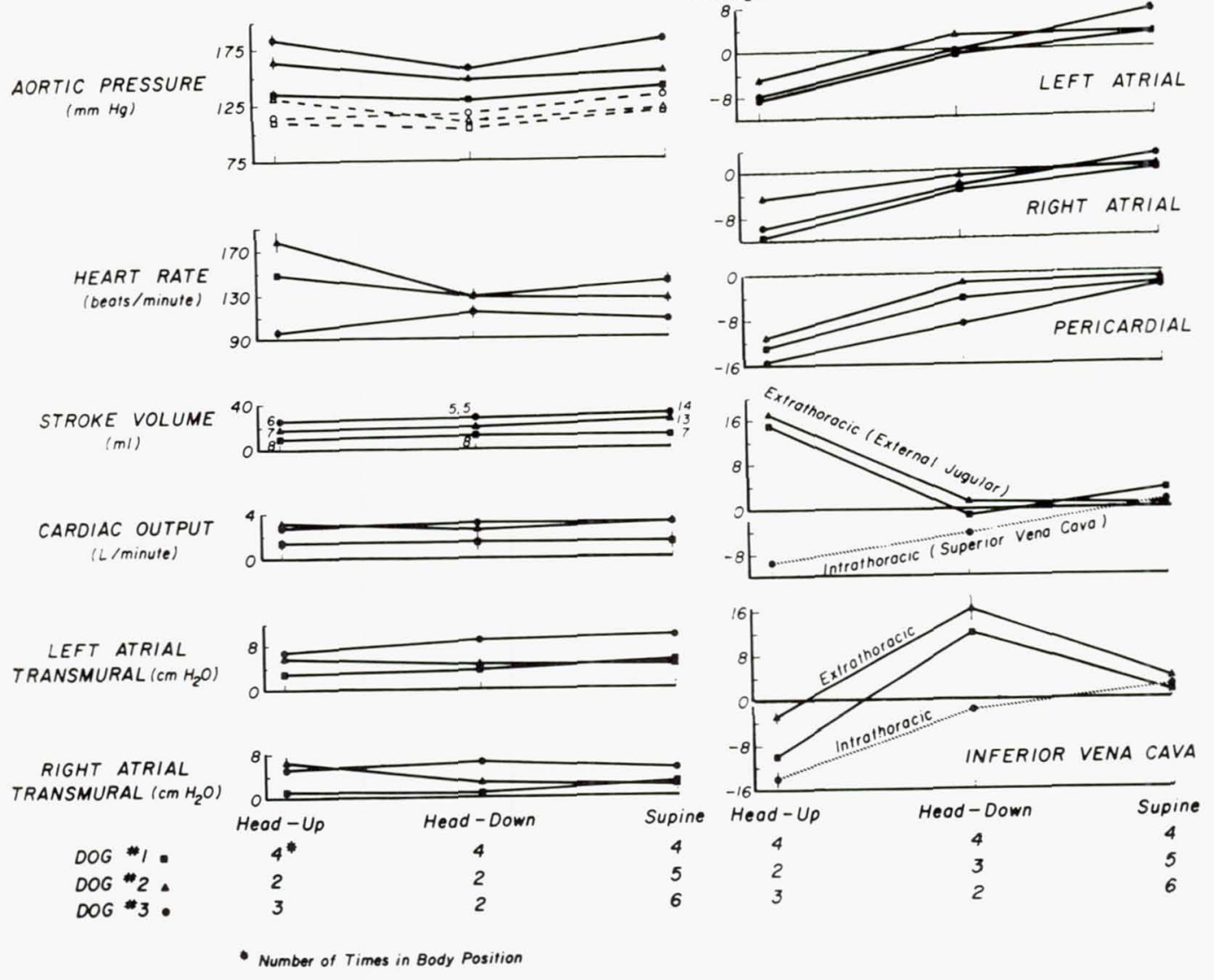

FIG. 3. Intrathoracic and venous pressure relationships and hemodynamic responses to changes in body position. Averages of right and left atrial transmural pressures, cardiac output, stroke volume, heart rate, and systemic pressures (left) and average abdominal vena cava, external jugular, pericardial, and right and left atrial pressures (right) in supine, head-down, and head-up position in 3 dogs. Adjacent to curves for stroke volume, number of cardiac-output measurements. [From Avasthey and Wood (11).] 
role of venous pressure $\left(\mathrm{P}_{\mathrm{v}}\right)$ in determining capillary pressure $\left(\mathrm{P}_{c}\right)$ can be stated as

$$
P_{c}=P_{v}+R_{v} \cdot \frac{P_{a}-P_{v}}{R_{a}-R_{v}}
$$

where $P_{a}$ is arterial pressure, $R_{a}$ is arterial resistance, and $R_{v}$ is venous resistance $(136,169)$. Maintenance of $\mathrm{P}_{\mathrm{c}}$ determines the bulk movement of fluid in and out of the capillary network. Recent data $(165,235)$ suggest that local adjustments in the relationship of pre- to postcapillary resistance are important in the microvascular response to changes in hydrostatic loading. The local response of the pre- and postcapillary vessels may include a myogenic component of the smooth muscle cells of the vessel wall (168). The principal autoregulatory adjustments occur on the arteriolar rather than the venous side. The relative contribution of metabolic and myogenic mechanisms may be different in different vascular beds (168). A change from the supine to the upright position does not normally increase extracellular fluid in dependent regions enough to produce manifest edema. Transmural pressure tends to remain constant; any change is offset by an alteration in the pre- to postcapillary resistance to maintain $\mathrm{P}_{c}$. In conditions such as heart failure, where dependent edema can occur, the underlying cause is the increase in the dynamic value of $\mathrm{P}_{\mathrm{v}}$.

Evidently several mechanisms modify the hydrostatic effects of posture changes in many regions of the cardiovascular system. The best example of a simple hydrostatic system in the human is the pulmonary circulation. Regional pulmonary blood flow in normal individuals at rest depends on the pressure in the pulmonary artery generated by the heart (dynamic pressure) and the hydrostatic pressure gradient in the column of blood in the lungs (static pressure). West (352) has convincingly shown that in the upright position the blood flow to the apex of the lung is less than the blood flow to the base of the lung. In the supine position the gradient in flow is from the superior (anterior) to the dependent (posterior) regions. Coulam and Wood (68) have found a simple hydrostatic fluid pressure gradient in the pleura as body position changes. These two findings imply that transmural pressure in the lungs varies with changes in the height of the hydrostatic fluid column relative to a reference point. Blood enters the system near the center of each lung, and this level may serve as a reference point. Increasing the gravitational field should accentuate the regional differences in pressure and flow in the direction of the gravitational force vector. Conversely, removing the gravitational force should shift pressure and flow toward superior regions, such as the apex in the upright position. This hypothesis has been tested by exposing humans to $0 \mathrm{~g}$ in a high-performance aircraft during parabolic flight (322). Pulmonary blood flow, measured with macroaggregated human serum albumin injected before and during the parabolic flight profile, was higher in the apical regions of the lungs (Fig. 4) during $0 \mathrm{~g}$ than during a seated 1-g control period.

IMMEDIATE CARDIOVASCULAR RESPONSES TO POSTURE CHANGES AND BLOOD VOLUME REDISTRIBUTION

\section{Experimental Conditions}

The principal hemodynamic effect of posture change is redistribution of venous volume with marked secondary changes in ventricular filling and stroke volume. The magnitude of the volume shift is an important determinant of the physiological response. Experimental procedures that cause reproducible and quantifiable redistribution of volume are essential to the study of cardiovascular responses. Skeletal muscle activity in the legs markedly affects venous pressures and volumes $(213,214,264)$. Muscle activity is difficult to control and monitor during standing. Studies of the mechanisms producing orthostatic cardiovascular changes in humans have therefore often been based on alternate methods that approximate the degree of venous pooling during standing but minimize muscle activity.

LOWER-BODY NEGATIVE PRESSURE. In aerospace medicine lower-body negative pressure (LBNP) has been used extensively as a research tool and clinical method (355). It has the inherent advantage of producing a gravity-independent redistribution of venous volume, and during space flight it can uncover changes in orthostatic tolerance (172). Furthermore during LBNP the subject remains at rest in the supine position, which facilitates physiological measurements and minimizes the likelihood of confounding activity in skeletal muscle. Measuring changes in leg volume is easy and can provide at least a semiquantitative measure of shifts in venous volume. Many different LBNP devices have been constructed, including metal cylinders and hemicylinders and wooden boxes. The bottom of the low-pressure chamber is usually fitted with a saddle to prevent movement into the device during suction. A rubber or plastic seal surrounds the subject and attaches to the opening of the LBNP chamber. The effective level of the seal is usually about the iliac crests. A commercial vacuum cleaner can produce the vacuum. A system including valves and a pressure gauge automatically or manually regulates the pressure. The degree of venous pooling is proportional to the negative pressure. In general LBNP at $-50 \mathrm{mmHg}$, standing, and head-up tilt at $+70^{\circ}$ similarly change heart rate and systolic pressure (355).

PASSIVE TILT. During passive tilt the subject rests on a table that can be rotated around an axis corresponding to a transverse body diameter, preferably at a level approximating the body's center of mass. A restraint system including a saddle prevents longitudinal changes in body position. The position of the table 
FIG. 4. Regional pulmonary blood flow at 1 $g$ and $0 \mathrm{~g}$ at various lung levels. Measured in volunteer by injecting radioactive tracer during $0 \mathrm{~g}$ and in seated position at $1 \mathrm{~g}$. Note flow shifts toward apex of lungs. Similar results in 6 subjects. Zero distance, apex of lung; opposite end of scale, toward base of lung. Top: control measurements; Bottom: 0-g measurements.
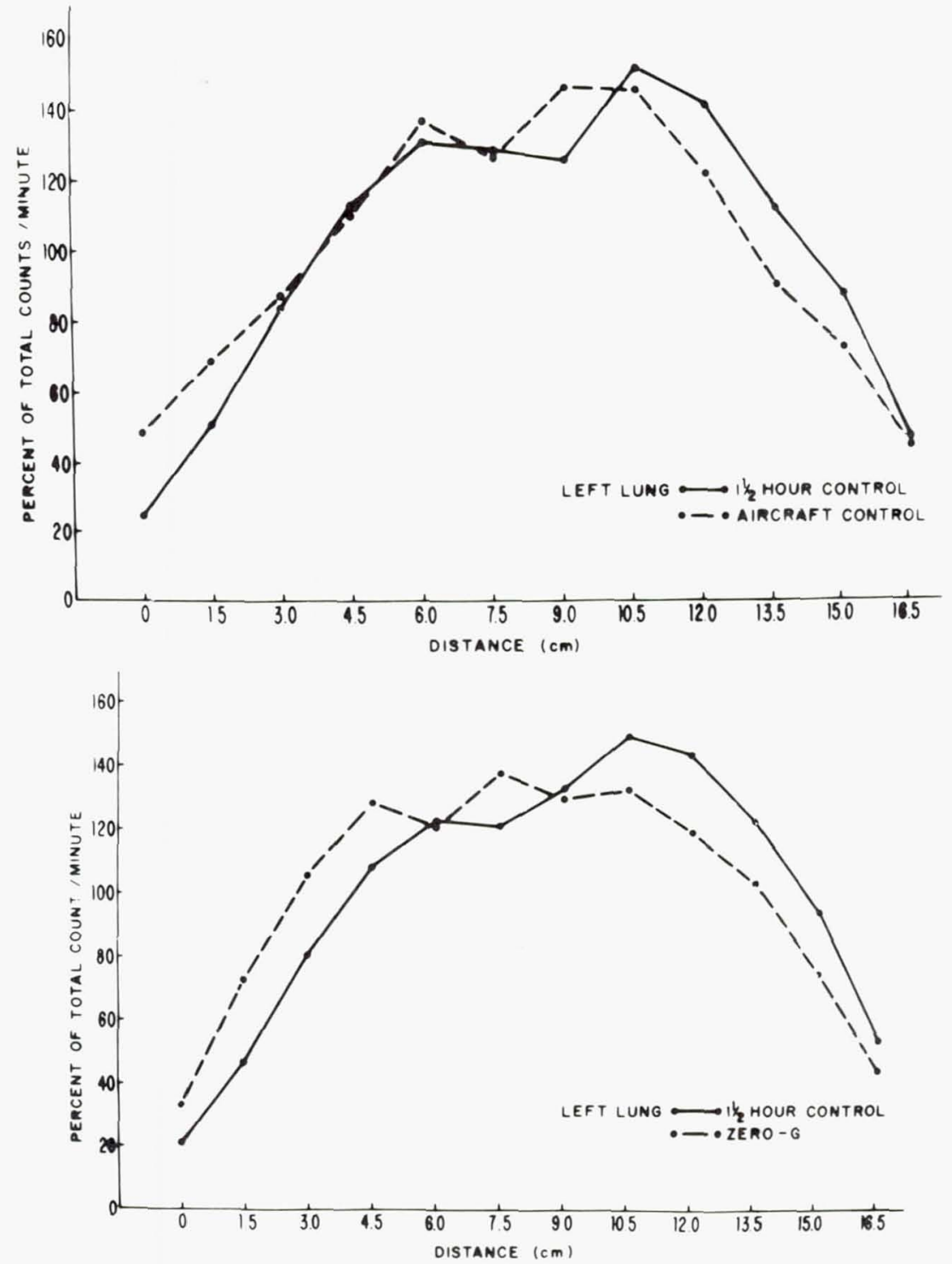

and the subject is usually specified in terms of angular deviation from the horizontal plane, positive for headup and negative for head-down positions. The direct hydrostatic effects are proportional to the sine of the angle between the table and the horizontal plane, i.e., $+30^{\circ}$ produces $50 \%$ and $+75^{\circ}$ as much as $95 \%$ of the effects of a full $90^{\circ}$ change from supine to upright.

IMMERSION. This intervention produces a marked central fluid shift. Water immersion has been used extensively as a therapeutic agent (hydrotherapy) since the beginning of history. More recently immersion has been applied to investigate the renal effects of a central redistribution of blood volume $(16,17,87-$ $90,105,108)$ and to simulate zero gravity $(121,122)$.

Epstein (87) has recently reviewed the technical and physiological aspects of immersion in detail, including conditions that may modify the cardiovascular response. The temperature of the bath is critical. Ther- moregulatory mechanisms disturb the hydrostatic effects if the bath is not thermoneutral, i.e., kept at $33^{\circ} \mathrm{C}-35^{\circ} \mathrm{C}$. Water is the common medium, but silicone fluid and saline minimize fluid exchange across the skin and prevent skin lesions due to maceration. The external application of hydrostatic pressure alters respiratory mechanics. Upright immersion is equivalent to negative-pressure breathing, which by itself has significant cardiovascular and renal effects that are directionally similar to the primary vascular hydrostatic effects.

G-SUIT DEVICES. Systems with inflatable rubber bladders compressing the legs and the abdomen, called $\mathrm{G}$ suits, have been widely used in aviation and recently also in emergency medicine to prevent venous pooling and produce a central blood volume shift in hypovolemic shock. Recent hemodynamic studies (103) have shown, however, that the primary effect is an increase 
of systemic resistance rather than an increase in ventricular filling.

LOWER-BODY POSITIVE PRESSURE. Applied with a chamber analogous to an LBNP apparatus, lowerbody positive pressure (LBPP) has been used to study the renal and hormonal responses to a central fluid shift in primates (239).

\section{Blood Volume and Distribution}

Total blood volume in mammals is an essentially linear function of total body weight, but there are fairly large species differences. Physically active animals generally have larger volumes than inactive animals. Mean values in normal adult humans cluster around $75 \mathrm{ml} / \mathrm{kg}$ body wt, or 5-5.5 liters for a $70-\mathrm{kg}$ man. Sources of interindividual variations include body composition, age, climate, and physical activity (306).

Available estimates on the normal distribution of blood volume in the human are based on incomplete regional measurements and extrapolation from more precise measurements in experimental animals. Approximately $70 \%$ of the total blood volume is contained in the systemic veins; the heart and lungs account for about $15 \%$, the systemic arteries for $10 \%$, and the capillaries for $5 \%(107,124,298,307)$. Hydrostatic pressure changes and regional variations in compliance are the primary determinants of the pattern of postural redistribution of intravascular volume. There are important modifiers, however, including the compliance of perivascular tissues, hydrostatic changes in tissue pressure, and myogenic and neurogenic effects on venous tone. Also vasomotor activity causes postural redistribution of venous volume $(48,53,254,277)$.

The term compliance is often applied without being rigorously defined. In common usage within this subject area, it is equivalent to the change in volume for a given pressure change $(\mathrm{dV} / \mathrm{dP})$ within the physiological pressure range. Nonlinearities in the pressurevolume relationship are often disregarded. The systemic veins supply most of the overall compliance of the cardiovascular system. Effective total vascular compliance, as derived from measurements of central venous pressure during acute changes in blood volume, is of the order $2-3 \mathrm{ml} \cdot \mathrm{mmHg}^{-1} \cdot \mathrm{kg}^{-1}$ body wt in the human and $\operatorname{dog}(80,108,140,189,299)$. Measuring systemic vascular compliance in the intact subject is complicated by reflex-induced hemodynamic adjustments, delayed compliance (i.e., viscoelastic creep of vessel walls), and blood volume changes caused by tissue filtration $(7,358)$. Nevertheless the low-pressure compartment of the circulation, i.e., the systemic veins, the right heart, the pulmonary circulation, and the left atrium, which together contain $85 \%$ of the total blood volume, clearly contributes an even larger percent of total vascular compliance. The pulmonary veins account for most of the lung blood volume and the total compliance of the pulmonary circuit. The pulmonary capillaries are relatively noncompliant ( 72 , $86,360)$. Total pulmonary vascular compliance in the rabbit is $\sim 0.1 \mathrm{ml} \cdot \mathrm{mmHg}^{-1} \cdot \mathrm{kg}^{-1}$ body wt (86). Compliance of the systemic arteries is lower by an order of magnitude, or $\sim 0.01 \mathrm{ml} \cdot \mathrm{mmHg}^{-1} \cdot \mathrm{kg}^{-1}$ body wt (80), which corresponds to less than $1 \%$ of the total vascular compliance.

Regional partition of the overall compliance is difficult because of nonlinearities of the basic vascular pressure-volume relationship, discontinuities in the distribution of venous pressures, and the inaccuracies inherent in in vivo measurements of regional blood volumes $(138,223,277)$. The potential of volume measurements based on scintigraphic techniques is yet to be fully explored. Pressure measurements during pneumatic compression of the lower half of the body and during upright immersion $(81,189)$ suggest that the intrathoracic component of the low-pressure system contributes about $50 \%$ of total vascular compliance.

Changing from a supine to an upright position increases venous volume of the legs by about $500 \mathrm{ml}$ (110). Most of the translocated volume is contained in the deep intra- and intermuscular leg veins $(213,214)$. Additional volume, probably $200-300 \mathrm{ml}$, is transferred to the veins in the buttocks and the pelvic area. It has been thought that the translocated volume is derived principally from the intrathoracic compartment of the low-pressure system $(110,305)$ because the hydrostatic counterpressure from the abdominal organs tends to minimize postural changes in transmural venous pressures and venous volume in the splanchnic area. Nevertheless reflex-induced splanchnic vasoconstriction (70, 354) probably produces a passive decrease in venous volume. Measurements based on radionuclear techniques suggest a large contribution also from the splanchnic region $(220,221)$.

Lower-body negative pressure at -40 to $-50 \mathrm{mmHg}$ and standing cause similar shifts in blood volume (355), but the distribution patterns within the lower half of the body are probably somewhat different. The primary pressure gradient along the longitudinal axis of the body (created by decrease in ambient pressure below seal) is stepwise rather than linear (as during standing) and is modified by the tissues surrounding the blood vessels. Wolthuis et al. (355) estimated changes in regional blood volumes and found no changes in plasma-bound isotope activity over the upper abdomen during LBNP at $-40 \mathrm{mmHg}$, whereas the mean increase in activity over the foot, calf, thigh, buttock, and pelvis equaled $24 \%, 54 \%, 49 \%, 39 \%$, and $20 \%$. This heterogeneity can be at least partially attributed to regional differences in the ratio between soft and bony tissues.

There is little quantitative information on the acute intravascular volume shifts during head-down tilt. Significant leg volume changes-as large as during orthostasis-occur during the initial hours after a change from supine to $5^{\circ}$ head-down tilt (37). The magnitude 


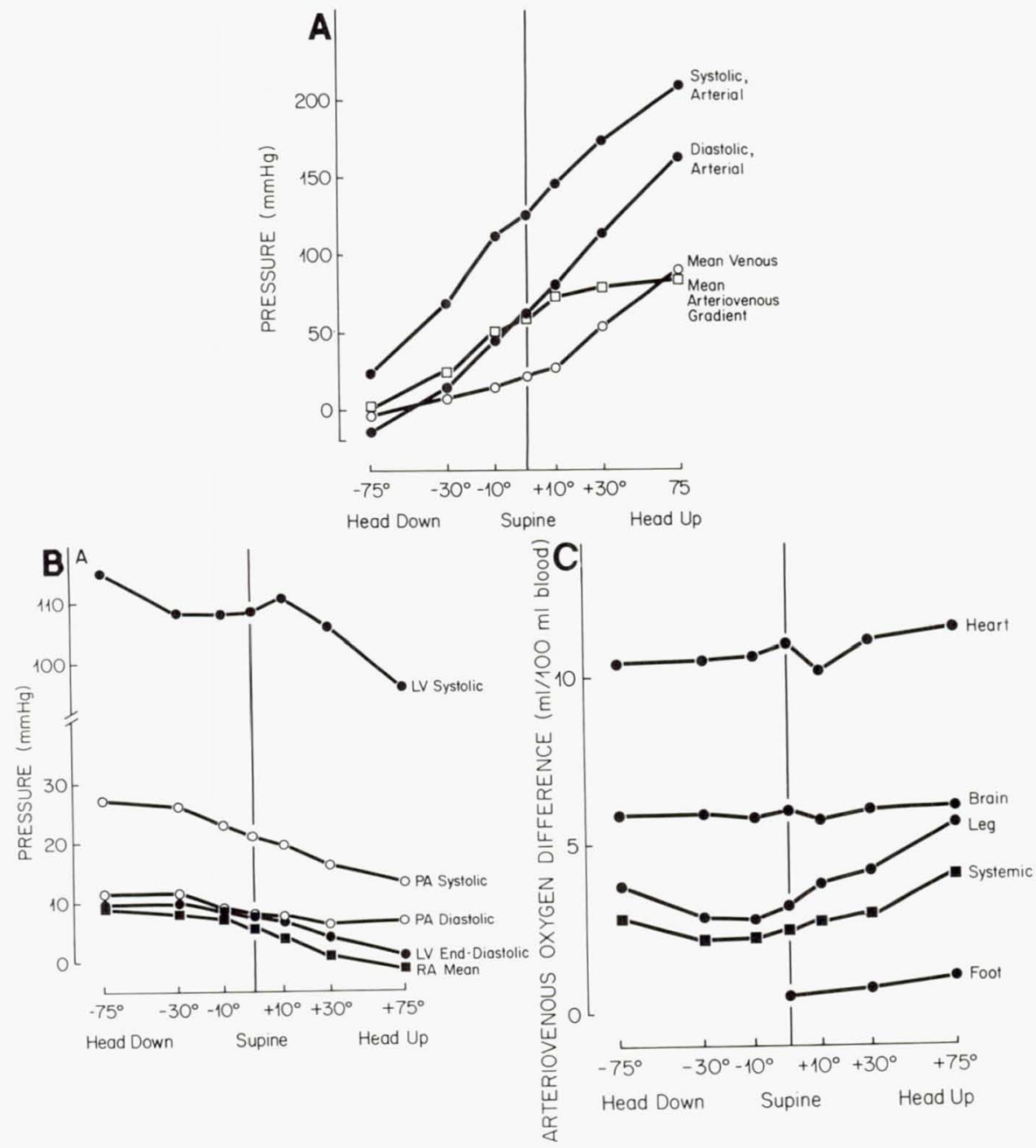

FIG. 5. Responses to graded head-up and head-down tilt in 10 humans. LV, left ventricle; PA, pulmonary artery; RA, right atrium. Intravascular pressures in foot $(A)$ and in central circulation $(B)$, and regional and systemic arteriovenous $\mathrm{O}_{2}$ differences $(C)$. Angle of tilt (horizontal axis) plotted as sine function to provide linear scale for primary hydrostatic effects of body-position changes.

[Based on data from Katkov and Chestukhin (178).]

of the fluid shift during immersion depends on depth and body position. Supine head-out immersion produces no significant acute hemodynamic effects (18) and presumably only insignificant volume shifts. Upright immersion to the level of the diaphragm abolishes the hemodynamic changes that are normally associated with standing. The hemodynamic state is similar to that at rest supine (269). Upright immersion to the level of the neck reverses the normal peripheral orthostatic redistribution of blood volume and increases central blood volume (as determined by indicator-dilution technique) by some $700 \mathrm{ml}$ (4). Farhi and Linnarsson (95) have also demonstrated progressive but nonlinear hemodynamic changes as immersion depth increased.

\section{Intravascular and Intracardiac Pressures}

Actual postural pressure changes within the arterial system closely conform to alterations in the hydro- static pressure component as predicted from the change in vertical distance between the point of pressure measurement and the reference point. Katkov and Chestukhin (178) directly measured pressure at tilt-table positions ranging from $+75^{\circ}$ head up to $-75^{\circ}$ head down (see mean data in Fig. 5). In the foot, systolic arterial pressures in these two positional extremes differed by $188 \mathrm{mmHg}$, which is remarkably close to the expected hydrostatic gradient of 195 $\mathrm{mmHg}$ (as calculated from data on distance between right atrium and foot, angle of tilt, and sp gr of blood).

Thin walls and valves make the systemic veins much more complicated than the arteries. Venous pressures in the foot of supine humans are $10-15 \mathrm{mmHg}(110$, 178). There is a decrease of $2-3 \mathrm{mmHg}$ from the foot to the inferior vena cava at the level immediately below the diaphragm. An additional sharp pressure drop of 2-3 $\mathrm{mmHg}$ accompanies entry into the thoracic cavity. A similar gradient is recorded at the thoracic inlet when a catheter is passed from the internal 
jugular vein into the superior vena cava $(9,110)$. The stepwise change in intravascular pressure has the same order of magnitude as the average negative pleural pressure during quiet respiration at rest (232), suggesting that there is little change in transmural venous pressure.

A transition from a supine to an upright position introduces significant nonlinearities. The intravenous pressure distribution (as referred to the level of the right atrium) deviates markedly from the predicted distribution in a simple and uniform closed hydrostatic system, particularly in the regions cephalad to the heart. Even at negative intravascular pressure the intracranial veins are kept open by periosteal adhesions and by parallel hydrostatic pressure changes in the cerebrospinal fluid. Pressures at the level of the thoracic inlet change from a few $\mathrm{mmHg}$ positive pressure in the supine position to about $8-10 \mathrm{mmHg}$ negative pressure in the standing position. The neck veins and even the upper part of the superior vena cava collapse in erect normal human subjects, causing a discontinuity in the pressure distribution. The jugular veins form a separate hydrostatic column within which pressures during orthostasis are independent of the right atrial pressure $(9,178)$.

Deviations from a simple hydrostatic pattern are evident also in the leg veins (Fig. 5). Early postural venous changes in the foot are significantly smaller than the corresponding arterial changes during headup and head-down tilt. The relationship of the intravenous pressure to the height of the hydrostatic column is curvilinear (178). The data suggest a partial collapse of the leg veins in the head-down position and a significant effect of the venous valves during headup tilt. However, the valves cannot support the full hydrostatic pressure in the upright position and eventually become incompetent as the veins are distended $(151,182)$. The collapse of the veins above the level of the heart is also likely to modify lower-body intravenous pressures in the upright position. Part of the venous hydrostatic column is supported by the elastic forces of the intrathoracic tissues as diagrammed in Figure $1 C$. There is no convincing evidence for venous collapse at the level of the diaphragm (110).

Immediate postural changes in mean atrial and enddiastolic ventricular pressures are essentially linearly related to the hydrostatic component over the entire range from full head-up to head-down tilt with the exception of little or no increase at an angle steeper than $-30^{\circ}$ head down (see Fig. 5). The difference between the extreme positions is about $10 \mathrm{mmHg}$. Right and left ventricular filling pressures change in parallel (178). Several investigators (21-24, 119, 120, $328,329)$ have reported similar or slightly smaller changes in filling pressures after a transition from supine to sitting or standing (Table 1) and from supine to moderate degrees of head-down tilt $(37,250)$.

These measurements of intracardiac and central venous pressures may not accurately reflect the postural changes in effective or transmural filling pres-
TABle 1. Direct Hemodynamic Measurements in Normal Subjects at Rest

\begin{tabular}{lrrc}
\hline \multicolumn{1}{c}{ Parameter } & Supine & Sitting & $P$ \\
\hline Heart rate, beats/min & $73 \pm 4$ & $84 \pm 4$ & $<0.001$ \\
Pressure, mmHg & & & \\
Brachial artery & $96 \pm 3$ & $99 \pm 4$ & \\
$\quad$ Systolic & $130 \pm 5$ & $132 \pm 5$ & \\
$\quad$ Diastolic & $76 \pm 3$ & $82 \pm 3$ & $<0.05$ \\
Pulmonary artery & $13 \pm 1$ & $13 \pm 1$ & \\
Pulmonary capillary wedge & $6 \pm 1$ & $4 \pm 1$ & $<0.001$ \\
Left ventricular end diastolic & $8 \pm 1$ & $4 \pm 1$ & $<0.001$ \\
Stroke index, ml/m ${ }^{2}$ & $50 \pm 5$ & $35 \pm 3$ & $<0.001$ \\
Cardiac index, liters $\cdot \mathrm{min}^{-1} \cdot \mathrm{m}^{-2}$ & $3.5 \pm 0.3$ & $2.8 \pm 0.2$ & $<0.001$ \\
\hline
\end{tabular}

Means \pm SE for 10 sedentary men, age 32-58. [From Thadani and Parker (328).]

sures; the effect of posture on pleural and pericardial pressures should also be considered. Such pressure changes-as discussed in HYDROSTATIC PRESSURE, $p$. 1025-have been studied in the anesthetized dog (10, 68 ). The pleura and pericardium behaved much like a simple hydrostatic system. The transmural atrial pressures recorded in the head-up and head-down position did not differ significantly, and cardiac output did not change. The extent to which these findings apply to humans is unknown. Measurements of cardiac dimensions and performance provide overwhelming, if indirect, evidence for significant postural changes in the effective filling pressures in the human. Significant concurrent changes in intrinsic or effective transmural ventricular compliance are unlikely. The different responses in intact humans and anesthetized animals may be due to different locations of the HIP, different extracardiac hydrostatic conditions, reflex activity, or a combination of these factors.

Head-out upright immersion produces an increase in central venous pressure that is proportional to the depth and that averages $10-13 \mathrm{mmHg}$ above the normal standing level $(4,81,269)$. Applying LBNP at -40 to $-50 \mathrm{mmHg}$ causes a decrease in central venous pressure similar to that during a change from the supine to upright position $(37,167,244,250,355)$.

\section{Cardiac Dimensions and Pump Performance}

The principles governing cardiac pump performance to a large extent determine the cardiovascular responses to changes in posture. Comprehensive analysis of ventricular function includes simultaneous consideration of force, velocity, and fiber length (238). The velocity axis can often be disregarded without serious loss of information in the analysis of the performance of the intact heart. The ventricular pressure-volume relationship $(133,286,324,347)$ is useful for analysis and links muscle mechanics and ventricular function. Contractile state is defined as the maximal tension or pressure that can be developed at any given fiber length or volume. Maximal ventricular pressure is normally a linear function of volume. The amount of shortening or stroke volume that can be achieved from 
any given fiber length or volume can be increased only by reducing afterload or enhancing the contractile state. Similarly an increase in the amount of shortening at a given afterload requires either an increased end-diastolic volume or an increased contractile state. Decreased filling pressure, e.g., caused by venous pooling during the transition from the supine to standing position, therefore causes stroke volume to decrease unless compensated for by an increased contractile state or decreased afterload. However, the systolic reserve capacity of the normal human heart is limited. The left ventricular ejection fraction at rest is about $70 \%$. Powerful reflex mechanisms maintain arterial pressure and afterload. A large decrease in preload therefore inevitably decreases stroke volume. Cardiac output can only be maintained by increasing heart rate.

There is ample evidence that postural changes produce significant changes in the dimensions of the heart. Studies based on single or biplane X-rays have demonstrated a decrease in total heart size after a change from the supine to standing position. Although there are fairly large interindividual variations, the average decrease in an adult normal man is $100-200$ $\mathrm{ml}$, or $10 \%-20 \%$ of normal total heart volume of up to $500 \mathrm{ml} / \mathrm{m}^{2}$ body surface area $(152,176,245)$.

More recently, noninvasive imaging methods have provided detailed data on cardiac dimensions and performance in humans. A calibrated nongeometric scintigraphic technique measured left ventricular volumes supine and sitting (Table 2). The relative change in left ventricular end-diastolic volume was of similar magnitude to that in total heart volume. Ejection fraction and end-systolic volume did not change significantly. Thus the postural decrease in stroke volume was primarily caused by a reduced preload. Nixon, Blomqvist, et al. (251) used M-mode echocardiography to study the left ventricle at supine rest, during LBNP at $-40 \mathrm{mmHg}$ and head-down tilt at $-5^{\circ}$. These interventions significantly decreased the estimated enddiastolic volume $28 \%$ during LBNP and increased it $23 \%$ during head-down tilt. There were only small changes in ejection fraction with an increase during head-down tilt and a decrease during LBNP but large

TABLE 2. Left Ventricular Dimensions and Performance at Rest

\begin{tabular}{lccc}
\hline \multicolumn{1}{c}{ Parameter } & Supine & Sitting & $P$ \\
\hline Volume, ml & & & \\
$\quad$ End diastolic & $107 \pm 10$ & $85 \pm 6$ & $<0.02$ \\
$\quad$ End systolic & $34 \pm 4$ & $32 \pm 5$ & \\
$\quad$ Stroke & $76 \pm 8$ & $55 \pm 5$ & $<0.05$ \\
Ejection fraction, \% & $76 \pm 2$ & $72 \pm 4$ & \\
Heart rate, beats/min & $71 \pm 6$ & $89 \pm 5$ & $<0.05$ \\
Arterial pressure, mmHg & & & \\
$\quad$ Systolic & $125 \pm 8$ & $125 \pm 5$ & \\
$\quad$ Diastolic & $76 \pm 4$ & $84 \pm 4$ & \\
\hline
\end{tabular}

Means $\pm \mathrm{SE}$ for 7 normal subjects. [Scintigraphic data from Poliner, Blomqvist, et al. (262), by permission of the American Heart Association, Inc.] effects on stroke volume (+35\% and $-33 \%)$. The heart rate and arterial pressures remained stable, and the velocity of circumferential fiber shortening did not change. These data are also consistent with a marked preload effect on ventricular performance with little change in contractile state. Sandler et al. (292) and Ahmad, Blomqvist, et al. (5) have reported similar results during LBNP.

Parker and Case (259) recently suggested that the normal human left ventricle operates at or near its maximal functional size at rest in the supine position, but data obtained during head-down tilt $(250,251)$, supine exercise (262), and immersion clearly indicate a diastolic reserve capacity. The increased central venous pressure during upright immersion is associated with a large increase in heart size and stroke volume $(4,18,40,81,95,195,269)$.

\section{Cardiac Output}

Thadani and Parker (328) studied hemodynamics in normal sedentary sitting and supine men (see Table 1). Many other investigators (21, 24, 119, 120, 287, 309, 345 ) have reported similar results. Stroke volume decreases in the upright position by about $33 \%$. The modest increase in heart rate does not fully compensate for the decrease in stroke volume. Therefore cardiac output decreases by about $20 \%$. Mean arterial pressure is maintained and systemic resistance increases in direct proportion to the fall in cardiac output. The systemic arteriovenous oxygen difference also increases. A change from the supine to standing position causes qualitatively similar but slightly larger hemodynamic adjustments than a change from the supine to sitting position $(23,24)$. Matalon and Farhi (224) demonstrated an inverse linear relationship between cardiac output and the sine of the tilting angle during passive head-up tilt.

Blomqvist et al. (37) found that head-down tilt at $-5^{\circ}$ does not change arterial pressure or cardiac output but produces an early and transient increase in stroke volume, which causes compensatory bradycardia. Katkov et al. (179) recorded no significant change in right ventricular end-diastolic pressure but a $15 \%$ increase in stroke volume after $15 \mathrm{~min}$ at $-20^{\circ}$ headdown tilt. There was a small increase in heart rate, and cardiac output increased by $27 \%$. The lack of change in right ventricular pressure at $-20^{\circ}$ may seem paradoxical, but experimental data indicate that a steep head-down tilt may decrease filling pressures (110). Upright immersion increases cardiac output by $30 \%$ or more, mainly because of an increase in stroke volume without any compensatory bradycardia $(4,18)$.

\section{Regional Flow}

The data on arteriovenous oxygen differences presented in Figure 1 indicate that flow to vital organs, i.e., the brain and the myocardium, remains adequate over the entire range of short-term postural chal- 
lenges. Changes in posture, however, produce a complex set of regional adjustments.

BRAIN. The oxygen uptake of the brain changes little unless there are functional disturbances of clinical significance (197). Oxygen delivery to the brain is generally well protected during gravitational stresses, perhaps better in humans than in other species (240). Several factors combine to minimize the effects of gravity during postural changes and during acceleration (146), including an efficient autoregulation of blood flow, hydrostatic pressure changes in the cerebrospinal fluid (which are likely to parallel intravascular changes, particularly in arterial pressure), and the architectural and functional characteristics of the intracranial veins. Mean arterial pressure at eye level during tilting or hemorrhage can fall below $30 \mathrm{mmHg}$ before consciousness is seriously impaired and below $25 \mathrm{mmHg}$ before syncope develops (146, 193). The basic efficiency of this system does not necessarily preclude significant postural changes in total cerebral flow (197), but Katkov, Chestukhin, et al. (178, 179) found an essentially stable arteriovenous oxygen difference over the entire range of body positions from $-75^{\circ}$ to $+75^{\circ}$ (Fig. 2).

MyocaRdium. Changes in arterial pressures, heart rate, contractile state, and ventricular dimensions during posture changes are likely to change myocardial oxygen demand and perfusion. Langou et al. (196) found that head-up tilt at $+30^{\circ}$ decreased left ventricular end-diastolic diameter, myocardial oxygen uptake, and coronary flow in dogs. The arteriovenous oxygen difference across the myocardium also decreased. Neither the heart rate nor the contractile state changed. Similar detailed data on flow and oxygen demand in the human are unavailable. Katkov and Chestukhin (178) recorded no changes in myocardial oxygen extraction in their human subjects during head-up and head-down tilt.

SKIN AND MUSCLE. The effects of postural changes on blood flow to the resting arm and leg are directionally similar to the changes in overall systemic flow. Increasing degrees of venous pooling during LBNP cause a gradual and sustained reduction of forearm flow (167, 231, 271, 362). The relative importance of muscular and cutaneous vasoconstriction is controversial. Several investigators have concluded that the orthostatic vasoconstrictor response in resting skeletal muscle probably accounts for a major portion of limb flow reduction (8, 12, 128). McNamara (231) found only transient decreases in hand blood flow (primarily cutaneous) during mild degrees of LBNP. More severe LBNP stress caused a sustained flow reduction with no quantitative relation to the degree of venous pooling. Gauer and Thron (110) reviewed several series of experiments and also concluded that the orthostatic vasoconstrictor response in the leg primarily involved skeletal muscle with little or no contribution from the cutaneous circulation. On the other hand Rowell et al.
(282) attributed the decrease in forearm flow during LBNP equally to vasoconstriction in skin and muscle, consistent with significant baroceptor-mediated effects also on the cutaneous circulation (279).

McNamara et al. (231) noted the similarity between the peripheral responses to head-up tilt and LBNP, which imply that changes in systemic flow and reflex adjustments are more important determinants of limb blood flow than the direct hydrostatic effects. However, hydrostatic effects are evident during extreme degrees of head-down tilt. Katkov and Chestukhin (178) found that blood flow to the foot approached zero in the $-75^{\circ}$ head-down position.

SPLANCHNIC REGION. The splanchnic bed is a major source from which blood flow and venous volume can be redistributed to other areas during stress. The liver and the splanchnic area contain about $25 \%$ of the total blood volume and receive an equally large portion of cardiac output at rest, but they extract less than $20 \%$ of the available oxygen (278). Progressive peripheral pooling during LBNP gradually reduces splanchnic flow. Flow rates at $-40 \mathrm{mmHg}$ are less than $70 \%$ of control $(1,167)$.

KIDNEYS. The kidneys receive about $20 \%$ of the total systemic flow at rest. Orthostatic stress significantly reduces renal plasma flow, as judged from changes in p-aminohippuric acid clearance. Head-up tilt at $45^{\circ}$ reduces renal flow to about $50 \%$ of the supine rate $(295,351)$. Gilbert et al. (113) reported a $27 \%$ reduction in effective renal plasma flow during LBNP at -60 $\mathrm{mmHg}$. In contrast the increased cardiac output during upright immersion does not consistently change renal hemodynamics $(87,88)$.

\section{Postural Effects on Hemodynamic \\ Responses to Exercise}

Many of the postural hemodynamic effects that are evident at rest persist during exercise. Cardiac output is 1-2 liters/min higher in the supine than in the sitting position at rest and during dynamic exercise involving large muscle groups, e.g., bicycle exercise $(21-24,85,328,329)$. Body position does not affect the slope of the normal linear relationship between oxygen uptake and cardiac output. An increase in oxygen uptake of 1 liter/min is associated with an increase in cardiac output of about 6 liters/min in both positions. Thus the systemic arteriovenous oxygen difference is wider in the upright than in the supine position. Total systemic resistance is higher in the upright position at rest and during low-level submaximal exercise, but the differences are abolished during heavy submaximal work (22).

Stroke volume at rest is significantly larger and heart rate is lower in the supine position, but transition from rest to exercise causes a larger stroke volume increase in the upright position $(21-24,328,345)$. Heavy leg exercise tends to abolish the positional stroke volume differences. The postural effects tend to 


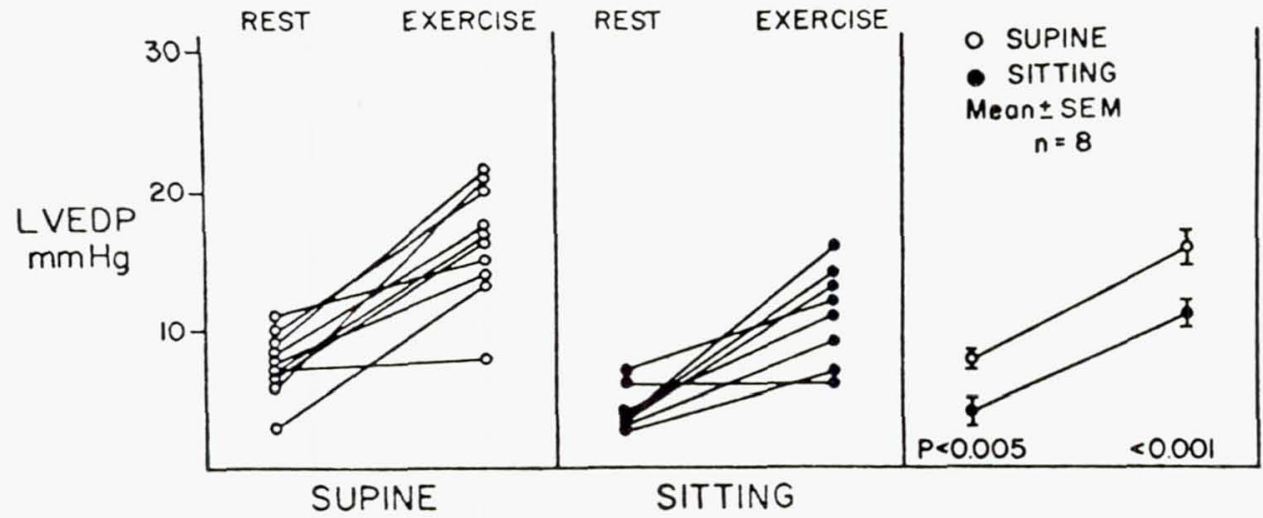

FIG. 6. Normal individual and group mean values of left ventricular end-diastolic pressure (LVEDP) in supine and sitting positions at rest and during exercise. [From Thadani and Parker (328).]

be larger during dynamic exercise with small muscle groups; e.g., arm exercise and stroke volumes are different also at maximal work levels. Relative tachycardia maintains a normal slope of the relationship between oxygen uptake and cardiac output, but absolute flows are 1-2 liters/min below supine levels also during arm exercise (22).

Right and left ventricular filling pressures are higher at rest in the supine position. According to most (85, $119,120,328)$ but not all $(117,276)$ investigators, exercise in either position progressively increases left ventricular filling pressures, but pressures remain higher in the supine position (Fig. 6). Mean right atrial and right ventricular end-diastolic pressures as referred to the atmosphere tend to remain unchanged or actually decline during exercise $(22,85)$. Mean pleural pressures, however, become increasingly negative with increasing ventilation and may average -10 $\mathrm{mmHg}$ during heavy exercise (232). This means that both right- and left-sided effective filling pressures probably increase during exercise but that the changes are larger in the left ventricle.

As discussed earlier in this section there is ample evidence that at rest left ventricular diastolic volume is larger in the supine than in the upright position. The increase in stroke volume that occurs between rest and exercise in the upright position is associated with an increase in total heart size and left ventricular end-diastolic volume $(69,152,285)$. There is general agreement that end-systolic volume decreases during exercise in both body positions $(46,69,117)$. The role of the Starling mechanism during exercise in the supine position is controversial $(46,69,117,296,311$, 348 ), however, perhaps because of methodological limitations. Poliner, Blomqvist, et al. (262), who used a quantitative nongeometric scintigraphic method to circumvent many of the problems inherent in echocardiography, contrast ventriculography, and the use of epicardial markers, found a significant increase in end-diastolic volume during supine exercise. Left ventricular end-diastolic volumes were higher in the supine position at rest as well as during submaximal and
TABLE 3. Hemodynamic Effects of Acceleration

\begin{tabular}{crrrr}
\hline Acceleration & $\begin{array}{c}\text { Cardiac } \\
\text { Output }\end{array}$ & $\begin{array}{c}\text { Heart } \\
\text { Rate }\end{array}$ & $\begin{array}{c}\text { Stroke } \\
\text { Volume }\end{array}$ & $\begin{array}{c}\text { Mean } \\
\text { Arterial } \\
\text { Pressure }\end{array}$ \\
\hline$G_{\mathrm{z}}$ & & & & \\
+2 & +7 & +14 & -24 & +9 \\
+3 & -18 & +35 & -37 & +21 \\
+4 & -22 & +56 & -49 & +27 \\
$G_{\mathrm{x}}$ & & & & \\
+2 & -12 & -2 & -10 & +11 \\
+3.5 & +9 & +17 & -7 & +18 \\
+5 & +27 & +40 & -8 & +25 \\
\hline
\end{tabular}

Effects of head-to-foot $\left(+G_{z}\right)$ and transverse gravitational force $\left(+G_{\mathrm{x}}\right)$ acceleration in 6 relaxed human volunteers. Values are \% change from control. [Data from Lindberg et al. (207, 208).]

maximal exercise. End-systolic volume was slightly smaller in the upright position, and maximal stroke volumes were similar (Table 3; Fig. 7). These data are consistent with a combined Starling effect and increased contractile state during exercise, both supine and upright.

The lower systemic arteriovenous oxygen difference during exercise in the supine position indicates a higher perfusion rate of inactive tissue. Blood flow in working limbs is more complex. During leg exercise limb flows are higher, and after exercise they are lower in the upright than in the supine position $(98,99,206)$. Greenleaf et al. (128) published exercise data that partially disagree, but their flow data were obtained immediately after exercise. Folkow et al. $(98,99)$ attributed the higher flow to a higher driving pressure in the upright position. A large hydrostatic component affects intravascular pressures in a dependent limb, but the reduction in venous pressure due to skeletal muscle activity is probably particularly prominent there. The arteriovenous pressure gradient and the perfusion pressure therefore tend to be greater when the working limb is dependent rather than at the level of the heart. Lind et al. (206) studied isometric exercise and found no postural effects on strength, arterial and right atrial pressures, or heart rate, but forearm flow increased and endurance improved in the upright po- 


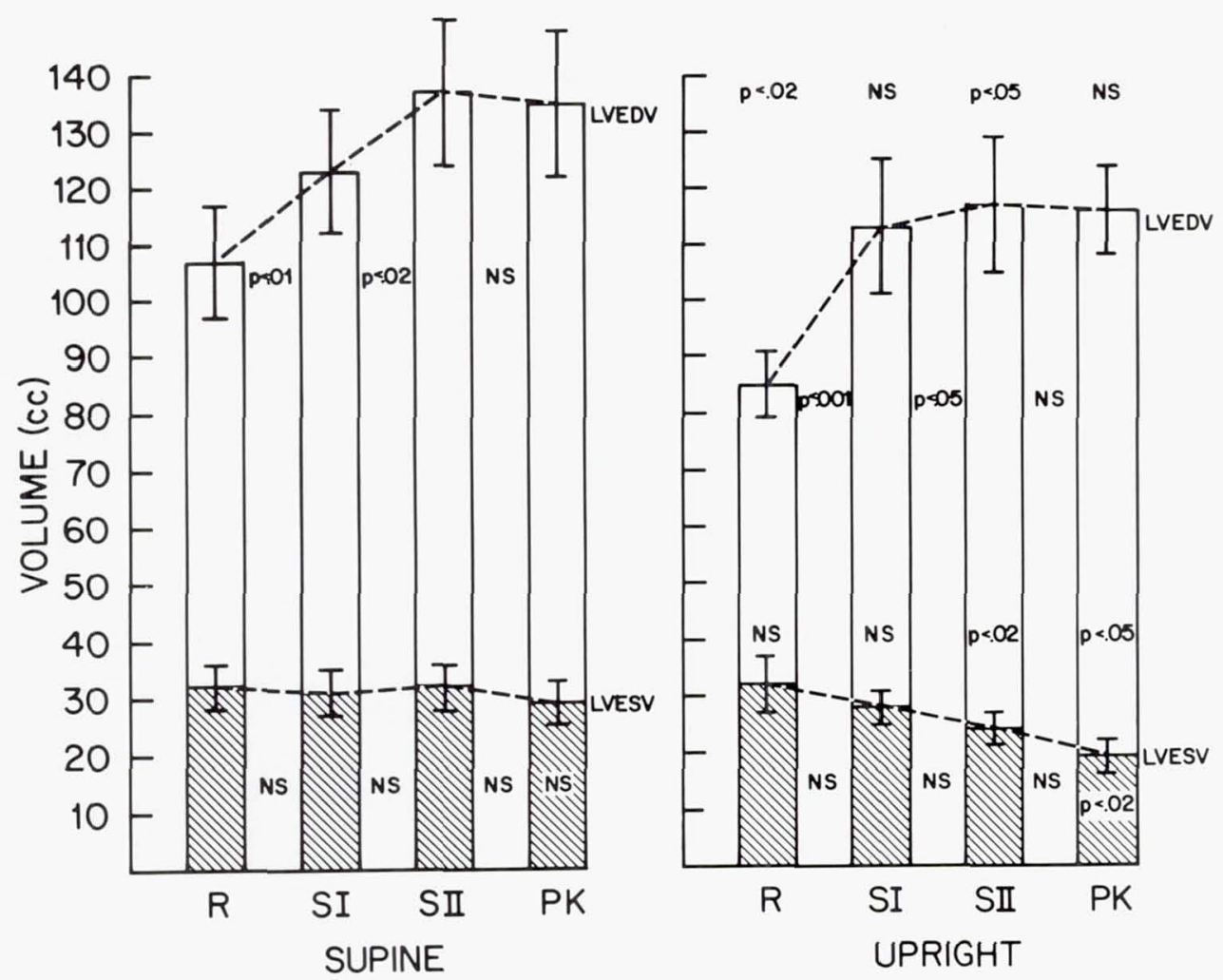

FIG. 7. Left ventricular end-systolic volume (LVESV; shaded portion), LVEDV (means \pm SE; tops of bars), and LV stroke volume (clear portion) at rest (R) and during 3 levels of exercise (SI, SII, PK). Above bars of right panel, $P$ values for corresponding upright and supine measurements of LVEDV at each work load; $P$ values above LVESV data for corresponding supine measurements of LVESV; $P$ values between adjacent bars for change between progressive work loads; $P$ values in small boxes of peak exercise (PK) bars for change from $\mathrm{R}$ to PK for LVESV in each position. Between $\mathrm{R}$ and PK, LVEDV also increased significantly in both positions ( $P<0.001$ supine, $P<0.02$ upright). SI, lowlevel work $(300 \mathrm{kpm} / \mathrm{min})$; SII, intermediate-level work $(600-750 \mathrm{kpm} / \mathrm{min})$. [From Poliner, Blomqvist, et al. (262), by permission of the American Heart Association, Inc.]

sition. No muscle pump is active during isometric exercise, and the position of the arm relative to the heart was similar in both body positions. These results are consistent with important neural rather than hydrostatic mechanisms. Lind et al. (206) discounted activation of the low-pressure baroceptor as a possible factor affecting peripheral flow. However, other investigators $(2,281)$ have found evidence for interaction during exercise between impulses originating in muscle receptors and in cardiopulmonary and carotid baroceptors. The upright position apparently modifies the inhibitory drive generated by the baroceptors (2). Bonde-Petersen et al. (41) showed larger systemic pressor responses to isometric knee extension and handgrip in the upright than in the supine position. The apparent disagreement between the absence of right atrial pressure changes reported by Lind et al. (206) and the conclusions of Abboud et al. (2) may be resolved by postulating significant changes in leftsided atrial and ventricular pressures during exercise.

There are no direct data on postural effects of myocardial blood flow during exercise in humans. However, patients with limited flow caused by coro- nary disease provide evidence for a more favorable relationship between total body and myocardial work in the upright than in the supine position $(196,201$, 329). Patients with effort-induced angina pectoris have a highly reproducible threshold of myocardial ischemia, i.e., the point at which myocardial oxygen demand exceeds the supply. The product of heart rate and systolic blood pressure reliably estimates myocardial oxygen demand if there are no major variations in left ventricular volume. The rate-pressure product at the onset of the angina pectoris is higher in the upright than in the supine position, probably because left ventricular filling pressures and volumes are lower (329). Wall tension and myocardial oxygen demand at any given left ventricular pressure are therefore higher during supine exercise.

\section{Dynamic Responses to Posture Changes}

REGULATORY MECHANISMS. Gauer argued forcefully that in humans the upright position is the normal reference and that basic vascular pressure-volume characteristics are regulated to provide optimal tissue 
perfusion in the upright position (110). Nevertheless the supine position continues to serve as the basal or control state in most human hemodynamic studies. Few investigators have concerned themselves with the immediate circulatory adjustments to a change from a standing or sitting to a lying position. Careful study would probably reveal hysteresis; however, for the purposes of this discussion it is assumed that the hemodynamic responses to the supine-standing and standing-supine transitions are mirror images.

Multiple mechanisms determine the dynamic responses to changes in posture, including neurogenic control mechanisms and the functional characteristics of the veins. The redistribution of intravascular fluid produces reflex responses that primarily involve three different sets of receptors $(49,79,188,219,257,298$, 333, 334): 1) carotid and aortic mechanoreceptors, 2) cardiopulmonary mechanoreceptors, and 3) hypothalamic osmoreceptors and angiotensin II receptors. The third group of receptors interacts with the first two in the control of blood volume and is a less important determinant of the acute responses. Angiotensin II release can stimulate the central nervous system and augment sympathetic vaso- and venoconstriction, but the direct and indirect hemodynamic effects are physiologically important only in the sodium-depleted state (97, 298). Activating the cardiopulmonary mechanoreceptors by distension inhibits both antidiuretic hormone $(\mathrm{ADH})$ and renin-aldosterone and produces a diuresis $(87,89,90,107)$.

Carotid and aortic mechanoreceptors. The mechanoreceptors in the walls of the carotid sinus and the aortic arch are stretch receptors. The degree of deformation and the rate of impulse flow are functions of transmural pressure. Afferent impulses travel in rapidly conducting myelinated and slowly conducting unmyelinated nerves with the glossopharyngeal nerve and the vagus to the cardiovascular centers. Efferent fibers reach the sinus and atrioventricular nodes, the ventricles, veins, and arterioles by vagal and spinal cord pathways. A fall in arterial pressure decreases afferent nerve activity and releases inhibitory activity in the cardiovascular centers. This results in increased heart rate and contractility, vaso- and venoconstriction, and reduced blood flow to the skin and skeletal muscle, the kidney, and the splanchnic region. Increased metabolic demands increase myocardial flow.

Cardiopulmonary mechanoreceptors. At least two sets of mechanoreceptors respond to changes in the intracardiac pressures (see chapter by Bishop et al. in this Handbook and refs. 49, 76, 79, 209, 218, 257, 333, 334): 1) discrete endocardial receptors at the junctions of the superior and inferior vena cava with the right atrium and the pulmonary veins with the left atrium, which are connected to the cardiovascular center by myelinated vagal fibers and 2) a diffuse receptor network of unmyelinated vagal fibers (C fibers) connecting all chambers of the heart with the cardiovascular centers. A similarly diffuse network of receptors with afferent sympathetic spinal cord fibers form a third set. The functions of the members of this group are largely unknown although some are probably pain receptors.

Activation by deformation of both discrete and diffuse receptors affects renal sympathetic drive (decrease) and renal blood flow (increase) identically, but the heart-rate effects are opposite. Increased stretch of the discrete venoatrial receptors causes tachycardia; increased stretch of the diffuse receptors (and of the carotid sinus/aortic arch receptors) causes bradycardia. The left ventricular receptors increase their inhibitory activity whenever cardiac diastolic filling is augmented, whereas dilating the right ventricle has little effect $(255,334)$. Reciprocal variations in atrial and ventricular/arterial pressures, e.g., high mean atrial and diastolic ventricular pressures and low arterial pressures, as in severe congestive heart failure, tend to minimize the systemic impact of impulses from the combined receptor system (76).

Local reflexes. Local reflex mechanisms may also contribute to the response to orthostatic stress. Henriksen $(143,144)$ has demonstrated vasoconstriction with decreased limb blood flow in response to local venous distension. Blocking studies indicated that the vasoconstriction was mediated by a local (axonal) sympathetic reflex mechanism. Activation of venous afferent fibers producing reflex-induced leg muscle activity may also counteract postural pooling (330, 331).

Regulation of venous system. Passive and active control mechanisms combine to regulate central venous pressure and the regional distribution of venous volume. Passive volume changes, which dominate in the pulmonary vasculature, are a function of changes in the effective transmural distending pressure, i.e., the difference between intravenous pressure and tissue pressure. Arterial pressure and arteriolar resistance, the pressure in the right atrium and central veins, and the hydrostatic load in turn determine venous pressure. The downstream pressure gradients within the venous system (disregarding hydrostatic pressures) are small, $10 \mathrm{mmHg}$ or less. Therefore the venous component of total peripheral resistance is small and arteriolar pressure is the major determinant of distending pressure and, indirectly, of venous volume. Arteriolar dilatation increases venous pressure and volume. Vasoconstriction has the opposite effect and displaces venous volume centrally (277).

Cardiovascular reflexes and circulating catecholamines mediate active changes in venous capacity. The level of $\alpha$-adrenergic stimulation is the primary control mechanism. The basic muscle length-tension relationship, which applies also to the venous wall, makes active regulation more effective. A distended vein contracts more effectively when stimulated than a nearly empty vessel $(7,254,297,298)$. Volume changes at low venous pressures are primarily passive, whereas active venomotor mechanisms dominate at 


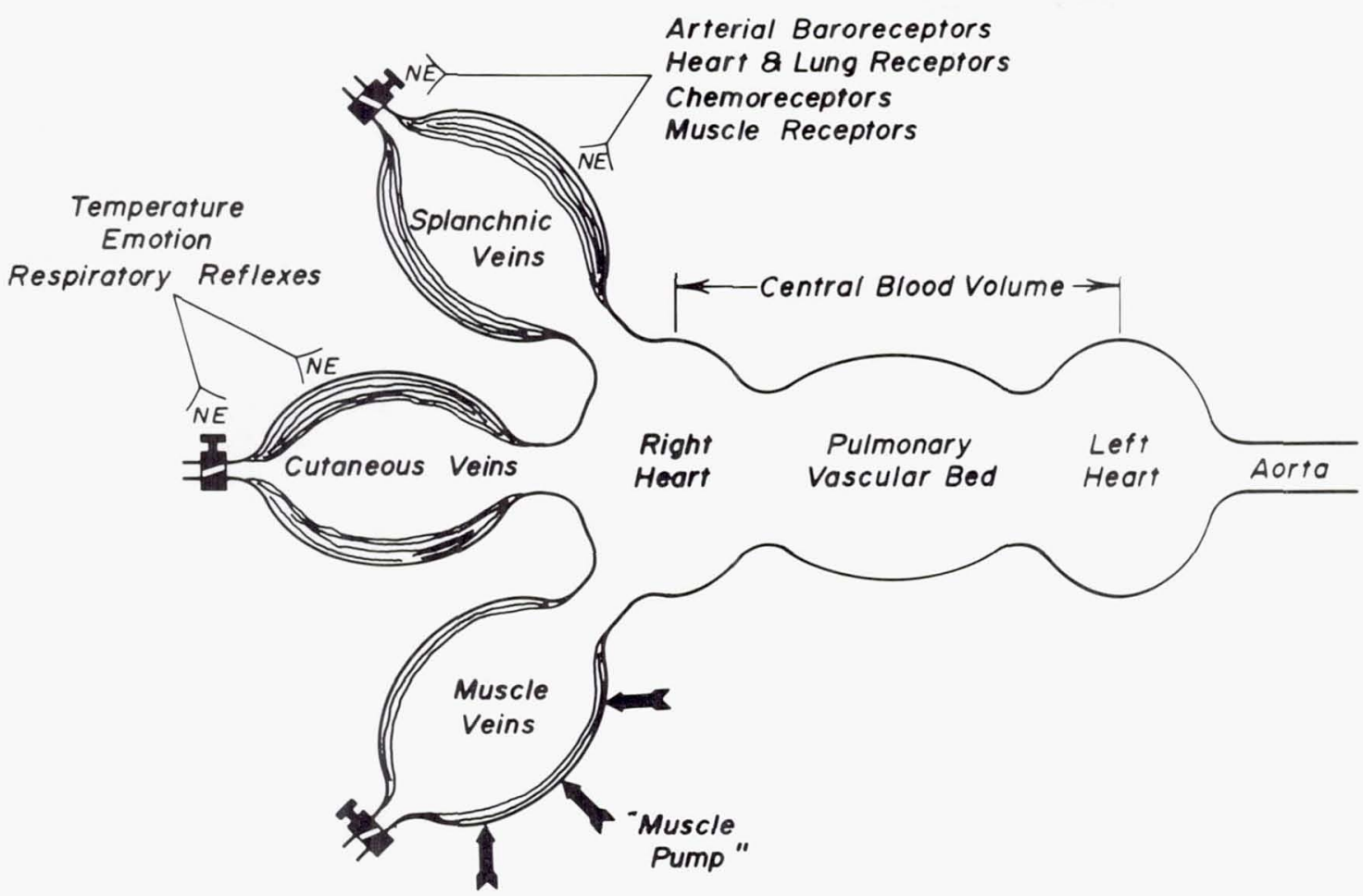

FIG. 8. Control of central blood volume and cardiac filling pressure by systemic veins. Contracting smooth muscle cells of venous wall, splanchnic veins in particular, actively changes filling of heart. Cutaneous veins mainly react to changes in temperature. Any change in distending pressure, whether due to gravity or changes in arteriolar resistance, passively changes capacity. NE, norepinephrine. [From The Human Cardiovascular System, 1979, by Shepherd and Vanhoutte (298), by permission of Raven Press, NY.]

high distending pressures (254). The importance of true autoregulatory changes (Bayliss effect) with increased myogenic activity in response to increased intravascular pressure is controversial (234). The opposite effect, i.e., relaxation after a prolonged increase in distending pressure (delayed compliance or viscoelastic creep), may be significant (358). By decreasing venous resistance due to relaxation of sphincters, e.g., in the hepatic vein, $\beta$-adrenergic stimulation may centrally displace venous volume (163).

Veins react differently to active stimulation (Fig. 8). Muscle veins respond weakly, if at all, to neural stimulation, including baroceptor-mediated reflexes. The capacitance of the cutaneous veins is primarily determined by the thermoregulatory stimuli. They dilate when temperature is increased, whereas deep limb veins dilate when perfused with cold blood (297). The splanchnic veins dilate when carotid and cardiopulmonary receptors are stimulated and contract when the muscle receptors (e.g., during exercise) and the chemoreceptors of the carotid body are activated (138, 297). Whether active venoconstriction is a determinant of acute postural hemodynamic responses is questionable. Gauer and Thron (110) thought that venoconstriction was not significant during orthostasis. Samueloff et al. (289) have shown only a weak and transient constriction of cutaneous veins at the onset of LBNP at $-60 \mathrm{mmHg}$. However, passive changes in venous volume caused by the splanchnic and peripheral vasoconstriction are probably significant $(48,70$, 354).

SYSTEMIC RESPONSES. Figure 9 shows the principal cardiovascular responses to LBNP. As discussed in LOWER-BODY NEGATIVE PRESSURE, p. 1029, and SKIN AND MUSCLE, p. 1035, there is evidence that the responses to LBNP, standing, and head-up tilt $\geq 70^{\circ}$ are qualitatively and quantitatively similar. The diagram comprises data from several series $(5,96,100-102,166$, 167, 241-244, 250, 251，266, 267, 280, 362). Linear interpolation compensated for differences between protocols for stepwise application of LBNP and gave uniform intermediate data points.

The degree of venous pooling is linearly related to the negative pressure. Left ventricular end-diastolic volume and stroke volume also decrease in a linear fashion to a level $25 \%-50 \%$ below that at rest. Cardiac output decreases $20 \%-40 \%$ (5, 100-102, 250, 266, 267). Initially heart rate and arterial pressure do not change. Peripheral and splanchnic arteriolar constriction compensate for the decrease in systemic flow. Progressive peripheral venous pooling eventually causes tachycardia, and the heart rate changes are closely linked to changes in arterial pulse pressure (167). The myocar- 
FIG. 9. Principal features of human response to progressive lower-body negative pressure.
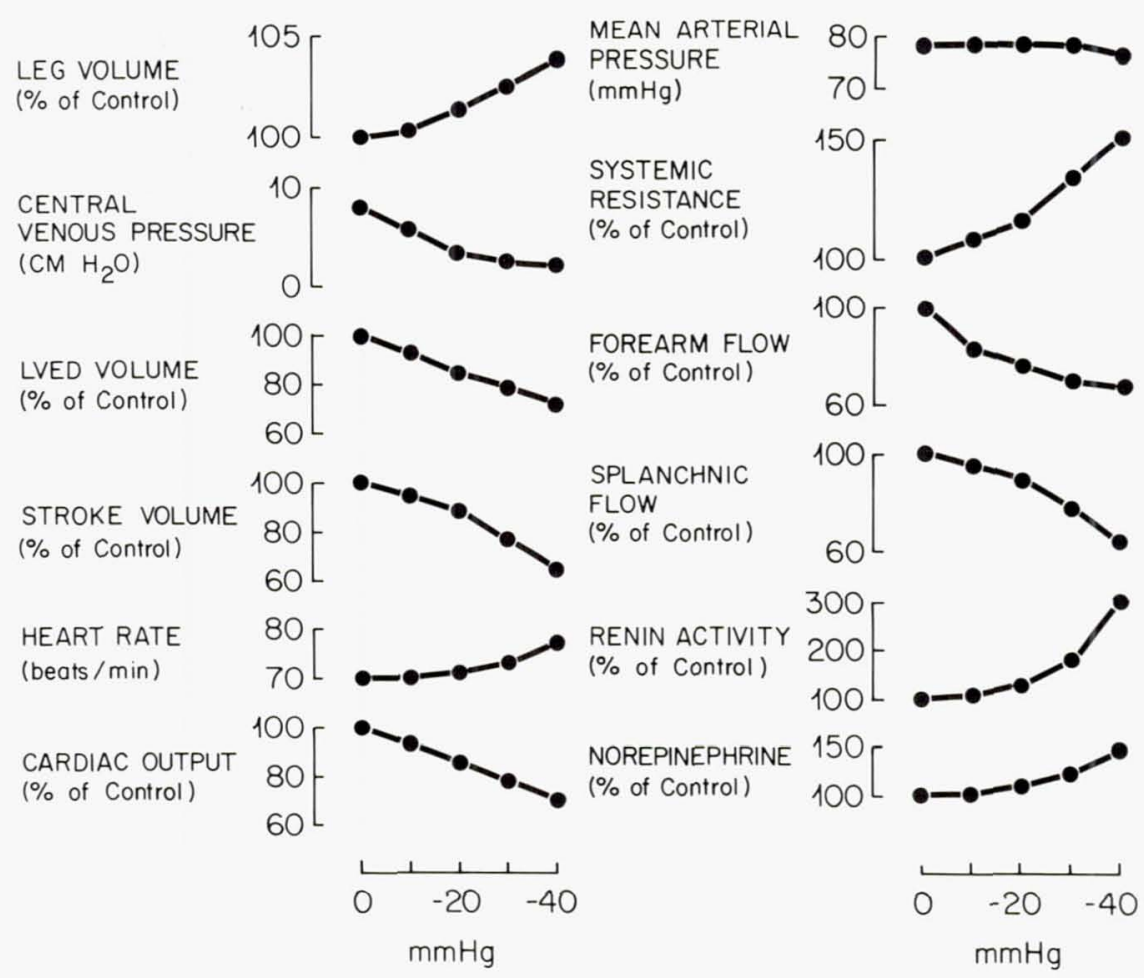

${ }_{100}^{150}[$
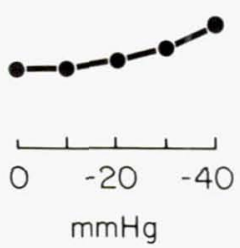

dial contractile state does not change until tachycardia develops. Thus the primary cardiac response is a negative Starling effect. An increase in plasma renin is apparent after about $2 \mathrm{~min}$, and there are parallel changes in plasma norepinephrine (F. A. Gaffney, unpublished observations).

The combined data are consistent with a generalized vasoconstriction in response to decreased intracardiac pressures and volumes mediated by a decreased level of stimulation of cardiopulmonary receptors and reflex $\alpha$-adrenergic stimulation. Increased sympathetic drive produces decreased renal blood flow and a release of renin. Progressive pooling with decreasing stroke volume and cardiac output eventually causes a fall in arterial pressure with compensatory tachycardia, increased contractility, and further vasoconstriction mediated by the arterial baroceptors. An increase in plasma catecholamines reflects sympathetic activation. Ewing et al. (94) thought that primarily vagal withdrawal mediated the early orthostatic heart-rate response, but data on autonomic blockade during head-up tilt or LBNP indicate that the true reflex response consists of a combined $\alpha$ - and $\beta$-adrenergic activation and vagal withdrawal (34-36, 211, 242, 293, 349 ). $\beta$-Adrenergic blockade attenuates the heart-rate response, and vagal withdrawal only partially compensates. The vasoconstrictor response, however, is enhanced. The relative contribution of $\beta$-adrenergic stimulation and vagal withdrawal to cardioacceleration may vary with experimental conditions. Atropine has little or no effect on orthostatic tolerance.

The sympathetic activation is clearly nonuniform. Vasoconstriction is manifest before heart rate or con- tractility is measurably affected. Forearm flow and conductance decrease significantly before splanchnic flow is affected $(1,167)$. The differential effects on limb flow and splanchnic flow are probably related to a predominance of low-pressure baroceptor effects at mild degrees of LBNP and increasing effects on the carotid sinus with progressive pooling and decreasing arterial pressures and pulse pressure $(1,167)$. Nonuniform regional vasoconstrictor responses may also be related to differential effects of changes in the impulse flow from ventricular and arterial baroceptors and to unequal levels of basal vasoconstrictor activity (350).

The baroceptor-mediated vasoconstriction in skin and muscle is apparent, although attenuated, even when opposed by thermoregulatory vasodilatory reflexes (166). Thus arterial and venous responses to a hot environment combine to increase the sensitivity to orthostatic stress. Conversely, cooling the skin attenuates the cardiovascular effects of LBNP (266, 267). The combined effects of a hot environment on resistance and capacitance vessels also impair ventricular filling during upright exercise $(166,279)$. may explain the relative lack of compensatory tachycardia when venous pooling has caused large decreases in stroke volume and cardiac output and falling arterial mean and pulse pressures. Presyncopal heart rates rarely exceed 130 beats/min; i.e., they remain at least 40 beats below normal maximal heart rate. This relatively slow rate may be the result of opposing chronotropic drives originating in the venoatrial and the cardiac and arterial receptors. This dissociation may
The involvement of multiple sets of the receptors 
have a role in hypovolemic syncope. Furthermore a reduction of ventricular dimensions during the presyncopal state may progress until the end-systolic volume approaches zero and until endocardial deformation receptors are stimulated by compression during systole rather than by high wall tension, as in obstruction of the left ventricular outflow tract (222). Bradycardia and vasodilatation would then be produced by a $\mathrm{Be}$ zold-Jarisch-type reflex (92). Echocardiographic studies $(5,251,292)$ support this mechanism by demonstrating a trend toward smaller end-systolic volumes with progressive venous pooling. The unstable autonomic state during presyncope with large oscillations in heart rate and arterial pressure (157) may reflect variations in the balance between opposing drives from atrial, ventricular, and arterial receptors.

\section{CARDIOVASCULAR ADAPTATION TO PROLONGED}

BED REST, ZERO GRAVITY, AND

RELATED CONDITIONS

\section{Experimental Conditions}

The human responses to prolonged exposure to zero gravity, bed rest, and water immersion have many important features in common. The hydrostatic intraand extravascular pressure gradients that are normally present in the upright position are abolished or minimized. This causes a central or cephalad fluid shift that initiates a complex series of adaptive changes in several organ systems. After adaptation, reexposure to normal gravitational forces produces signs of orthostatic intolerance.

BED REST. More information is available on prolonged bed rest than on other hypogravic conditions. A recent summary (249) lists more than 500 American, European, and Russian bed-rest studies performed between 1921 and 1978. Early experiments concentrated on the metabolic effects of bed rest and immobilization and documented increased nitrogen excretion (54), calcium loss $(6,71)$, and decreased glucose tolerance (38). Clinically important side effects of bed rest, including loss of muscle mass and strength, cardiovascular deconditioning, and an increased risk of venous thromboembolism, were recognized during the early 1940 s (75, $141,203,204)$. Taylor et al. $(326,327)$ and Dietrick et al. (74) described the principal effects on body-fluid distribution and cardiovascular function, i.e., decreased blood volume, orthostatic intolerance, and decreased exercise capacity in the upright position. The establishment of the US manned space-flight program in 1958 and extensive use of bed rest as a model of weightlessness yielded many studies during the 1960s.

HEAD-DOWN TILT. Russian investigators introduced bed rest with head-down (antiorthostatic) tilt, usually at $-4^{\circ}$ to $-6^{\circ}$, as a more effective technique of simulating zero gravity than horizontal bed rest (177).
Several Russian and American studies (37, 65, 177, $180,250,302,303,343)$ have demonstrated that the effects of head-down tilt are qualitatively similar to those of bed rest except that the adaptation is accelerated. During short-term experiments head-down tilt produces a greater degree of cardiovascular deconditioning than horizontal bed rest of equal duration. One study (158) has failed to demonstrate any difference between the two modes. In general the comparisons of the effects of space flight and head-down tilt support the use of tilt as a simulation method for cardiovascular studies $(37,250,291)$.

IMMERSION. The immediate effects of water immersion on fluid distribution and hemodynamic conditions are (as discussed in IMMERsion, p. 1030) more powerful than those of bed rest and head-down tilt. Prolonged immersion is logistically difficult, but hemodynamic measurements have been obtained over periods of several hours (4). Immersion periods of up to 56 days have been accomplished by protecting the subjects from water contact by wrapping them in thin plastic sheets (302).

ZERO GRAVITY. Only limited physiological data on the effects of zero gravity were collected during the early phases of the US and USSR manned space-flight programs (261). More extensive studies were made during the Apollo flights of 6-12 days (174), the three Skylab flights of 28-84 days (173), and the two Russian Salyut-6 flights of 96 and 140 days (359).

Data obtained during actual space flights are, of course, crucial in the study of the effects of gravity on the cardiovascular system, but the number of subjects that can be studied in space and the range of methods are, although rapidly expanding, still very limited. Ground-based simulation methods may closely reproduce many important aspects of weightlessness, but residual hydrostatic gradients are always present. The earth's gravitational field can be cancelled in aircrafts following parabolic or Keplerian flight patterns but only for periods of less than $45 \mathrm{~s}$ (291). However, there is no conclusive evidence that zero gravity has any unique or specific effects on the cardiovascular system that cannot be reproduced at least in kind during earthbound simulation studies. Similar considerations apply to the musculoskeletal system, but the effects of zero gravity on the vestibular system are probably specific. Motion sickness is common during the initial week of space flight (123). Provocative tests at normal gravity cannot predict susceptibility. Unusual movements and an altered relation between vestibular and visual inputs during space flight are thought to be major pathophysiological factors (123).

Age, sex, and physical fitness may affect the response to zero gravity, but no conclusive information is available. Astronauts and cosmonauts with few exceptions have been male, age 35-45, and physically fit. Most bed-rest studies have been performed in normal men in their twenties, but the NASA-Ames Research 
Center has during the past few years conducted a series of studies in women, 20-35 yr old, which in general fail to reveal any significant sex differences $(116,130,247)$. Convertino, Hung, and co-workers (66, 156) recently completed a 14 -day bed-rest study in 50 yr-old men. The responses, including the degree of post-bed-rest cardiovascular deconditioning, were qualitatively and quantitatively similar to those of younger men. Corresponding findings have also been made during and after head-down tilt (F. A. Gaffney and C. G. Blomqvist, unpublished observations).

The role of physical fitness in the response to bed rest and related conditions is complex. Exercise has been used extensively to counteract deconditioning. Very fit subjects on the other hand appear to recover more slowly from prolonged bed rest than sedentary subjects if pre-bed-rest exercise performance is the basis for comparison (287). Previously fit, deconditioned individuals are nevertheless likely to outperform sedentary subjects. Athletes have often been considered more sensitive to short- and long-term orthostatic stress than sedentary subjects (187), but objective comparisons of athletes and nonathletes have variable results $(47,246,310)$.

\section{Body Composition}

Bed rest, space flight, and water immersion initially decrease body weight $1-2 \mathrm{~kg}$ because of a loss of extracellular fluid. The magnitude of the initial weight loss closely corresponds to the cephalad fluid shift (37, $202,250,335,336,353$ ).

There is a brief and transient phase of plasma volume expansion because of transfer of fluid from the extravascular compartment, but a decrease in plasma volume accounts for about one-third of the early weight loss $(84,129,137,226-228,332)$. The fluidrelated weight loss occurs within 3-4 days during bed rest $(127,340)$ and within 1-2 days during head-down tilt and space flight $(37,150,250,261,335,336)$. The effect of water immersion is more rapid. A change of more than $1 \mathrm{~kg}$ has been recorded after a 6 -h period of immersion (90).

The average total weight loss during flights of 28-84 days in the nine Skylab crew members was $3 \mathrm{~kg}$, corresponding to $4 \%$ of total body weight $(335,336)$. Changes within the initial 3 days in space accounted for $\sim 50 \%$ of the total loss (Fig. 10). Leach et al. (199) identified three components of the changes in total body mass: 1) early obligatory water loss of about a liter as a consequence of a central fluid shift, 2) gradual loss of muscle mass due to disuse atrophy, and 3) variable change in the amount of body fat due to a caloric deficit. Early potassium losses were significant during the Apollo missions and may have contributed to the development of transient arrhythmias (20). Potassium loss with hypokalemia has also been observed during short-term simulation experiments (LBPP) in primates (239). Data from later flights, however, suggest that muscle atrophy and loss of body fat account for most observed overall losses of potassium, nitrogen, and protein $(199,200,202)$; arrhythmias have not been a significant problem. A calcium loss is physiologically important but numerically represents only a small fraction of the total weight loss.

Disuse atrophy of skeletal muscle can cause secondary changes of cardiovascular function by affecting muscle tone, venous pooling, and the response to exercise. Disuse atrophy preferentially affects red fibers in general (42) and postural muscles, which contain a high proportion of red or slow-twitch fibers (288). The atrophy is reversible; muscle mass is restored relatively rapidly $(\sim 2 \mathrm{wk})$ after experimental immobilization, but postural muscles (e.g., soleus) may require 34 mo to regain full strength (42). Similar observations have been made in rats after space flight $(60,256,325)$.

Loss of calcium is consistent in the response to bed rest and weightlessness. Prolonged bed rest has pro-
FIG. 10. Body-mass measurement of Skylab-3 scientist pilot at $0 \mathrm{~g}$ with spring-loaded oscillating system in which frequency of oscillation was proportional to mass. [From Thornton and Ord (336).]

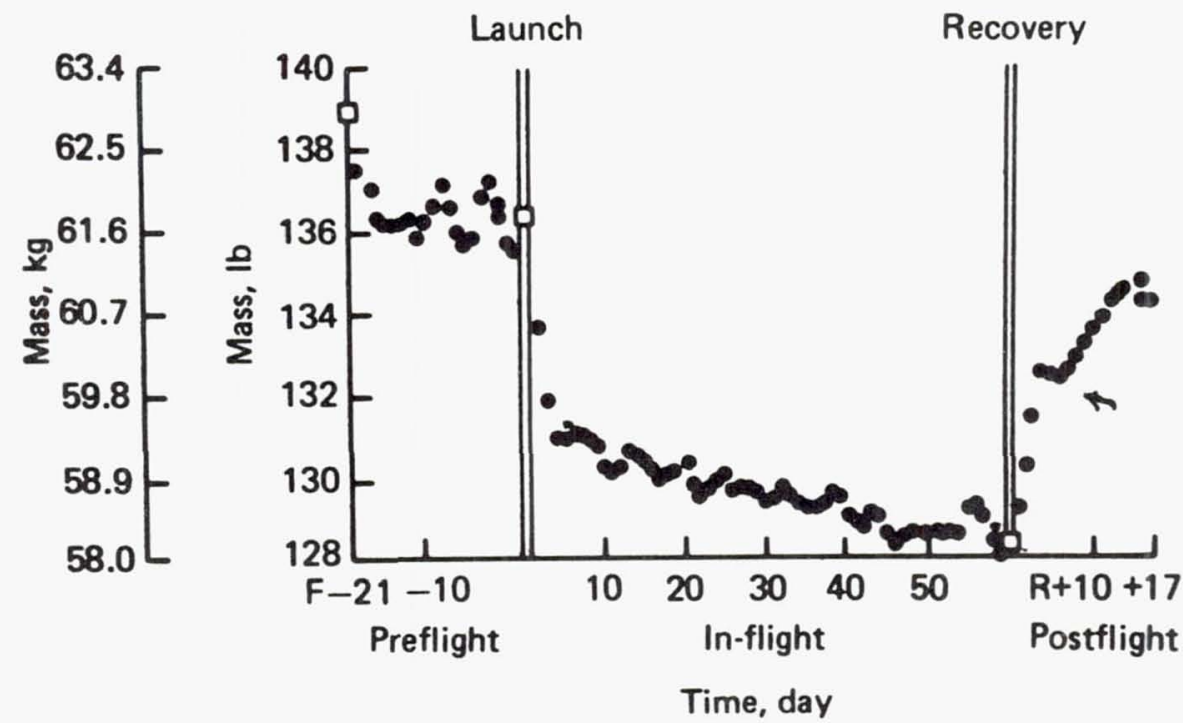


duced losses at a rate of $0.5 \%$ of total body calcium per month. The process is progressive, and the rate tends to accelerate $(74,77,287)$. The calcium loss appears to be more severe during weightlessness than during bed rest. Balance studies during the Skylab flights demonstrated combined urinary and fecal losses at a rate as high as $2.5 \%$ of total body calcium per month (265). The threshold for clinically important osteoporosis is a cumulative loss of about $20 \%$.

A balance between calcium uptake and loss is restored shortly after the return to normal gravity. Nevertheless prolonged exposure to weightlessness may cause irreversible skeletal damage. Urolithiasis is also a potential complication. Because it lacks effective countermeasures calcium loss is placed along with radiation exposure (337) as the other principal biological factor limiting the safe duration of space flight.

Calcium loss is almost certainly triggered by the absence or attenuation of the forces that normally support the body weight, i.e., compression forces acting on bone and shearing and tensile forces acting on periosteal surfaces. Bed-rest studies document failure of vigorous exercise in the supine position to prevent the calcium loss, whereas $3 \mathrm{~h}$ of quiet standing each day is effective $(77,164)$. Young patients immobilized with multiple fractures occasionally develop severe calcium loss from bone and secondary systemic manifestations of hypercalcemia, e.g., massive renal calcification with depressed function and hypertension. Dietary and pharmacological measures are ineffective $(6,64)$, but mobilization promptly normalizes calcium metabolism.

The exact cellular mechanisms mediating the calcium loss and the net absorption of bone during prolonged bed rest and space flight are unknown. Blood levels of calcium are usually only slightly elevated, and plasma levels of parathyroid hormone are low. No direct links to disturbances of cardiovascular function have been established.

\section{Blood Volume}

Plasma volume has been measured by similar techniques in many bed-rest studies, often by multiple determinations. The mass of red cells changes little during the initial $4 \mathrm{wk}$ (127), and changes in plasma volume approximate the changes in total blood volume. The data from several studies with bed-rest periods of $6 \mathrm{~h}$ to 30 days $(59,126,127,170,287,314$, $316,338,340-342$ ) indicate significant plasma volume decreases within $6 \mathrm{~h}$. The plasma volume contraction is progressive during the first 3 days, but then a plateau is reached at an average loss level of $350 \mathrm{ml}$ or about $12 \%$. Greenleaf et al. (126) performed a similar analysis of the literature and derived a nonlinear regression equation indicating a progressive loss through 60-80 days. Their estimate was heavily influenced by data from a single long-term study (77) with very large losses, $600-1,000 \mathrm{ml}$ at a duration of 70-200 days. However, a similar long-term Russian study (258) showed a loss of $12 \%$ after 120 days, a value equal to the typical loss after 4-30 days.

A blood volume loss of $5 \%-15 \%$ is also a feature of space flight and head-down tilt. Prolonged space flight produces a combined loss of red cell mass and plasma volume. Data from early US flights demonstrated loss of red cell mass also after relatively short missions, but exposure to a hypobaric but hyperoxic atmosphere may have affected these results. A significant combined loss of plasma volume $(-12.5 \%)$ and red cell mass $(-11.1 \%)$ was observed after the normoxic Skylab flights and also after the 96- and 140-day Salyut-6 flights. The etiology of the decrease in red cell mass is not known, but the mechanism is bone marrow inhibition rather than increased destruction (171, 359). The interaction between the initial decrease in plasma volume and the effects on red cell mass during space flight and bed rest of very long duration need further exploration. The initial plasma volume loss with an increase in hematocrit and oxygen-carrying capacity may inhibit erythropoietin production (171).

Head-down tilt at moderate angles, $-4^{\circ}$ to $-6^{\circ}$, and water immersion also cause blood volume losses of 350-500 ml. Most of these changes occur within $6 \mathrm{~h}$ $(37,108,250)$. Immobilization in the upright position (i.e., chair rest), combined with horizontal bed rest during sleep, is associated with a reduction in plasma volume. The time course appears to differ from that during bed rest, however, implying a different mechanism. Lamb et al. $(190,192)$ found no significant changes after chair-rest periods of 4-8 days but a mean decrease of $376 \mathrm{ml}$ after 10 days.

\section{Cardiovascular Function}

MAXIMAL OXYGEN UPTAKE. Maximal oxygen uptake as measured during a dynamic leg exercise is an important reference point in cardiovascular physiology. Pulmonary function does not limit uptake in normal subjects (except at high altitude); measurements of the maximal rate of oxygen uptake therefore estimate the overall functional capacity of the cardiovascular system. Cardiac pump function is probably the ratelimiting step under normal conditions, but peripheral mechanisms are likely to become important in many experimental situations. Thus, whereas measurements of maximal oxygen uptake accurately reflect changes in total cardiovascular performance, supplementary data are needed to isolate specific mechanisms.

In normal young men, bed rest of 3-4 wk decreases maximal oxygen uptake (measured during exercise in upright position) $13 \%-28 \%(31,237,287,327)$. Similar changes ( $-15 \%$ after 10 days) have recently been reported in 50-yr-old men (66). Changes during exercise in the supine position in comparable groups are much smaller $(66,67,112)$. Data on maximal oxygen uptake after space flight or immersion are not available. Nixon, Blomqvist, et al. (250) reported a decrease of 
$22 \%$ in normal young men after $24 \mathrm{~h}$ of head-down tilt at $-5^{\circ}$. Lamb et al. (192) found no significant changes in maximal oxygen uptake after prolonged chair rest.

CARDiac DIMENSIONS AND PERFormance. Adaptation to hypogravic conditions reduces heart size. Saltin, Blomqvist, et al. (287) estimated a significant $(-11 \%)$ decrease in total heart size in the supine position from biplane roentgenograms in young men after a 3-wk period of bed rest. Radiographic measurements after space flight have consistently demonstrated a decrease in heart size (248). Echocardiography before and after the Skylab-4 flight and two long Salyut-6 flights also showed a decrease in left ventricular end-diastolic diameter $(148,359)$.

Saltin, Blomqvist, et al. (287) noted that stroke volume was depressed in both the upright and supine positions after bed rest and postulated that prolonged bed rest depressed intrinsic myocardial function. They assumed that any abnormalities exclusively caused by decreased ventricular filling would be abolished in the supine position $(25,26)$. However, recent echocardiographic and scintigraphic studies have demonstrated decreased preload also in the supine position after adaptation and effectively ruled out any significant changes in contractile performance. Scintigraphic studies by Hung et al. (156) after bed rest showed an increased left ventricular ejection fraction at rest and during exercise both in the supine and upright position. Relative tachycardia was present during upright and supine exercise. The data, derived from a study of 50 -yr-old men, indicate that an increased ejection fraction combines with relative tachycardia to compensate for the effects of the decreased end-diastolic left ventricular volume. Head-down tilt $(37,250)$ also decreases upright and supine stroke volume without changing the contractile state.

Henry et al. (148) found no change in intrinsic cardiac performance after prolonged space flight. They evaluated by echocardiography the ventricular function curves relating left ventricular stroke volume to end-diastolic volume. Two of the three subjects showed a small decrease in estimated left ventricular mass. Russian investigators have recently described ultrastructural myocardial abnormalities affecting the mitochondria and sarcoplasmic reticulum as well as capillaries and venules in rats exposed to zero gravity for 20 days (274). Furthermore the reduced left ventricular size in the Salyut-6 cosmonauts after return to normal gravity was associated with increased left atrial diameter, according to echocardiography (359).

The combined data on cardiac dimensions after bed rest and after space flight strongly suggest a reduction in filling pressures in the postadaptive state. Few direct pressure measurements have been made. Katkov et al. (180) reported no significant changes in supine right ventricular end-diastolic pressure after 5 days of head-down tilt at $-4^{\circ}$, but Blomqvist et al. (37) recorded a significant decrease in central venous pressure (from 4.9 to $2.5 \mathrm{cmH}_{2} \mathrm{O}$ ) after $24 \mathrm{~h}$ of head- down tilt at $-5^{\circ}$. Hemodynamic data (see SYSTEMIC HEMODYNAMICS, below) are also consistent with decreased filling pressures after adaptation. On the other hand the early stages of supine bed rest and headdown tilt (37) are probably associated with a transient increase in filling pressures above the levels prevailing in the upright position. Water immersion and headdown tilt raise filling pressures above the normal supine level.

There are no longitudinal data on filling pressures and cardiac output from bed-rest studies. Direct measurements during head-down tilt indicate that the increase in central venous pressure is transient and lasts less than $2 \mathrm{~h}$, whereas the hemodynamic change during immersion persists for several hours with no signs of resolution $(4,37,81,250)$. Because no direct measurements are available the time course and magnitude of changes in filling pressures during space flight can only be guessed. Clinical observations indirectly support a sustained elevation of venous pressures, which may be associated with a hyperkinetic state. Distended neck veins, a puffy facies, and subjective sensations of fullness of the head are consistent features at zero gravity $(186,335)$. During the Skylab flights this condition persisted over periods of up to 84 days. Yegorov (359) reported a postflight increase in left atrial diameter, consistent with a sustained volume overload similar to conditions during immersion. Studies on supine cardiac dimensions immediately after return to normal gravity, however, clearly indicate an adaptation with decreased ventricular filling. Possibly the distension of the neck veins and the facial edema in space only reflect equilibration of systemic venous pressures. Regional differences in the compliance of the cutaneous vasculature and in tissue-filtration characteristics (186) may combine with an altered regional distribution of venous pressure to produce physical signs of venous congestion in the absence of any sustained elevation of cardiac filling pressures. The Skylab astronauts retained a normal capacity for heavy dynamic leg exercise in space (236); this is strong evidence against any major cardiovascular dysfunction at zero gravity.

Simulation studies provide no conclusive evidence for a sustained hyperkinetic state in space. The magnitude of the central fluid shift and the degree of postadaptive dysfunction are similar after space flight and head-down tilt. A sustained hyperkinetic state with an increase in filling pressures may be a unique product of the hydrostatic conditions that are associated with immersion, and the response to zero gravity may be better approximated by the adaptation to head-down tilt. Immersion causes tissue compression and a significant transthoracic pressure gradient, features that are absent at zero gravity and during headdown tilt.

SYSTEMIC HEMODYNAMICS. The principal effects on systemic hemodynamics of $3 \mathrm{wk}$ of bed rest in normal young men are illustrated in Figure 11. The most 


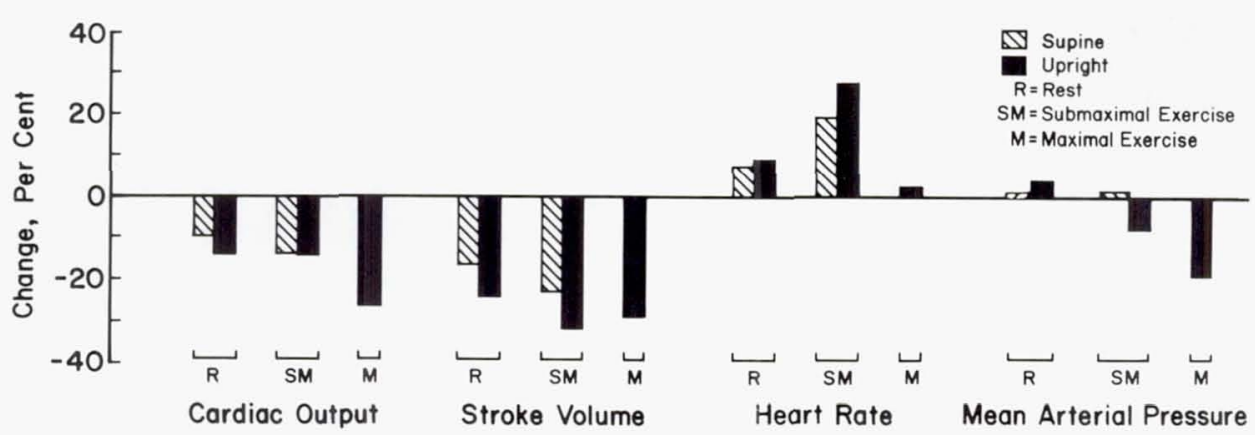

FIG. 11. Hemodynamic effects of 3 -wk bed rest on cardiac output, stroke volume, heart rate, and mean arterial pressure supine and upright at rest during exercise in 5 normal young men. Control measurements before bed rest $=100 \%$. [Data from Saltin, Blomqvist, et al. (287).]

important change was a marked reduction in stroke volume at rest and during exercise, particularly in the upright position but also in the supine position. After bed rest a relative tachycardia was noted at rest and during submaximal exercise, but cardiac output was still significantly reduced. Maximal heart rate did not change. The systemic arteriovenous oxygen difference was higher after bed rest at rest and during submaximal exercise but unchanged during maximal work. The maximal oxygen uptake decreased in direct proportion to stroke volume. Mean arterial pressure remained unchanged at rest and during submaximal exercise but was significantly lower at the maximal level. Systemic peripheral resistance was generally higher after bed rest, but the changes were small and nonsignificant.

Hyatt (157) studied a series of 16 subjects before and after a 2-wk bed-rest period. Results obtained at rest and during submaximal exercise in the supine position paralleled the findings by Saltin, Blomqvist, et al. (287). The stroke volume was significantly reduced also in the supine position, particularly during exercise $(-20 \%)$ and passive head-up tilt. Birkhead et al. (31) have reported similar results. Chobanian et al. (59) also found a markedly reduced stroke volume $(-50 \%)$ compared to measurements before bed rest during $70^{\circ}$ head-up tilt. Nixon, Blomqvist, et al. (37, 250) reported similarly large changes after a 24-h period of head-down tilt at $-5^{\circ}$. Stroke volume at rest supine decreased by $22 \%$. Limited observations are available on cardiac output and stroke volume at rest and during exercise after prolonged space flight. Measurements based on the $\mathrm{CO}_{2}$ rebreathing method were performed in the Skylab crew members after 28-84 days in space. Stroke volume during submaximal exercise decreased by more than $30 \%$ compared to preflight data $(51,236)$. Similar results were obtained after the 2- and 8-day flights of Soyuz 12 and 13 (181).

Extensive heart-rate data are also consistent with a significant stroke volume reduction at rest and during exercise after bed rest and related conditions. Postbed-rest heart rates during relatively heavy submaximal exercise increased 30 beats/min in the upright and 25 beats/min in the supine position in the study by Saltin, Blomqvist, et al. (287). Others have reported similar results after prolonged bed rest $(31,66,157$, $327)$, head-down tilt of short duration $(37,250)$, and space flight from 6 to 84 days $(51,236,283)$. In contrast the in-flight exercise data from the Skylab missions (236) showed little or no change from preflight data. Three of the nine Skylab crew members actually had lower heart rates during exercise in space, suggesting, if anything, an improved exercise capacity at zero gravity.

There is little information on the distribution of cardiac output during and after exposure to hypogravic conditions. Saltin, Blomqvist, et al. (287) found a normal systemic arteriovenous oxygen difference during maximal exercise consistent with a normal pattern of redistribution of flow to active tissues.

Physical signs and symptoms suggesting cranial venous congestion at zero gravity have raised concerns about the state of the cerebral circulation. However, there is no evidence for any significant impairment of cerebral function in space. Russian studies on the cerebral circulation at zero gravity and during headdown tilt, based on direct measurements of arteriovenous oxygen differences (179) and rheography or impedance plethysmography (359), suggest increased cerebral flow, but the significance of these findings has not been established.

ORTHOSTATIC INTOLERANCE. Many bed-rest studies measuring heart rate and indirect arterial pressure have evaluated changes in orthostatic tolerance. Head-up tilt at $70^{\circ}$ for $5-20 \mathrm{~min}$ is the most widely used method, but a variety of alternate procedures has also been employed, e.g., LBNP and $+G_{z}$ centrifugation. The maximal heart-rate difference between supine rest and head-up tilt typically increases from about +25 beats/min before bed rest to $+40-+50$ beats/min after bed rest $(59,194,327,340,342)$. Arterial pressures during orthostatic stress are lower after prolonged bed rest, and the incidence of presyncope and syncope increases significantly. Brief exposure to head-down tilt $(24 \mathrm{~h})$ and to water immersion $(6 \mathrm{~h})$ has produced equally large changes in orthostatic tolerance, as judged from the heart-rate response to LBNP and tilt $(37,228,250)$.

The Skylab-4 astronauts showed an average post- 
flight increase in heart rate during LBNP at -50 $\mathrm{mmHg}$ of 27 beats/min after 89 days in space. In-flight LBNP measurements demonstrated similar changes. Decreased tolerance developed during the first few days without further changes, and toward the end of the flight there was even some improvement (172). The Apollo astronauts (150) had after much shorter exposure to zero gravity a mean heart rate during LBNP at $-50 \mathrm{mmHg}$ of 109 beats/min compared to 76 beats/min preflight, i.e., a difference of 33 beats/ $\min$.

Countermeasures. Investigators have tested a wide variety of interventions in attempts to prevent the cardiovascular deconditioning induced by bed rest and space flight. Principal approaches include exercise, redistribution of venous volume, and blood volume expansion.

1. Even vigorous exercise in the supine position fails to prevent orthostatic intolerance after bed rest. The effects on exercise capacity in the upright position are variable. A significant decrease is rarely prevented, but the reduction tends to be smaller than in nonexercising controls $(29,30,45,56,194,237,323)$. Most investigators have used dynamic exercise, but static exercise had unexpectedly favorable effects in a study by Stremel et al. (323). Exercise may be a more valuable countermeasure during space flight than during bed rest. The crew members of Skylab 4 performed a large amount of exercise in space and had less cardiovascular dysfunction postflight than the crew members of Skylab 2 and 3, who exercised less vigorously during their shorter missions $(172,236)$. Current Russian in-flight regimens also include an extensive exercise program (359).

2. Intermittent redistribution of venous volume during bed rest to approximate the normal intravascular pattern during sitting or standing is helpful. Birkhead et al. $(29,30)$ demonstrated that a daily 3 -h standing or 8-h quiet sitting prevented the development of orthostatic intolerance. Prolonged application of LBNP is cumbersome but prevents or minimizes plasma volume loss and orthostatic intolerance (191, 314-316). Other devices, designed to simulate normal hydrostatic gradients, e.g., an elastic reverse-gradient garment, have been effective in short-term ( $<4 \mathrm{~h}$ daily) applications (67). Currently LBNP devices with relatively few restrictions on body movement in space are being evaluated in both the Russian and American space programs.

3. Reexpansion of the blood volume to pre-bed-rest levels has been achieved by oral administration of $9 \alpha$ fluorohydrocortisone during the last 3 days of a period of prolonged bed rest, but orthostatic intolerance persisted $(313,317)$. Hyatt (157) administered daily doses during a 10-day bed-rest study and produced a blood volume expansion relative to control values before bed rest. The heart rate during post-bed-rest tilt nevertheless remained slightly elevated. Later rehydration experiments by Hyatt and West (159) tested the effects of oral administration of saline at the end of a 1-wk bed-rest period. Saline alone did not restore plasma volume and orthostatic tolerance, but the combination of saline and a 4-h period of LBNP produced a transient return to pre-bed-rest levels. In a recent study after a $24-\mathrm{h}$ period of head-down tilt at $-5^{\circ}$ (37), intravenous saline infusion sufficient to bring central venous pressure back to pretilt levels in the supine position failed to restore orthostatic tolerance but essentially abolished the loss of exercise capacity in the upright position. Normalization of central venous pressure required a volume corresponding to twice the blood volume loss.

4. Other countermeasures, including exposure to simulated high altitude (317) and mechanical devices designed to introduce sudden large longitudinal $g$ forces (56), have generally been ineffective. Three recent approaches have provided intriguing but as yet unconfirmed results. Bhattacharya et al. (27) found that whole-body oscillation (half-sine function at $1 \mathrm{~Hz}$ for $20 \mathrm{~min}$ daily) prevented orthostatic intolerance after immersion. Prophylactic treatments with a $\beta$ adrenergic blocking agent (233) and a calcium antagonist (39) have also been used successfully in small groups of subjects.

Mechanisms. Postural hypotension, i.e., an abnormally low arterial pressure in the upright position, is a common clinical problem. Some aspects of the pathophysiology provide relevant background material for the analysis of the orthostatic intolerance after bed rest and related conditions. There are two principal primary mechanisms: 1) an abnormal degree of orthostatic central hypovolemia and 2) inadequate cardiovascular regulatory responses. The regulatory and hemodynamic patterns in the hypovolemic group exaggerate the normal response, i.e., increased adrenergic drive reflected by elevated plasma catecholamines, marked tachycardia, and vasoconstriction. The second group is heterogeneous and includes conditions that abolish or attenuate the cardiovascular responses to physiological redistribution of hydrostatic pressure gradients and intravascular volumes.

1. Hypovolemic hyperadrenergic postural hypotension [arterial circulatory anemia (33) and sympathicotonic orthostatic hypotension (253)] is caused by a reduction in total blood volume or an abnormal volume distribution during orthostatic stress. Variations in total blood volume well within the physiological range affect orthostatic tolerance. Murray et al. (241) examined the combined effects of venesection and LBNP. Measurable orthostatic intolerance appeared after an acute blood volume loss of $500 \mathrm{ml}$. Bergenwald et al. (19) studied normal subjects during prolonged head-up tilt and found that fainters had significantly lower $(-8 \%)$ total blood volume than nonfainters. The size of the central blood volume pool may also be an important determinant. Women have larger increases in heart rate and decreases in arterial pressure and stroke volume than men at a given degree of venous 
pooling and also a smaller basal end-diastolic ventricular volume and a limited systolic reserve $(101,292)$.

Gaffney, Blomqvist, et al. $(100,102)$ have studied patients with mitral valve prolapse and hyperadrenergic postural hypotension. The functional characteristics of the abnormal valve probably contribute to the orthostatic intolerance by causing an abnormally large decrease in stroke volume in the upright position although these patients also have an inappropriately large increase in vasoconstrictor activity in the upright position and a significantly reduced total blood volume. The combination of a chronically vasoconstricted state, hypovolemia, and postural hypotension is also present in some patients with essential hypertension or pheochromocytoma.

Conditions that increase peripheral venous pooling are associated with orthostatic intolerance. Patients with massive venous varicosities or a congenital absence of the venous valves have postural hypotension and decreased exercise capacity in the upright position (26). They also have an increased compliance of nonvaricose veins (363). The most important physiological mechanisms affecting the degree of pooling are linked to thermoregulation. Venous compliance and pooling are proportional to skin temperature. Heat significantly reduces and cold increases orthostatic tolerance $(145,147,266,267)$.

2. Normovolemic regulatory postural hypotension [postural (44), orthostatic (33), and asympathicotonic (253) hypotension] can be caused by 1) abnormal baroceptor function, 2) peripheral or central lesions of the nervous system interrupting afferent or efferent neural pathways or causing dysfunction of the medullary cardiovascular control centers, or 3) end-organ failure to respond to autonomic stimuli. Such failure may be caused by nonneural lesions, e.g., lack of postural heart-rate response in patients with a degenerative disease of the sinus node (sick-sinus syndrome) or complete heart block. High- and low-pressure baroceptor function is altered in many different cardiovascular disorders $(2,76,82)$, but the efferent rather than the afferent limb is usually involved in patients with severe orthostatic hypotension. The response pattern is hypoadrenergic, with a lack of tachycardia and vasoconstriction. Parasympathetic involvement may also be a factor. Autonomic dysfunction with hypoadrenergic orthostatic hypotension may be idiopathic or one of several clinical manifestations of many different systemic and neurological disorders, e.g., diabetic neuropathy, tabes dorsalis, amyloid diseases, syringomyelia, traumatic lesions of the spinal cord, cerebrovascular disease, tumors, and degenerative or demyelinating diseases of the central nervous system (21, 25, 160-162, 212, 297, 298, 344).

Idiopathic orthostatic hypotension and the ShyDrager syndrome are relatively rare forms. They are diseases of late middle age with general signs of dysfunction of the autonomic nervous system, e.g., bowel and bladder disturbances, inability to sweat, and im- potence. The Shy-Drager syndrome (304) identifies a distinct group of patients who have orthostatic hypotension and signs of extrapyramidal tract involvement (Parkinson's disease); there are widespread but nonspecific degenerative lesions of the central nervous system. Patients with the Shy-Drager syndrome or idiopathic orthostatic hypotension often have abnormal cardiovascular function also at rest supine. The functional characteristics of the heart suggest denervation. Stroke volume is low, perhaps because of a decreased contractility, and there is mild tachycardia at a relatively fixed rate. Peripheral resistance increases rest, but the postural vasoconstrictor responses are absent or greatly attenuated $(161,162)$. Humoral abnormalities can also be demonstrated. The catecholamine response to orthostatic stress is attenuated or absent $(263,361)$, and postural changes in plasma renin levels are often but not always $(43,212)$ subnormal, consistent with an efferent autonomic block. Some patients also have diminished aldosterone responses and a decreased ability to conserve sodium (142).

The hypovolemic-hyperadrenergic and the normovolemic-hypoadrenergic varieties of postural hypotension cannot always be clearly distinguished. Ibrahim et al. (160-162) have shown that patients with idiopathic orthostatic hypotension have a reduced blood volume and vasoconstriction at rest supine with increased arterial pressure and total peripheral resistance.

Orthostatic tolerance is often increased in certain clinical conditions, e.g., hypertension and congestive heart failure $(3,243,298)$. Cardiac performance characteristics with attenuated preload effects on the stroke volume, decreased venous compliance, and increased total and central blood volumes together counteract autonomic dysfunction with blunted reflex responses $(76,79,82)$.

Orthostatic intolerance after prolonged bed rest and related conditions. A critical analysis of the descriptive material that has been presented on the effects of prolonged bed rest and related conditions and on countermeasures identifies the following salient points:

1. Prolonged bed rest (horizontal, with head-down tilt), water immersion, and exposure to zero gravity produce actual and functional hypovolemia.

2. Postintervention cardiovascular dysfunction is characterized by orthostatic intolerance and decreased exercise capacity. Left ventricular end-diastolic volume and stroke volume are reduced in both the upright and supine positions. Intrinsic myocardial function is not depressed.

3. The degree of cardiovascular dysfunction is more severe than expected from the magnitude of the blood volume loss. Volume for volume replacement significantly improves hemodynamics but does not fully restore normal function.

4. The altered distribution of body fluids with a 
headward shift is probably more important than inactivity in the development of cardiovascular dysfunction. Intermittent redistribution of venous volume (LBNP, short periods of standing) to match the conditions that normally prevail in the upright position protects against orthostatic intolerance. Vigorous exercise is less effective. Furthermore the cardiovascular dysfunction induced by prolonged bed rest or space flight is similar to that induced by periods of water immersion or head-down tilt of $24 \mathrm{~h}$ or less. Adaptation to inactivity, as reflected by functional and structural changes in the musculoskeletal system and the myocardium, is slower.

The discrepancy between the magnitude of the blood volume loss and the severity of the cardiovascular dysfunction suggests that adaptation produces changes in venous function, e.g., increased compliance, an abnormal pattern of postural redistribution of blood volume, systemic regulatory abnormalities, or a combination of these features. The increased heart-rate response to orthostatic stress after exposure to hypogravic conditions is consistent with a hypovolemichyperadrenergic pattern. However, there is only inconclusive evidence for a postadaptive increase in venous compliance and the degree of venous pooling needed to amplify the effects of the modest decrease in blood volume. Immersion produces an increase in peripheral venous compliance that persists for the duration of the intervention (81). Stevens et al. (316) found an increased venous compliance after bed rest reflected by measurements of leg volume changes during LBNP. Occlusion plethysmography during and after the Skylab-4 flight suggested increased venous compliance, whereas measurements of leg volume changes during LBNP showed increased pooling only at zero gravity (335). On the other hand estimates of the compliance of the arm (occlusion plethysmography), the leg (leg volume changes during LBNP), and the systemic veins (relating central venous pressure to leg volume changes during LBNP) showed no changes after adaptation to head-down tilt (37). Thornton et al. (335) suggested that decreased skeletal muscle tone contributes to an increased degree of venous pooling after space flight and bed rest.

Data on autonomic function after bed rest and space flight are inconclusive. As discussed earlier in this section, the postadaptive heart-rate response to orthostatic stress is increased, which may be an appropriate compensation for a decrease in stroke volume. The normal vasoconstrictor responses also appear to be intact (37). Chobanian et al. (59) found no bedrest-induced changes in the pressor responses to norepinephrine and angiotensin infusions. Plasma catecholamines were reduced during bed rest, but the response to tilt was unchanged. The apparent turnover rate of norepinephrine was also normal. However, Schmid et al. (294) demonstrated decreased vaso- and venoconstrictor responses to intra-arterial tyramine after a 12-day bed-rest period. The responses to nor- epinephrine did not change. These findings are consistent with normal receptor function but impaired release of endogenous norepinephrine, perhaps caused by a decreased rate of synthesis. Furthermore Billman, Dickey, Stone, and associates $(28,73)$ have recently documented reduced baroceptor sensitivity and altered responses to vasoactive drugs after long-term horizontal immobilization in rhesus monkeys.

The combined data, although incomplete and inconclusive, suggest that the orthostatic intolerance after bed rest and related conditions is a multifactorial disorder. Changes in effective venous compliance and perhaps also subtle autonomic dysfunction appear to amplify the effects of a moderate absolute hypovolemia.

\section{Dynamic Responses}

Most studies of prolonged bed rest and related conditions have been limited to static before-and-after comparisons, and little is known of the dynamic response. Nevertheless there is strong evidence that the primary stimulus for the adaptation is the shift of intravascular and interstitial fluid from the lower to the upper half of the body, particularly to the central circulation. The absolute magnitude and exact time course of the responses to bed rest, head-down tilt, immersion, and weightlessness vary for specific functions, but enough similarities have been documented to justify the use of head-down tilt as a tentative model for analysis of the general features of adaptation to hypogravic conditions.

Figure 12 is based on two experiments with 24 -h head-down tilt at $-5^{\circ}$, each including five normal young men $(37,250)$. The base line for all measurements was supine rest. A decrease in leg volume of

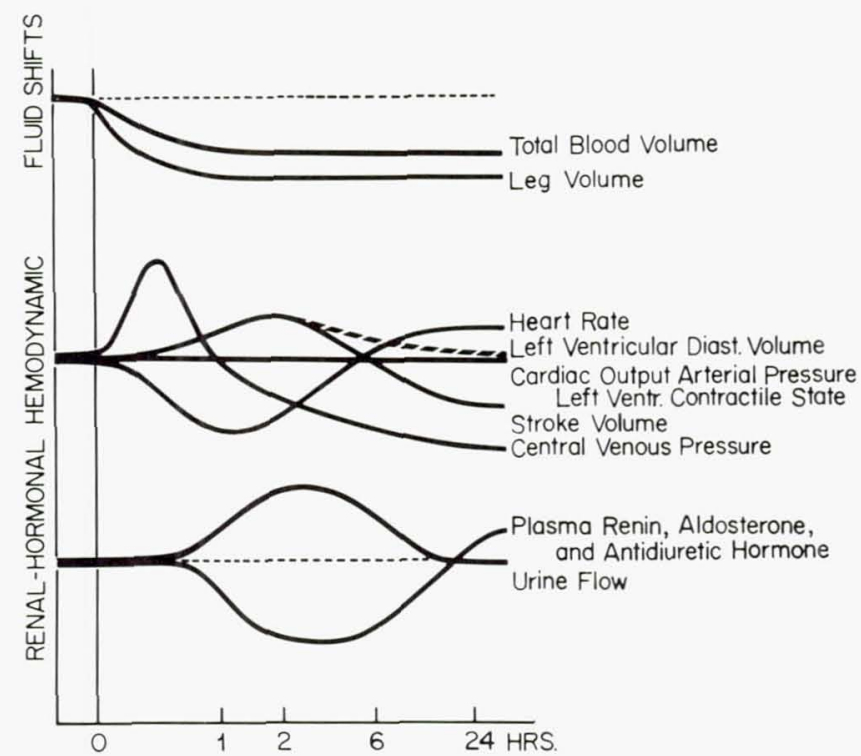

FIG. 12. Diagram of early adaptation to simulated $0 \mathrm{~g}$ (headdown tilt, $-5^{\circ}$ ). [From Blomqvist et al. (37).] 
about 1 liter during the initial $2 \mathrm{~h}$ indicates a central fluid shift. Central venous pressure increased significantly by $2.5 \mathrm{cmH}_{2} \mathrm{O}$ but returned to the base line within $1 \mathrm{~h}$. This decrease was associated with a transient apparent increase in venous compliance, whereas effective systemic and peripheral venous compliances were normal at the end of $24 \mathrm{~h}$. Stroke volume and left ventricular end-diastolic volume also increased transiently and reached a maximum somewhat later than central venous pressure, or at about $2 \mathrm{~h}$. The contractile state did not change, nor did cardiac output. The increase in stroke volume was offset by relative bradycardia. Arterial pressures also remained unchanged. Central venous pressure and stroke volume were at $24 \mathrm{~h}$ below the base line, and the heart rate was slightly elevated.

Plasma renin, aldosterone, and $\mathrm{ADH}$ levels decreased transiently during the initial $6 \mathrm{~h}$ and a diuresis produced a weight loss equal to the loss in leg volume and more importantly decreased total blood volume $350 \mathrm{ml}$. Neither plasma osmolality nor electrolyte concentrations changed, but the urinary sodium/potassium excretion ratio increased.

Gauer and Henry (107) considered activation of lowpressure baroceptors, reflex inhibition of $\mathrm{ADH}$, and a water diuresis as the primary responses to a central fluid overload. The discrete venoatrial receptors are probably important (209), but impulses originating in the atrial and ventricular $\mathrm{C}$ fibers may also have a significant impact on renal function and the fluidelectrolyte balance (334). The role of atrial distension has been disputed (115). Epstein et al. $(87,89,90)$ have clearly documented inhibition of the renin-aldosterone system and a saluresis during immersion experiments. Their data also indicate that it is unlikely that osmoreceptors or changes in renal hemodynamics have a major role. Data on fluid balance and hormonal responses at zero gravity (200) differ from the results obtained during head-down tilt and immersion. No demonstrable diuresis coincided with the early weight loss during the Skylab flights, but fluid intake decreased. Data on the early hormonal responses in space are not available. Measurements during the early recovery phase after the Skylab flight (200) and after a study on head-down tilt by Volicer et al. (343) were consistent with a relative combined inhibition of $\mathrm{ADH}$ and aldosterone during exposure to hypogravic conditions and a reactivation during the recovery phase. The role of other hormones (prostaglandins, natriuretic hormone) is doubtful (87).

The apparent overshoot of the hemodynamic adaptation at $24 \mathrm{~h}$ with a reduced filling pressure and stroke volume relative to base-line levels in the supine position supports Gauer's thesis that the upright position is the normal operating condition. When the adaptation to the hypogravic state (i.e., bed rest, headdown tilt, or space flight) is complete, hemodynamic conditions approach those that normally prevail during sitting or standing. A system adapted in this fash- ion has little reserve capacity to manage additional stresses caused by postural fluid redistribution. The cardiovascular dysfunction after bed rest and space flight therefore results from a successful adaptation that has suddenly been rendered inappropriate by the reexposure to normal gravitational fields and to large hydrostatic gradients.

\section{HYPERGRAVIC CONDITIONS}

\section{Experimental Conditions}

Hypergravic conditions can be generated within the earth's gravitational field by acceleration (i.e., changing velocity or direction of motion of a body). Linear acceleration occurs when the rate of motion increases or decreases without changing direction, and angular acceleration occurs when the direction of motion changes. For example, a car that is gaining or losing speed traveling down a straight road exposes the passenger to linear acceleration, whereas going around a curve creates angular acceleration. The terms gravitational force and acceleration are interchangeable because the physical quantity of gravity is defined as an acceleration. The acceleration of a body falling freely toward the earth's surface in airless space is $1 \mathrm{~g}$, or $981 \mathrm{~cm} / \mathrm{s}^{2}$. It is correct to speak of a gravitational force $(\mathrm{F})$ as the product of the mass of an object $(\mathrm{m})$ and acceleration $(a)$, or $\mathrm{F}=m a$, if the mass is a constant. Mass then becomes a proportionality factor. In biomedical applications the mass of the object being studied, either a human subject or an experimental animal, does not change significantly over the course of an experiment.

A standard nomenclature has been developed that defines the anatomical direction of the gravitational force (Fig. 13). The two gravitational forces shown in Figure 13 act either through the long axis of the body $\left( \pm G_{z}\right)$ or across the body from back to front or front to back $\left( \pm G_{\mathrm{x}}\right)$. A third gravitational force, not shown in Figure 13, acts across the lateral aspect of the body $\left( \pm G_{y}\right)$. In general the gravitational force is expressed in multiples of unity. A force of $3+G_{z}$ is 3 times the normal gravitational force acting in the head-to-foot direction. In the following discussion the major emphasis is placed on gravitational forces acting in the $+G_{\mathrm{z}}$ direction over periods of several seconds to minutes. Such forces may be viewed as an exaggeration of the forces acting during a change in body position from supine to upright. Gravitational forces of short duration (impact forces), i.e., $1 \mathrm{~s}$ or less, are not considered, and little information is available on the circulatory changes with $-G_{\mathrm{z}}$ and $\pm G_{\mathrm{y}}$ accelerations.

Hydrostatic pressure is a linear function of the force of gravity. Tripling the gravitational force triples the hydrostatic component of pressure along any fluid column parallel to the gravitational force. Hydrostatic pressure changes $\sim 1 \mathrm{cmH}_{2} \mathrm{O} / \mathrm{cm}$ vertical distance at 1 
FIG. 13. Standard reference system (direction and nomenclature) for gravitational forces acting on a subject through long axis of body $\left( \pm G_{2}\right)$, through sternum to backbone $\left( \pm G_{x}\right)$, and through lateral aspect ( $\pm G_{y}$, not shown).

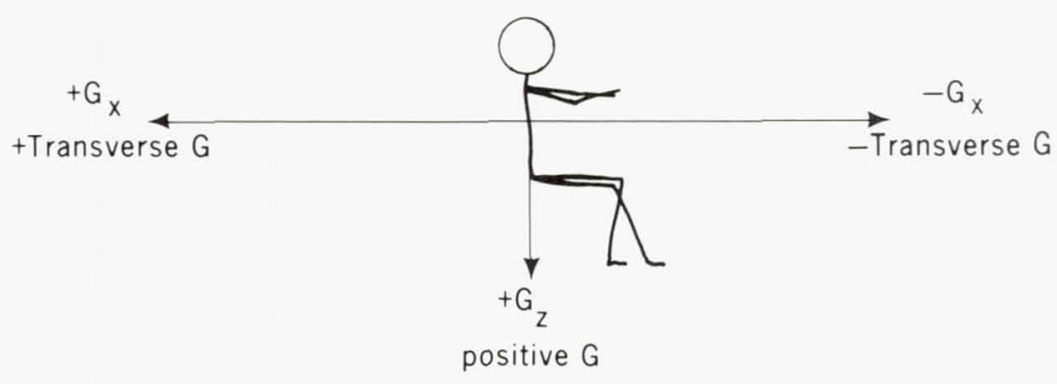

g. At $3+G_{\mathrm{z}}$ the corresponding hydrostatic pressure change is $3 \mathrm{cmH}_{2} \mathrm{O} / \mathrm{cm}$ vertical distance. In a fluid column exposed to an increased gravitational force, the local pressure at any site along the column varies directly with the position in the column either above or below the HIP.

\section{Fluid Shifts}

A $+G_{z}$ increase accentuates orthostatic fluid shifts from the intrathoracic compartment to the legs. Early work (104) in Germany on human volunteers demonstrated a large increase in the volume of the lower leg at $6-8+G_{z}$. Chest X-ray films taken during aircraft flight and centrifuge experiments indicated that the lung fields became clearer during increasing acceleration, which is consistent with a decrease in pulmonary blood volume or a redistribution of pulmonary blood flow. A loss of plasma volume to the interstitial space also accompanies the redistribution of blood volume. The amount of plasma volume loss depends on the duration and magnitude of the gravitational force (62, 132). Large volumes may be lost very rapidly at high $G$ forces, e.g., $216-270 \mathrm{ml}$ at $3.5-5.0+G_{\mathrm{z}}$ maintained for 3-5 min.

The human regulatory responses to $+G_{\mathrm{z}}$ acceleration have many features in common with the changes during standing. The shift of blood out of the thorax leads to an increase in plasma ADH levels (127, 183, 273). Plasma renin activity did not change with the increased gravitational force in these experiments, perhaps because of a large increase in plasma $\mathrm{ADH}$ or simply the short duration of the $+G_{z}$ exposure. Plasma renin activity increases in volunteers exposed to $+G_{\mathrm{x}}$ acceleration for up to $30 \mathrm{~min}(91,272)$. The increase in plasma $\mathrm{ADH}$, not a result of a change in plasma osmolarity, probably is caused by the shift in blood volume and decreased activation of cardiopulmonary receptors $(107,108)$. In human volunteers $+G_{z}$ also causes a central blood volume shift that is associated with a reduction in plasma $\mathrm{ADH}$ and a diuresis (273). Exposure to high $G$ forces, however, also produces mechanical effects that may modify the regulatory responses.

\section{Cardiac Dimensions and Performance}

The heart is normally suspended by the central vasculature and the pericardium, which tends to make the heart vulnerable to increased gravitational forces, particularly to $+G_{\mathrm{z}}$ acceleration. Gauer (104) initiated radiographic studies of the response to hypergravic conditions in cats and monkeys in 1936. Centrifuge experiments showed that $+G_{\mathrm{z}}$ acceleration pushed the heart caudally and reduced both systolic and diastolic volumes. The apical portions of the ventricles were devoid of contrast material during systole. Contrast material was injected intravenously prior to the acceleration exposure, and no distinction could be made between the right and left sides. The obliteration of the apical cardiac chambers during $+G_{\mathrm{z}}$ acceleration led to the hypothesis that the endocardial walls may actually rub against each other during systole, causing cardiac damage (111).

The end-systolic volume of the ventricles depends on the level of autonomic nervous system activity (contractile state) and the pressure in the aorta during ejection (afterload). The level of $+G_{\mathrm{z}}$ acceleration greatly influences direct mechanical effects, the autonomic activity, and the aortic pressure. Erickson, Sandler, and Stone (93) studied anesthetized dogs during $+G_{\mathrm{z}}$ acceleration and also demonstrated that the heart was progressively shifted caudally as the level of $+G_{z}$ acceleration was increased. In recent studies with similar conditions H. Sandler (unpublished observations) obtained cineangiograms from anesthetized dogs during $+G_{z}$ acceleration. Left ventricular diastolic and systolic volumes were reduced, but there was no evidence that the walls of the left ventricle actively hit each other during systole. The aorta and vessels leaving the arch of the aorta are stretched during $+G_{\mathrm{z}}$ acceleration, and the diameter of the vessels is reduced. The coronary vessels apparently are not involved, and mechanical obstruction 
during $+G_{\mathrm{z}}$ acceleration is unlikely (93). During transverse acceleration $\left(+G_{\mathrm{x}}\right)$ the heart is displaced toward the posterior portion of the thorax with minor changes in ventricular chamber dimensions (290).

The electrical activity of the human heart during acceleration stresses has been studied extensively for more than 35 years in both centrifuge and aircraft experiments. Gauer (104) described flattening of the T waves in the limb leads, sometimes associated with S$\mathrm{T}$ segment elevation at higher acceleration levels. Cardiac dysrhythmias ranging from atrioventricular block to premature ventricular contractions were also seen. Gauer noted the similarity between these changes and those during myocardial ischemia and suggested that coronary flow was compromised during acceleration stress. In a subsequent study Zuidema et al. (364) found potentially serious cardiac arrhythmias in four subjects, one of whom also had chest pain. These findings may support the view that myocardial ischemia limits the ability of humans to tolerate $+G_{z}$ acceleration. However, acceleration levels as high as $9+G_{z}$ $(50,63,114,153,300)$ have failed to produce any significant arrhythmias persisting after deceleration. In several studies premature ventricular contractions and multiform arrhythmias were observed during the early portion of the various acceleration profiles, but they disappeared either before or at the termination of the acceleration stress. This time course is inconsistent with ischemia. The movement of the heart in the chest cavity and increased efferent cardiac sympathetic activity could explain the electrocardiographic (ECG) changes in normal volunteer subjects. $\beta$-Adrenergic blockade prevents the T-wave changes induced by acceleration (63).

Blood flow to the myocardium during $+G_{z}$ acceleration has been examined in experimental animals (58, $93,198,300,320)$, but the results are inconclusive. Chimoskey (58) found a decrease in coronary flow when unanesthetized dogs were exposed to brief durations (10 s) of $+G_{z}$ acceleration. The decrease in coronary flow coincided with the development of Twave changes of the ECG. Shubrooks (300) found that coronary flow increased up to $3.5+G_{z}$ in anesthetized dogs during the early portion of the acceleration stress and either remained elevated or returned to control levels by the end of the 60 -s stress period, whereas Erickson, Sandler, and Stone (93) found a decreased coronary flow in anesthetized dogs exposed to up to 4 $+G_{\mathrm{z}}$. As coronary flow decreased so did coronary sinus oxygen saturation. This study would suggest some potential for myocardial ischemia. Using unanesthetized miniature swine, Stone et al. (320) found that coronary flow decreased up to levels of $9+G_{z}$ with the most significant decreases above $5+G_{\mathrm{z}}$. Using microspheres to measure coronary flow and distribution in miniature swine, Laughlin et al. (198) found that coronary flow increased up to $7+G_{z}$. They used aortic pressure as a reference point for the measurement of coronary flow, however, and made no measurements if the pressure fell below $100 \mathrm{mmHg}$. This and other variations in methodology may at least partially explain the divergent results of the flow measurements.

Flow measurements cannot provide information on the potential for ischemia without data relating to myocardial oxygen demand. The effect of $+G_{z}$ acceleration on the oxygen demand of the heart and on the balance between oxygen demand and supply is uncertain. Demand probably increases because of the increase in heart rate with maintenance or elevation of aortic root pressure, but the effect on wall tension is modified by a changing cardiac chamber geometry and probably also by changes in the contractile state.

Ultrastructural and biochemical changes have been observed in hearts taken from miniature swine immediately after exposure to various levels of $+G_{\mathrm{z}}$ acceleration. Burton and MacKenzie (52) found left ventricular subendocardial hemorrhage that was directly related to the level and duration of acceleration exposure. Heart rate and/or the sympathetic nervous system were involved because $\beta$-adrenergic blockade reduced heart rate during acceleration and reduced the degree of subendocardial hemorrhage. In the same animals MacKenzie et al. (215) studied the ultrastructural changes and found myofibrillar degeneration, pooling of mitochondria, and involvement of the Purkinje fibers. Lindsey, Stone, et al. (210) also examined the ultrastructural changes of myocytes from swine exposed to $9+G_{\mathrm{z}}$. They found changes similar to those described by MacKenzie et al. (215) and also evidence of disruption of contractile fibers in some cells. Biochemical studies (78) have demonstrated an increase in proteolytic enzyme activity in the myocardial cells up to $2 \mathrm{wk}$ after acceleration exposure. Whether these signs of myocardial damage are caused by ischemia, hypoxia, or increased release of catecholamines is not known. How significant these findings are to potential hazards of acceleration stress $\left(+G_{z}\right)$ to humans is uncertain, but they should not be ignored.

\section{Cardiac Output and Regional Flow}

The ability of the cardiovascular system to withstand $+G_{z}$ acceleration is defined clinically by the appearance of limiting symptoms. The usual endpoint criteria for measuring acceleration tolerance progress from the loss of vision to unconsciousness. Loss of vision usually occurs around $4.0+G_{\mathrm{z}}$ and blackout occurs around $4.5+G_{z}$ in relaxed humans (153). These endpoints vary considerably between and within individuals, and the threshold level can be altered by protective devices (anti-G suit) or maneuvers (straining). Lambert and Wood (193) measured eye-level arterial pressure in volunteers and found that vision was lost at an average arterial pressure of $20 \mathrm{mmHg}$. Figure 14 is a representative graph of the acceleration tolerance for $+G_{\mathrm{z}}$. Levels of acceleration and times of exposure below the curve can be well tolerated by most relaxed humans. 
FIG. 14. A representative average curve for $+G_{2}$ acceleration tolerance in relaxed humans in seated position. Top of graph, reported symptoms at these acceleration levels. Increased tolerance above $10 \mathrm{~s}$ is probably circulatory reflex compensating for increased gravitational force.

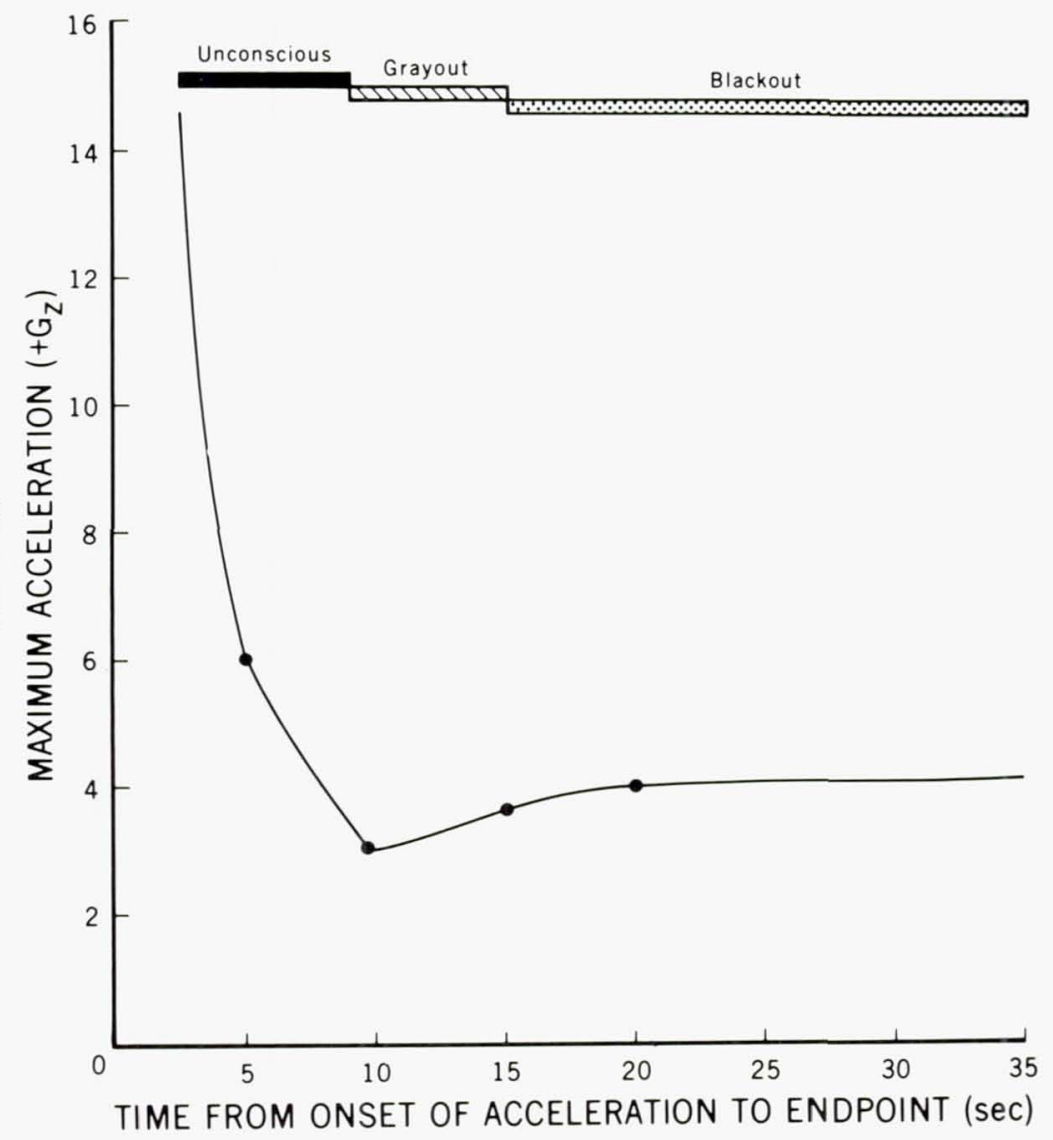

Shubrooks (300) found that heart rate increased in an almost linear fashion with increasing $+G_{\mathrm{z}}$ acceleration up to levels of $\sim 6+G_{\mathrm{z}}$ in subjects protected from the usual endpoints of acceleration stress. Maximal heart-rate responses were achieved within 3-12 s after the occurrence of peak $G$ levels, and rates tended to remain at this level for the duration of the experiment. Peak heart rates measured in this study ranged from 155 to 205 beats/min and were not related to the preacceleration heart-rate level. When the acceleration is terminated a considerable bradycardia usually ensues. The increase in heart rate in human subjects during $+G_{\mathrm{z}}$ acceleration appears to be mediated mainly by the sympathetic nervous system with a minor contribution from vagal withdrawal $(34,35)$. The relative importance of sympathetic and parasympathetic mechanisms, however, is likely to vary with preexisting or background levels of autonomic activity (270). Upon cessation of the acceleration stress atropine can block the bradycardia (205), which clearly indicates a strong reversal of the autonomic nervous system balance occurring at the sinoatrial node. During $+G_{\mathrm{x}}$ acceleration the heart rate also increases but less than during $+G_{\mathrm{z}}$ acceleration. During $-G_{\mathrm{z}}$ acceleration the heart rate decreases as the pressure rises in the region of the head and the carotid sinus.

Cardiac output and stroke volume have been measured in human volunteers during $+G_{\mathrm{z}}$ acceleration
(207, 208, 275, 357). Table 3 shows representative results. Both cardiac output and stroke volume fall progressively with increasing gravitational force, but the aortic pressure measured at the heart level actually increases, indicating peripheral vascular adjustments during this type of stress. The decrease in cardiac output is the result of the peripheral shift in blood volume, a decreased venous return, and a reduced enddiastolic volume of the ventricles. Rosenhamer (275) found that cardiac output at $3+G_{z}$ remains about 3 liters/min below the expected levels at $1+G_{\mathrm{z}}$ also during exercise. However, the rate of increase in cardiac output relative to oxygen uptake is similar at 1 and $3+G_{z}$, or about 6 liters/min for a 1 liter $/ \mathrm{min}$ increase in $\mathrm{O}_{2}$ uptake. Stroke volume also remains subnormal during exercise at $3+G_{\mathrm{z}}$, but the increase on transition from rest to exercise is larger than at 1 $+G_{\mathrm{z} .}$

Cardiac output in the human does not decrease during $+G_{\mathrm{x}}$ acceleration (Table 3 ). Results were similar during moderate levels of $+G_{\mathrm{x}}$ acceleration in experimental animals. Arterial pressure referenced to heart level was maintained and even increased slightly. There was a small decrease in stroke volume. A decrease in cardiac output was recorded at $15+G_{\mathrm{x}}(318)$. Exceedingly high levels of $+G_{\mathrm{x}}$ acceleration probably compromise ventricular filling when the heart is being pushed against the posterior chest wall. 
PULMONARY BLOOD FLOW. The effect of $1+G_{z}$ on the regional distribution of pulmonary blood flow is well documented, and an increase in $+G_{\mathrm{z}}$ acceleration is expected to accentuate it (352). Blood flow in the lungs shifts from the superior region of the lungs (apex) toward the more dependent lung region (base). This might cause greater right-to-left shunting of blood, which would reduce the oxygen content of arterial blood. Decreases in arterial oxygen saturation have been demonstrated in both humans and experimental animals exposed to acceleration stress (13-15, 252, 268, $312,356)$. The decline in arterial oxygen content is progressive during $+G_{\mathrm{z}}$ acceleration and can lead to saturation values less than $80 \%$ at $5+G_{\mathrm{z}}(356)$. Oxygen breathing reduces but does not abolish the decline in oxygen saturation (14). The effective alveolar-arterial oxygen difference decreases on the transition from rest to exercise at normal gravity but increases during exercise at $3+G_{\mathrm{z}}$, presumably because of an increase in the number of alveoli with low ventilation/perfusion ratios (275). During $+G_{\mathrm{x}}$ acceleration arterial oxygen saturation at rest can decline to as low as $75 \%$ at 8 $+G_{\mathrm{x}}(312)$. The increase in accelerative forces increases alveolar size in superior lung regions and decreases it in the dependent regions, causing a greater ventilation/perfusion mismatch $(57,131,339)$.

BRAIN. The distribution of cardiac output has been examined to a limited extent in human volunteers and in experimental animals. As mentioned previously, loss of vision and unconsciousness are experimental endpoints for the termination of $+G_{\mathrm{z}}$ acceleration. Clearly blood flow to the head must be reduced, since arterial pressure at eye level can fall below the range of cerebral blood flow autoregulation $(149,193)$. Total perfusion of the brain measured by the radioisotopeclearance technique was reduced at 2,3 , and $4+G_{\mathrm{z}}$ in humans. The long time required to accomplish these measurements precluded studies at higher levels of acceleration (155) and also raises some questions concerning the measurements at $2-4+G_{z}$, since a steadystate condition is a prerequisite for accurate measurement. In anesthetized primates, cerebral blood flow remained almost constant until arterial pressure at the base of the brain dropped below $65 \mathrm{mmHg}$ at which point cerebral flow declined as arterial pressure fell (H. L. Stone, unpublished observations). This occurred at 3.0-3.5 $+G_{\mathrm{z}}$ in all animals studied. Clearly there is no way to relate this level to loss of vision in these anesthetized animals, but the decreasing pressures strongly suggest a reduction in blood flow to the brain. Cerebral blood flow has not been measured during $-G_{z}$ acceleration, but there is no reason to suspect that it is compromised.

SPLANCHNIC AND MUSCLE BLOOD FLOW. Howard and Garrow (154) and Stone (318) measured forearm blood flow, splanchnic blood flow, and arterial pressure in six normal volunteers (Fig. 15). Forearm blood flow, measured by a mercury-in-Silastic strain gauge, de- creased considerably at $3+G_{\mathrm{z}}$ compared to $1 \mathrm{~g}$. Resistance increased, indicating active vasoconstriction. Splanchnic blood flow (indocyanine-green clearance) changed little, and the pressure-flow ratio increased, suggesting splanchnic vasoconstriction. In experimental animals (322) splanchnic blood flow decreased drastically during acceleration when the position of the animal's body was changed from a $+G_{\mathrm{x}}$ acceleration position to $\mathrm{a}+G_{\mathrm{z}}$ acceleration position. Greenleaf et al. (127) measured leg blood flow in three subjects exposed to increasing levels of $+G_{\mathrm{z}}$ acceleration. Flows decreased from mean resting values of $6-9 \mathrm{ml} \cdot \mathrm{min}^{-1}$. $100 \mathrm{ml}^{-1}$ tissue to $3-4 \mathrm{ml} \cdot \mathrm{min}^{-1} \cdot 100 \mathrm{ml}^{-1}$ tissue.

Tissue flows, when measured during $+G_{\mathrm{x}}$ acceleration, change little up to about $12+G_{\mathrm{x}}$. Above this level, tissue compression may contribute to flow reduction. Peripheral vascular damage can occur when the intravascular pressure (or force) exceeds the tensile strength of the surrounding vascular wall. Small cutaneous blood vessels are ruptured in humans exposed to high levels of $+G_{z}$ acceleration, particularly around the ankles and in areas of the legs not protected by a pressure suit. The areas immediately under the pressure garment are exposed to a static counterpressure that prevents the vessels from rupturing. It is not known if human deep muscle vessels also rupture, but it does not seem likely because of the muscle pressure usually generated to sustain the high levels of $+G_{\mathrm{z}}$.

In summary, with increasing $+G_{\mathrm{z}}$ acceleration, cardiac output falls, stroke volume falls, heart rate increases, arterial pressure at eye level falls while the arterial pressure at the aortic arch increases slightly, cerebral blood flow falls, and the peripheral blood flow decreases. Arterial oxygen saturation decreases because of an increased shunting of blood through the lungs.

\section{Dynamic Responses and Reflex Adjustments}

The hemodynamic responses to $+G_{\mathrm{z}}$ acceleration are similar to those during orthostatic stress and hemorrhage, including a reduction in arterial pressure in the head region. Activation of the arterial baroceptor reflex explains the increase in heart rate and the peripheral vasoconstriction. In 1933 Jongbloed et al. (175) sectioned the carotid sinus nerve and abolished the tachycardia response to $+G_{\mathrm{z}}$ acceleration in experimental animals. Greenfield (125) found that the compensatory rise in arterial pressure during prolonged acceleration did not occur after stripping the carotid sinus region.

Other reflexogenic areas may be involved to either amplify the carotid sinus reflex or attenuate the response (32). Attenuation of the baroceptor response may occur through activation of vagal cardiopulmonary mechanoreceptors and prevent the maximum compensatory effect. Plasma levels of $\mathrm{ADH}$ increase during $+G_{\mathrm{z}}$ acceleration (127), which is consistent with activation of cardiopulmonary receptors. Other recep- 

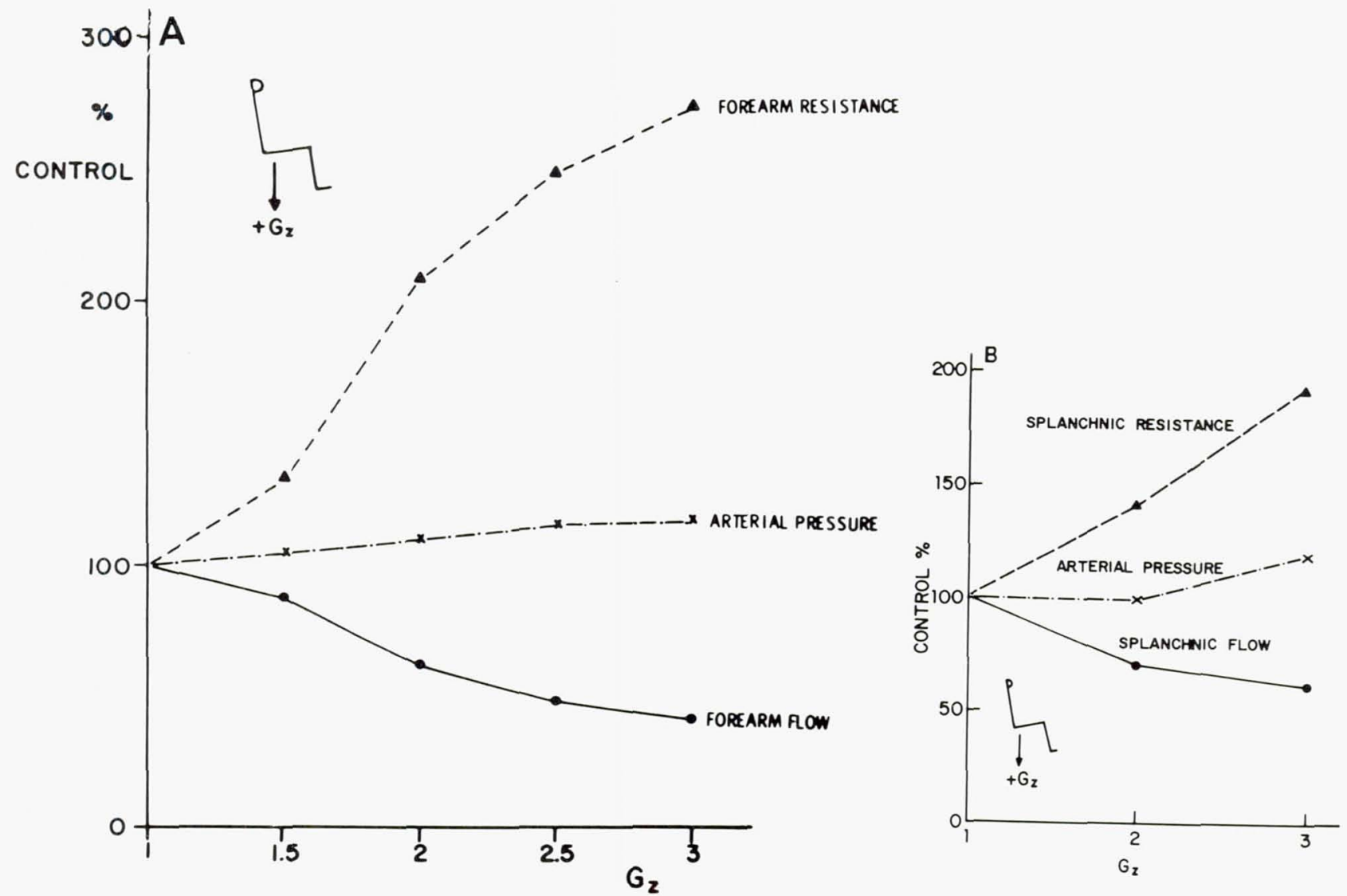

FIG. 15. Average \% change from control in forearm blood flow and resistance $(A)$ and splanchnic flow and resistance $(B)$ in 6 volunteers. Arm suspended at heart level throughout experiments. Arterial pressure was referenced to heart level. [Adapted from Stone et al. (318) and H. L. Stone, unpublished observations.]

tor areas, such as the splanchnic and skeletal muscle regions, could also send afferent information to the central nervous system to modify the overall responses to this type of stress. This area has not been investigated extensively and needs future work.

\section{R E F E R E N C E S}

1. Abboud, F. M., D. L. Eckberg, U. J. Johannsen, and A. L. MARK. Carotid and cardiopulmonary baroceptor control of splanchnic and forearm vascular resistance during venous pooling in man. J. Physiol. London 286: 173-184, 1979.

2. Abboud F. M., A. L. Mark, and M. D. Thames. Modulation of the somatic reflex by carotid baroreceptors and by cardiopulmonary afferents in animals and humans. Circ. Res. 48, Suppl. 1: 131-137, 1981.

3. Abelmann, W. H., and K. Fareeduddin. Circulatory response to upright tilt in patients with heart disease. Aerosp. Med. 38: 60-65, 1967.

4. Aborelius, M., Jr., U. I. Balldin, B. Lilija, and C. E. G. LUNDGREN. Hemodynamic changes in man during immersion with the head above water. Aerosp. Med. 43: 590-592, 1972.

5. Ahmad, M., C. G. Blomqvist, C. B. Mullins, and J. T WILLERSON. Left ventricular function during lower body negative pressure. Aviat. Space Environ. Med. 48: 512-515, 1977.

6. Albright, F., C. H. Burnett, O. Cope, and W. Parsons. Acute atrophy of bone osteoporosis simulating hyperparathyroidism. J. Clin. Endocrinol. 1: 711-716, 1941.
We are indebted to Carolyn Donahue for her expert secretarial assistance. Michelle Anderson (National Aeronautics and Space Administration, Lyndon Baines Johnson Space Center, Houston, TX) provided helpful advice and assistance in locating US government documents and translations of USSR publications.

7. Alexander, R. S. The peripheral venous system. In: Handbook of Physiology. Circulation, edited by W. F. Hamilton. Washington, DC: Am. Physiol. Soc., 1965, sect. 2, vol. II, chapt. 31, p. 1075-1098.

8. Amery, A., H. Bossaert, M. Deruyttere, L. Van der Linden, AND M. VerstraEte. Influence of body posture on leg blood flow. Scand. J. Clin. Lab. Invest. Suppl. 128: 29-36, 1973.

9. Avasthey, P. Venous pressure changes during orthostasis. Cardiovasc. Res. 6: 657-663, 1972.

10. Avasthey, P., C. M. Coulam, and E. H. Wood. Positiondependent regional differences in pericardial pressures. $J$. Appl. Physiol. 28: 622-629, 1970.

11. Avasthey, P., And E. H. Wood. Intrathoracic and venous pressure relationships during responses to changes in body position. J. Appl. Physiol. 37: 166-175, 1974.

12. Balldin, U., C. E. G. Lundgren, J. Lundvall, and S. Mellander. Changes in the elimination of ${ }^{133}$ Xenon from the anterior tibial muscle in man induced by immersion in water and by shifts in body position. Aerosp. Med. 42: 489-493, 1971. 
13. Banchero, N., L. Cronin, W. J. Rutishauser, A. G. TsakIRIS, AND E. H. WOOD. Effects of transverse acceleration on blood oxygen saturation. J. Appl. Physiol. 22: 731-739, 1967.

14. BARR, P. -O. Hypoxemia in man induced by prolonged acceleration. Acta Physiol. Scand. 54: 128-137, 1962.

15. Barr, P. -O., H. Bjurstedt, and J. C. G. Coleridge. Blood gas changes in the anesthetized dog during prolonged exposure to positive radial acceleration. Acta Physiol. Scand. 47: 16-27, 1959 .

16. Bazett, H. C. Studies on the effects of baths on man. I. Relationship between the effects produced and the temperature of the bath. Am. J. Physiol. 70: 412-429, 1924.

17. Bazett, H. C., S. Thurlow, C. Crowell, and W. Stewart. Studies on the effects of baths on man. II. The diuresis caused by warm baths, together with some observations on urinary tides. Am. J. Physiol. 70: 430-452, 1924.

18. Begin R., M. Epstein, M. A. Sackner, R. Levinson, R. Dougherty, AND D. Duncan. Effects of water immersion to the neck on pulmonary circulation and tissue volume in man. J. Appl. Physiol. 40: 293-299, 1976.

19. Bergenwald, L., U. Freyschuss, and T. Sjöstrand. The mechanism of orthostatic and haemorrhagic fainting. Scand. J. Clin. Lab. Invest. 37: 209-216, 1977.

20. Berry, C. A. Medical legacy of Apollo. Aerosp. Med. 45: 10461057,1974

21. BEVEGARD, S. Studies in the regulation of the circulation in man. Acta Physiol. Scand. Suppl. 200: 1-36, 1962.

22. Bevegård, S., U. Freyschuss, and T. Strandell. Circulatory adaptation to arm and leg exercise in supine and sitting position. J. Appl. Physiol. 21: 37-46, 1966.

23. BevegÅRD, S., A. Holmgren, And B. Jonsson. Effect of body position on the circulation at rest and during exercise with special reference to the influence on the stroke volume. Acta Physiol. Scand. 49: 279-298, 1960

24. Bevegård, S., A. Holmgren, and B. Jonsson. Circulatory studies in well trained athletes at rest and during heavy exercise, with special reference to stroke volume and the influence of body position. Acta Physiol. Scand. 57: 26-50, 1963.

25. Beveg̊̊rd, S., B. Jonsson, and I. Karlof. Circulatory response to recumbent exercise and head-up tilting in patients with disturbed sympathetic cardiovascular control (postural hypotension). Acta Med. Scand. 172: 623-636, 1962.

26. BEvegÅRD, S., AND A. Lodin. Postural circulatory changes at rest and during exercise in five patients with congenital absence of valves in the deep veins of the legs. Acta Med. Scand. 172: 21-29, 1962.

27. Bhattacharya, A., C. F. Knapp, E. P. McCutcheon, and A. CORNISH. Oscillating acceleration for the prevention of cardiovascular deconditioning (Abstract). Physiologist 22(4): 10, 1979.

28. Billman, G. E., K. K. Teoh, D. T. Dickey, and H. L. Stone. Horizontal body casting and baroceptor sensitivity: the role of central blood volume shifts in the rhesus monkey (Preprint). Annu. Sci. Meet. Aerosp. Med. Assoc., p. 82-83, 1981.

29. Birkhead, N. C., J. J. Blizzard, J. W. Daly, C. J. Haupt, B. IsSEKUTZ, JR., R. N. Myers, AND K. RoDAHL. Cardiodynamic and metabolic effects of prolonged bed rest with daily recumbent or sitting exercise and with sitting inactivity. Dayton, OH: Wright-Patterson AFB, 1964. (WADD-AMRL-TDR-6461.)

30. Birkhead, N. C., J. J. Blizzard, B. Issekutz, JR., and K. RODAHL. Effect of exercise, standing negative trunk and positive skeletal pressure on bed rest-induced orthostasis and hypercalciuria. Dayton, OH: Wright-Patterson AFB, 1966. (WADD-AMRL-TR-66-6.)

31. Birkhead, N. C., G. J. Haupt, and R. N. Myers. Effect of prolonged bed rest on cardiodynamics. Am. J. Med. Sci. 245: $118-119,1963$.

33. BJure, A., AND H. Laurell. Om abnorma statiska circulations-fenomen och därmed sammanhängande sjukliga symtom. Den arteriella orthostatiska anämien en försummad sjukdomsbild. Uppsala Laekarefoeren. Foerh. 33: 1-23, 1927.
34. Buurstedt, H. G., G. Rosenhamer, and G. Tydén. Acceleration stress and effects of propranolol on cardiovascular responses. Acta Physiol. Scand. 90: 491-500, 1974.

35. Buurstedt, H., G. Rosenhamer, and G. Tydén. Gravitational stress and autonomic cardiac blockade. Acta Physiol. Scand. 96: 526-531, 1976.

36. Buurstedt, H., G. Rosenhamer, and G. Tydén. Lower body negative pressure and effects of autonomic heart blockade on cardiovascular responses. Acta Physiol. Scand. 99: 353-360, 1977.

37. Blomqvist, C. G., J. V. Nixon, R. L. Johnson, JR., And J. H. MitcheLl. Early cardiovascular adaptation to zero gravity simulated by head-down tilt. Acta Astronautica 7: 543-553, 1980.

38. BLotner, H. Effects of prolonged physical inactivity on tolerance of sugar. Arch. Intern. Med. 75: 39-44, 1945.

39. Bogolyubov, V. M., O. D. Anashinin, Z. K. Trushinskiy, V. S. Shashkov, T. P. Shatunina, and F. V. Reva. Effectiveness of isoptin in the prophylaxis of orthostatic instability after hypokinesia (transl. from Russian). Voyenno-Med. Zh. 11: 6466, 1978. (Library of Congress, Sci. Technol. Alert, Abstract 5230.)

40. Bonde-Petersen, F., N. J. Christensen, O. Henriksen, B. Nielsen, C. Nielsen, P. Norsk, L. B. Rowell, T. Sadámoto, G. Suøgaard, K. Skagen, and Y. Suzuki. Aspects of cardiovascular adaptation to gravitational stresses. Physiologist 23 (6): S7-S10, 1980.

41. Bonde-Petersen, F., Y. Suzuki, and T. Sadámoto. Cardiovascular responses to isometric exercise during simulated zero gravity. Physiologist 22(6): S37-S38, 1979.

42. Booth, F. W., AND M. J. Seider. Recovery of skeletal muscle after 3 mo of hindlimb immobilization in rats. J. Appl. Physiol.: Respirat. Environ. Exercise Physiol. 47: 435-439, 1979.

43. Boźović, L., J. Castenfors, and L. Orö. Plasma renin activity in patients with disturbed sympathetic vasomotor control (postural hypotension). Acta Med. Scand. 188: 385-388, 1970.

44. Bradbury, J., and C. Eggleston. Postural hypotension: a report of three cases. Am. Heart J. 1: 73-86, 1925.

45. Brannon, E. W., C. A. Rockwood, and P. Potts. The influence of specific exercises in the prevention of debilitating musculoskeletal disorders: implication in physiological conditioning for prolonged weightlessness. Aerosp. Med. 34: 900906, 1963.

46. Braunwald, E., A. Goldblatt, D. C. Harrison, and D. T. MASON. Studies on cardiac dimensions in intact, unanesthetized man. III. Effects of muscular exercise. Circ. Res. 13: 460467, 1963.

47. Brock, P. J., D. Sciaraffa, and J. E. Greenleaf. Effect of physical training in cool and hot environments on $+\mathrm{G}_{\mathrm{Z}}$ acceleration tolerance in women. Physiologist 22(6): S41-S42, 1979

48. Brooksby, G. A., and D. E. Donald. Dynamic changes in splanchnic blood flow and blood volume in dogs during activation of sympathetic nerves. Circ. Res. 29: 227-238, 1971.

49. Brown, A. M. Cardiac reflexes. In: Handbook of Physiology. The Cardiovascular System. The Heart, edited by R. M. Berne and N. Sperelakis. Bethesda, MD: Am. Physiol. Soc., 1979, sect. 2, vol. I, chapt. 19, p. 677-690.

50. BRowne, M. K., AND J. T. Fitzsimons. Electrocardiographic changes during positive acceleration. Br. Heart J. 21: 23-30, 1959 .

51. Buderer, M. C., J. A. Rummel, E. L. Michel, D. G. MaulDIN, AND C. F. SAwIN. Exercise cardiac output following Skylab Missions: the second manned Skylab Mission. Aviat. Space Environ. Med. 47: 365-372, 1976.

52. Burton, R. R., and W. F. Mackenzie. Cardiac pathology associated with high sustained $+\mathrm{G}_{i}$ : I. Subendocardial hemorrhage. Aviat. Space Environ. Med. 47: 711-717, 1976.

53. Caldini, P., S. Permutt, J. A. Waddell, and R. L. Riley. Effect of epinephrine on pressure, flow, and volume relationships in the systemic circulation of dogs. Circ. Res. 34: 606623, 1974 .

54. Campbell, J. A., And T. A. Webster. Day and night urine 
during complete rest, laboratory routine, light muscular work and oxygen administration. Biochem. J. 15: 660-664, 1921.

55. Caro, G. G., T. J. Pedley, R. C. Schroter, and W. A. Seed. Basic ideas in fluid mechanics: hydrostatic pressure. In: The Mechanics of the Circulation. New York: Oxford Univ. Press, 1978 , p. $32-34$

56. Chase, G. A., C. Grave, and L. B. Rowell. Independence of changes in functional and performance capacities attending prolonged bed rest. Aerosp. Med. 37: 1232-1238, 1966.

57. Chevalier, P. A., J. H. Reed, JR., R. A. Vandenberg, and E. H. Wood. Effect of gravitational and inertial forces on vertical distribution of pulmonary blood flow. Aviat. Space Environ. Med. 49: 768-778, 1978.

58. Chimoskey, J. E. Coronary blood flow and electrocardiogram during headward acceleration in unanesthetized dogs. Aerosp. Med. 41: 1028-1030, 1970.

59. Chobanian, A. V., R. D. Lille, A. Tercyak, and P. Blevins. The metabolic and hemodynamic effects of prolonged bed rest in normal subjects. Circulation 49: 551-559, 1974.

60. Chui, L. A., AND K. R. Castleman. Morphometric analysis of rat muscle fibers following space flight and hypogravity. Physiologist 23(6): S76-S82, 1980.

61. ClaARK, J. H., D. R. Hooker, AND L. H. Weed. The hydrostatic factor in venous pressure measurements. Am. J. Physiol. 109: $166-177,1934$.

62. Clatrk, W. G., D. R. Gordiner, A. K. Mcintyre, and H. JoRGENSON. The effect of positive acceleration on fluid loss from blood to tissue spaces in human subjects on the centrifuge (Abstract). Federation Proc. 5: 17-18, 1946.

63. Cohen, G. H., AND W. K. Brown. Changes in ECG contour during prolonged $+\mathrm{G}_{\mathrm{z}}$ acceleration. Aerosp. Med. 40: 874-879, 1969.

64. Conley, S. B., G. D. Shackelford, and A. M. Robson. Severe immobilization hypercalcemia, renal insufficiency, and calcification. Pediatrics 63: 142-145, 1979.

65. Convertino, V. A., R. Bisson, R. Bates, D. Goldwater, AND H. SANDLER. Effects of antiorthostatic bed rest on the cardiorespiratory responses to exercise. Aviat. Space Environ. Med. 52: 251-255, 1981.

66. Convertino, V., J. Hung, D. Goldwater, R. F. DeBusk. Cardiovascular responses to exercise in middle-aged men after 10 days of bedrest. Circulation 65: 134-140, 1982.

67. Convertino, V. A., H. Sandler, and P. Webb. The effect of an elastic reverse gradient garment on the cardiorespiratory deconditioning following 15-days bed rest (Preprint). Annu. Sci. Meet. Aerosp. Med. Assoc., p. 148-149, 1978.

68. Coulam, C. M., and E. H. Wood. Regional differences in pleural and esophageal pressure in head-up and head-down positions. J. Appl. Physiol. 31: 277-287, 1971.

69. Crawford, M. H., D. H. White, and K. W. Amon. Echocardiographic evaluation of left ventricular size and performance during handgrip and supine and upright bicycle exercise. Circulation 59: 1188-1196, 1979.

70. Culbertson, J. W., R. W. Wilkins, F. J. Ingelfinger, And S. E. BRADLEY. The effects of the upright posture upon hepatic blood flow in normotensive and hypertensive subjects. J. Clin. Invest. 30: 305-311, 1951

71. Cuthbertson, D. P. The influence of prolonged muscular rest on metabolism. Biochem. J. 23: 1328-1345, 1929.

72. Daly, W. J., S. T. Giammona, and J. C. Ross. The pressurevolume relationship of the normal pulmonary capillary bed. $J$. Clin. Invest. 44: 1261-1269, 1965.

73. Dickey, D. T., K. K. Teoh, H. Sandler, and H. L. Stone. Changes in blood volume and response to vaso-active drugs in horizontally casted primates. Physiologist 22(6): S27-S28, 1979.

74. Dietrick, J. E., G. D. Whedon, E. Shorr, V. Toscani, and V. B. Davis. Effects of immobilization on metabolic and physiologic function of normal men. Am. J. Med. 4: 3-35, 1948.

75. Dock, W. The evil sequelae of complete bed rest. J. Am. Med. Assoc. 125: 1083-1085, 1944.
76. Donald, D. E., AND J. T. Shepherd. Cardiac receptors: normal and disturbed function. Am. J. Cardiol. 44: 873-878, 1979.

77. Donaldson, C. L., D. E. McMillan, S. B. Hulley, R. S. HATTNER, AND J. H. BAYERS. The effects of long-term bed rest on mineral metabolism. In: Hypogravic and Hypodynamic Environments, edited by R. H. Murray and M. McCally. Washington, DC: Natl. Aeronaut. Space Admin., 1971, SP-269, p. 249-254.

78. Dowell, R. T., L. A. Sordahl, J. N. Lindsey, H. L. Stone, AND H. H. ERICKson. Heart biochemical response in miniature swine subjected to $+\mathrm{G}_{\mathrm{z}}$ acceleration. Aviat. Space Environ. Med. 46: 1378-1382, 1975.

79. Downing, S. E. Baroreceptor regulation of the heart. In: Handbook of Physiology. The Cardiovascular System. The Heart, edited by R. M. Berne and N. Sperelakis. Bethesda, MD: Am. Physiol. Soc., 1979, sect. 2, vol. I, chapt. 17, p. 621652.

80. Echt, M., J. Düweling, O. H. Gauer, and L. Lange. Effective compliance of the total vascular bed and the intrathoracic compartment derived from changes in central venous pressure induced by volume changes in man. Circ. Res. 34: 61-68, 1974.

81. Echt, M., L. LANGe, AND O. H. Gauer. Changes of peripheral venous tone and central transmural pressure during immersion in a thermoneutral bath. Pfluegers Arch. 352: 211-217, 1974.

82. ECKBERG, D. L. Parasympathetic cardiovascular control in human disease: a critical review of methods and results. Am. J. Physiol. 239 (Heart Circ. Physiol. 8): H581-H592, 1980.

83. EDHolm, O. G. Effect of gravity on the blood pressure of the cat. J. Physiol. London 98: 79-96, 1940.

84. Eisenberg, S., M. F. CAMP, AND M. Horn. Effect of posture and position of the venous sampling site or hematocrit and serum protein concentration. J. Lab. Clin. Med. 61: 755-760, 1963.

85. Ekelund, L. G., And A. Holmgren. Central hemodynamics during exercise. Circ. Res. 20-21, Suppl. I: 33-43, 1967.

86. Engelberg, J., AND A. B. DuBors. Mechanics of pulmonary circulation in isolated rabbit lungs. Am. J. Physiol. 196: 401414, 1959.

87. Epstein, M. Renal effects of head-out water immersion in man: implications for an understanding of volume homeostasis. Physiol. Rev. 58: 529-581, 1978.

88. Epstein, M., R. Levinson, and R. Loutzenhiser. Effects of water immersion on renal hemodynamics in normal man. $J$. Appl. Physiol. 41: 230-233, 1976.

89. Epstein, M., D. S. Pins, AND M. Miller. Suppression of ADH during water immersion in normal man. J. Appl. Physiol. 38: 1038-1044, 1975 .

90. Epstein, M., and T. Saruta. Effect of water immersion on renin-aldosterone and renal sodium handling in normal man. J. Appl. Physiol. 31: 368-374, 1971.

91. Epstein, M., S. J. Shubrooks, L. M. Fishman, and D. C. Duncan. Effects of positive acceleration $\left(+G_{z}\right)$ on renal function and plasma renin in normal man. J. Appl. Physiol. 36: 340-344, 1974.

92. Eipstein, S. E., M. Stampfer, and G. D. Beiser. Role of the capacitance and resistance vessels in vaso-vagal syncope. Circulation 37: 524-533, 1968.

93. Erickson, H. H., H. Sandler, and H. L. Stone. Cardiovascular function during sustained $+\mathrm{G}_{\mathrm{z}}$ stress. Aviat. Space Environ. Med. 47: 750-758, 1976.

94. Ewing, D. J., L. Hume, I. W. Campbell, A. Murray, J. M. M. Neilson, and B. F. Clarke. Autonomic mechanisms in the initial heart rate response to standing. J. Appl. Physiol.: Respirat. Environ. Exercise Physiol. 49: 809-814, 1980.

95. FARHI, L. E., AND D. LinNarsson. Cardiopulmonary readjustments during graded immersion in water at $35^{\circ} \mathrm{C}$. Respir. Physiol. 30: 35-50, 1977.

96. FAsola, A. F., AND B. L. Martz. Peripheral venous renin activity during $70^{\circ}$ tilt and lower body negative pressure. Aerosp. Med. 43: 713-715, 1972. 
97. Ferrario, C. M., S. Takishita, M. P. Lynn, J. E. Szilágyi, and K. B. Brosnihan. Effect of dietary sodium depletion on central and peripheral nervous system mechanisms regulating arterial pressure in the dog. In: Disturbances in Neurogenic Control of the Circulation, edited by F. M. Abboud, H. A Fozzard, J. P. Gilmore, and D. J. Reis. Bethesda, MD: Am. Physiol. Soc., 1981, p. 119-131.

98. Folkow, B., P. Gaskell, and B. A. WaAler. Blood flow through limb muscles during heavy rhythmic exercise. Acta Physiol. Scand. 80: 61-72, 1970.

99. Folkow, B., U. Haglund, M. Jodal, and O. Lundgren. Blood flow in the calf muscle of man during heavy rhythmic exercise. Acta Physiol. Scand. 81: 157-163, 1971.

100. Gaffney, F. A., B. C. Bastian, W. F. Taylor, J. E. Schutte, R. M. Graham, W. A. Pettinger, and C. G. Blomqvist Adrenergic control mechanisms in the mitral valve prolapse syndrome (MVPS) (Abstract). Circulation 62, Suppl. 3: 206, 1980.

101. Gaffney, F. A., W. G. Campbell, E. S. Karlsson, and C. G. BLOMQVist. Sex differences in response to orthostatic stress simulated by lower body negative pressure (Abstract). Clin Res. 26: 232A, 1978.

102. Gaffney, F. A., E. S. Karlsson, W. Campbell, J. E. Schutte, J. V. Nixon, J. T. Willerson, and C. G. BlomQVIST. Autonomic dysfunction in women with mitral valve prolapse syndrome. Circulation 59: 894-901, 1979.

103. Gaffney, F. A., E. R. Thal, W. F. Taylor, B. C. Bastian, J. A. Weigelt, J. M. Atkins, and C. G. Blomqvist. Hemodynamic effects of the medical anti-shock trousers (MAST garment). J. Trauma 21: 931-937, 1981.

104. GaUer, O. The physiological effects of prolonged acceleration. Ger. Aviation Med. 1: 554-583, 1950.

105. Gauer, O. H. Panel discussion. In: Proc. Skylab Life Sci. Symp. Houston, TX: LBJ Space Center, 1974, vol. II. (NASA TM X-58A4.)

106. Gauer, O. H., AND J. P. Henry. Circulatory basis of fluid volume control. Physiol. Rev. 43: 423-481, 1963.

107. Gauer, O. H., AND J. P. Henry. Neurohormonal control of plasma volume. In: Cardiovascular Physiology II, edited by A. C. Guyton and A. W. Cowley. Baltimore, MD: University Park, 1976, vol. 9, p. 145-190. (Int. Rev. Physiol. Ser.)

108. Gauer, O. H., J. P. Henry, AND C. Behn. The regulation of extracellular fluid volume. Annu. Rev. Physiol. 32: 547-595, 1970.

109. Gauer, O. H., And H. L. Thron. Properties of veins in vivo: integrated effects of their smooth muscle. Physiol. Rev. 42(5): 283-303, 1962

110. Gauer, O. H., and H. L. Thron. Postural changes in the circulation. In: Handbook of Physiology. Circulation, edited by W. F. Hamilton. Washington, DC: Am. Physiol. Soc., 1965, sect. 2, vol. III, chapt. 67 , p. 2409-2439

111. Gauer, O., and G. Zuidema. In: Gravitational Stress in Aerospace Medicine. Boston, MA: Little, Brown, 1961, p. 1637.

112. Georgiyevskiy, V. S., L. I. Kakurin, B. S. Katkovskiy, and Yu. A. Senkevich. Maximum oxygen consumption and the functional state of the circulation in simulated zero gravity. In: The Oxygen Regime of the Organism and Its Regulation, edited by N. V. Lauer and A. Z. Kolchinskaya. Kiev, USSR: Naukova Dumka, 1966, p. 181-184. (In English: NTIS JPRS61020.)

113. Gilbert, C. A., L. A. Bricker, W. T. Springfield, JR., P. M. Stevens, and B. H. WarRen. Sodium and water excretion and renal hemodynamics during lower body negative pressure. J. Appl. Physiol. 21: 1699-1704, 1966

114. Gillingham, K. K., AND P. P. CRump. Changes in clinical cardiologic measurements associated with high $+G_{z}$ stress. Aviat. Space Environ. Med. 47: 726-733, 1976.

115. Gilmore, J. P., AND I. H. Zucker. Failure of left atrial distension to alter renal function in the nonhuman primate. Circ. Res. 42: 267-270, 1978
116. Goldwater, D., H. Sandler, and L. Mortgomery. Exercise capacity, hematology, and body composition of females during bed rest Shuttle flight simulation (Preprint). Annu. Sci. Meet. Aerosp. Med. Assoc., p. 146-147, 1978.

117. Gorlin, R., L. S. Cohen, W. C. Elliott, M. D. Klein, and F. J. LANE. Effect of supine exercise on left ventricular volume and oxygen consumption in man. Circulation 32: 361-371, 1965

118. Gow, B. S. Circulatory correlates: vascular impedance, resistance, and capacity. In: Handbook of Physiology. The Cardiovascular System. Vascular Smooth Muscle, edited by D. F. Bohr, A. P. Somlyo, and H. V. Sparks, Jr. Bethesda, MD: Am. Physiol. Soc., 1980, sect. 2, vol. II, chapt. 14, p. 353-408.

119. Granath, A., B. Jonsson, and T. Strandell. Circulation in healthy old men studied by right heart catheterization at rest and during exercise in supine and sitting position. Acta Med. Scand. 176: 425-447, 1964.

120. Granath, A., and T. Strandell. Relationships between cardiac output, stroke volume, and intracardiac pressures at rest and during exercise in supine position and some anthropometric data in healthy old men. Acta Med. Scand. 176: 447-467, 1964.

121. Graveline, D. E., and M. M. Jackson. Diuresis associated with prolonged water immersion. J. Appl. Physiol. 17: 519-524, 1962.

122. Graybiel, A., and B. Clark. Symptoms resulting from prolonged immersion in water: the problem of zero $G$ asthenia. Aerosp. Med. 32: 181-196, 1961.

123. Graybiel, A., E. F. Miller, II, AND J. L. Homick. Experiment M 131. Human vestibular function. In: Biomedical Results From Skylab, edited by R. S. Johnston and L. E. Dietlein. Washington, DC: Natl. Aeronaut. Space Admin., 1977, SP-377, p. 74-103.

124. Green, H. D. Circulatory system: physical principles. In: Medical Physics, edited by O. Glasser. Chicago, IL: Year Book, 1944, vol. 2., p. 228-251.

125. GREENFIELD, A. D. M. Effect of acceleration on cats, with and without water immersion. J. Physiol. London 104: 5P-6P, 1945.

126. Greenleaf, J. E., E. M. Bernauer, L. T. Juhos, H. L. YounG, J. T. MORSE, AND R. W. STALEY. Effects of exercise on fluid exchange and body composition in man during 14-day bed rest. J. Appl. Physiol.: Respirat. Environ. Exercise Physiol. 43: 126-132, 1977.

127. Greenleaf, J. E., P. J. Brock, R. F. Haines, S. A. Rositano, L. D. Montgomery, and L. C. KeIL. Effect of hypovolemia, infusion, and oral rehydration on plasma electrolytes, $\mathrm{ADH}$, renin activity, and $+\mathrm{G}_{\mathrm{z}}$ tolerance. Aviat. Space Environ. Med. 48: 693-700, 1977.

128. Greenleaf, J. E., L. D. Montgomery, P. J. Brock, and W. VAN BEAUMONT. Limb blood flow: rest and heavy exercise in sitting and supine positions in man. Aviat. Space Environ. Med. 50: 702-707, 1979

129. Greenleaf, J. E., E. Shvartz, S. Kravik, and L. C. Keil. Fluid shifts and endocrine responses during chair rest and water immersion in man. J. Appl. Physiol.: Respirat. Environ. Exercise Physiol. 48: 79-88, 1980.

130. Greenleaf, J. E., H. O. Stinnett, G. L. Davis, J. Kollias, AND E. M. BERNAUER. Fluid and electrolyte shifts in women during $+\mathrm{G}_{\mathrm{z}}$ acceleration after 15 days' bed rest. J. Appl. Physiol.: Respirat. Environ. Exercise Physiol. 42: 67-73, 1977.

131. Greenleaf, J. F., E. L. Ritman, P. A. Chevalier, D. J. Sass, AND E. H. Wood. Spatial distribution of pulmonary blood flow in dogs in increased force environments. J. Appl. Physiol.: Respirat. Environ. Exercise Physiol. 44: 384-396, 1978.

132. Greenleaf, J. W., W. van Beaumont, E. M. Bernauer, R. F. Haines, H. Sandler, R. W. Staley, H. L. Young, and J. W. YUSKEN. Effects of rehydration on $+\mathrm{G}_{\mathrm{z}}$ tolerance after 14days bed rest. Aerosp. Med. 44: 715-722, 1973.

133. Grossman, W., E. Braunwald, T. Mann, L. P. Mclaurin, AND L. GREEN. Contractile state of the left ventricle in man as evaluated from end-systolic pressure-volume relations. Circu- 
lation 56: 845-852, 1977.

134. Guyton, A. C., G. G. Armstrong, and P. L. Chipley. Pressure-volume curves of the arterial and venous systems in live dogs. Am. J. Physiol. 184: 253-258, 1956.

135. Guyton, A. C., and F. P. Greganti. A physiologic reference point for measuring circulatory pressures in the dog-particularly venous pressure. Am. J. Physiol. 185: 137-141, 1956.

136. Haddy, F. J., J. B. Scott, and G. J. Grega. Peripheral circulation: fluid transfer across the microvascular membrane. In: Cardiovascular Physiology II, edited by A. C. Guyton and A. W. Cowley. Baltimore, MD: University Park, 1976, vol. 9, p. 63-109. (Int. Rev. Physiol. Ser.)

137. Hagan, R. D., F. J. Diaz, and S.-M. Horvath. Plasma volume changes with movement to supine and standing positions. $J$. Appl. Physiol.: Respirat. Environ. Exercise Physiol. 45: 414418, 1978.

138. Hainsworth, R., AND R. J. Linden. Reflex control of vascular capacitance. In: Cardiovascular Physiology III, edited by A. C. Guyton and D. B. Young. Baltimore, MD: University Park, 1979, vol. 18, p. 69-113. (Int. Rev. Physiol. Ser.)

139. Hamilton, W. F., R. A. Woodbury, and H. T. Harper, Jr. Physiologic relationships between intrathoracic, intraspinal and arterial pressures. J. Am. Med. Assoc. 107: 835-856, 1946.

140. Harlan, J. C., E. E. Smith, and T. Q. Richardson. Pressurevolume curves of systemic and pulmonary circuit. Am. J. Physiol. 213: 1499-1503, 1967.

141. Harrison, T. R. Abuse of rest as a therapeutic means for patients with cardiovascular disease. J. Am. Med. Assoc. 125: 1075-1077, 1944

142. Hedeland, H., J. F. Dymling, and B. Hökfelt. Catecholamines, renin, and aldosterone in postural hypotension. Acta Endocrinol. 62: 399-410, 1969.

143. HeNRIKSEN, O. Local sympathetic reflex mechanism in regulation of blood flow in human subcutaneous adipose tissue. Acta Physiol. Scand. Suppl. 450: 7-48, 1977

144. Henriksen, O., and P. Sejrsen. Local reflex in microcirculation in human skeletal muscle. Acta Physiol. Scand. 99: 1926,1977

145. Henry, J. P., And O. H. Gauer. The influence of temperature upon venous pressure in the foot. J. Clin. Invest. 29: 855-861, 1950.

146. Henry, J., O. Gauer, S. Kety, and K. Kramer. Factors maintaining cerebral circulation during gravitational stress. $J$. Clin. Invest. 30: 292-301, 1951.

147. Henry, J. P., O. L. Slaughter, and T. Greiner. A medical massage suit for continuous wear. Angiology 6: 482-494, 1955.

148. Henry, W. L., S. E. Epstein, J. M. Griffith, R. E. GoldSTEIN, AND D. R. REDWOOD. Effects of prolonged space flight on cardiac function and dimensions. In: Biomedical Results From Skylab, edited by R. S. Johnston and L. F. Dietlein. Washington, DC: Natl. Aeronaut. Space Admin. 1977, SP-377, p. 366-371.

149. Hernandez-Perez, M. J., M. E. Raichle, and H. L. Stone. The role of the peripheral sympathetic nervous system in cerebral blood flow autoregulation. Stroke 6: 284-292, 1975.

150. Hoffler, C. W., and R. L. Johnson. Apollo flight crew cardiovascular evaluation. In: Biomedical Results of Apollo, edited by R. L. Johnson, L. F. Dietlein, and C. A. Berry. Washington, DC: Natl. Aeronaut. Space Admin., 1975, SP-368, p. $227-264$

151. Höjensgard, I. C., And H. Stürup. Static and dynamic pressures in superficial and deep veins of the lower extremity in man. Acta Physiol. Scand. 27: 49-67, 1952.

152. Holmgren, A., And C. O. Ovenfors. Heart volume at rest and during muscular work in the supine and sitting position. Acta Med. Scand. 167: 267-277, 1960.

153. Howard, P. The physiology of positive acceleration. In: $A$ Textbook of Aviation Physiology, edited by J. A. Gillis. London: Pergamon, 1965, p. 603-612.

154. Howard, P., AND J. S. Garrow. Changes in the vascular resistance of the forearm and hand during radial acceleration (Abstract). J. Physiol. London 143: 83P, 1958.
155. Howard, P., and D. H. Glaister. The effects of positive acceleration upon cerebral blood flow (Abstract). J. Physiol. London 171: 39P, 1964.

156. Hung, J., D. Goldwater, V. Convertino, J. McKillop, M. GoRIS, AND R. DEBUSK. Effects of bedrest deconditioning on exercise ventricular function in man (Abstract). Am. J. Car. diol. 47: 477, 1981.

157. Нуатт, K. H. Hemodynamic and body fluid alterations induced by bed rest. In: Hypogravic and Hypodynamic Environments, edited by R. H. Murray and M. McCally. Washington, DC: Natl. Aeronaut. Space Admin., 1971, SP-269, p. 187-209.

158. Hyatt, K. H., and D. A. West. A comparison of antiorthostatic and horizontal bed rest as simulators of weightlessness (Preprint). U.S. Public Health Serv. Prof. Assoc., p. 38, 1976.

159. Hyatt, K. H., AND D. A. West. Reversal of bedrest-induced orthostatic intolerance by lower body negative pressure and saline. Aviat. Space Environ. Med. 48: 120-124, 1977.

160. Iвrahim, M. M. Localization of lesion in patients with idiopathic orthostatic hypotension. Br. Heart J. 37: 868-872, 1975.

161. Ibrahim, M. M., R. C. Tarazi, and H. P. Dustan. Orthostatic hypotension: mechanisms and management. Am. Heart J. 90: 513-520, 1975.

162. Ibrahim, M. M., R. C. Tarazi, H. P. Dustan, and E. L. Bravo. Idiopathic orthostatic hypotension: circulatory dynamics in chronic autonomic insufficiency. Am. J. Cardiol. 34: 288294, 1974

163. Imai, Y. K. SATOH, AND N. TAIRA. Role of the peripheral vasculature in changes in venous return caused by isoproterenol, norepinephrine, and methoxamine in anesthetized dogs. Circ. Res. 43: 553-561, 1978.

164. Issekutz, B., Jr., J. J. Blizzard, N. C. Birkhead, and K. RODAHL. Effect of prolonged bed rest on urinary calcium output. J. Appl. Physiol. 21: 1013-1020, 1966.

165. Johansson, B., and S. Mellander. Static and dynamic components in the vascular myogenic response to passive changes in length as revealed by electrical and mechanical recordings from the rat portal vein. Circ. Res. 36: 76-83, 1975.

166. Johnson, J. M., M. Niederberger, L. B. Rowell, M. M. Eisman, and G. L. Brengelmann. Competition between cutaneous vasodilator and vasoconstrictor reflexes in man. $J$. Appl. Physiol. 35: 798-803, 1973.

167. Johnson, J. M., L. B. Rowell, M. Niederberger, ANd M M. EISMAN. Human splanchnic and forearm vasoconstrictor responses to reductions of right atrial and aortic pressures. Circ. Res. 34: 515-524, 1974

168. Johnson, P. C. The microcirculation, and local and humoral control of the circulation. In: Cardiovascular Physiology II, edited by A. C. Guyton and C. E. Jones. Baltimore, MD: University Park, 1975, vol. 1, p. 163-195. (Int. Rev. Physiol. Ser.)

169. Johnson, P. C. Principles of peripheral circulatory control. In: Peripheral Circulation, edited by P. P. Johnson. New York: Wiley, 1978, p. 111-139.

170. Johnson, P. C., T. B. Driscoll, W. R. Carpentier. Vascular and extravascular fluid volume changes during six days of bed rest. Aerosp. Med. 42: 875-878, 1971 .

171. Johnson, P. C., R. B. Driscoll, and A. D. LeBlance. Blood volume changes. In: Biomedical Results from Skylab, edited by R. S. Johnston and L. F. Dietlein. Washington, DC: Natl. Aeronaut. Space Admin., 1977, SP-377, p. 235-241.

172. Johnson, R. L., G. W. Hoffler, A. E. Nicogossian, S. A. BERGMAN, AND M. M. JACKSON. Lower body negative pressure: third manned Skylab mission. In: Biomedical Results From Skylab, edited by R. S. Johnston and L. F. Dietlein. Washington, DC: Natl. Aeronaut. Space Admin., 1977, SP-377, p. 284-312.

173. Johnston, R. S., And L. F. Dietlein (editors). Biomedical Results From Skylab. Washington, DC: Natl. Aeronaut. Space Admin., 1977, SP-377, $491 \mathrm{p}$.

174. Johnston, R. S., L. F. Dietlein, And C. A. Berry (editors). Biomedical Results of Apollo. Washington, DC: Natl. Aeronaut. Space Admin., 1975, SP-368, 592 p. 
CHAPTER 28: RESPONSE TO STRESS: GRAVITY

175. Jongbloed, J., AND A. K. Noyons. Der Einfluss von Beschleunigungen auf den Kreislaufapparat. Pfluegers Arch. Gesamte Physiol. Menschen Tiere 233: 67-97, 1933.

176. Jonsell, S., AND T. SJöstrand. Herzgrösse und Vitalkapazität bei Schwankungen der Blutverteilung. Acta Physiol. Scand. 3: 49-53, 1941.

177. Kakurin, L. I., V. I. Lobachik, M. Mikhailov, and Yu. A. SENKEVICH. Antiorthostatic hypokinesia as a method of weightlessness simulation. Aviat. Space Environ. Med. 47: 1083-1086, 1976.

178. Katkov, V. E., and V. V. Chestukhin. Blood pressures and oxygenation in different cardiovascular compartments of a normal man during postural exposures. Aviat. Space Environ. Med. 51: 1234-1242, 1980.

179. Katkov, V. E., V. V. Chestukhin, V. A. Lapteva, V. M. Mikhailov, O. Kh. ZyBin, and V. V. UtKin. Central and cerebral hemodynamics of the healthy man during head-down tilting. Aviat. Space Environ. Med. 50: 147-153, 1979.

180. Katkov, V. E., V. V. Chestukhin, L. I. Shefter, A. Z. Troshin, N. S. Zakharova, A. Sokolov, and A. A. Petrov. Short-term immobilization of healthy men: right ventricular function and metabolism during graded exercise. Cor Vasa 21: 61-70, 1979.

181. KatKovskiY, B. S., AND Y. D. Ромyotov. Cardiac output during physical exercises following real and simulated space flight. In: Life Sciences and Space Research XIV, edited by P. A. Sneath. Berlin: Springer-Verlag, 1976, p. 301-305.

182. Keane, T. F. L., and W. G. Fegan. Physiology of the calf veins. Angiology 20: 489-495, 1969.

183. KeIl, L. C., AND S. Ellis. Plasma vasopressin and renin activity in women exposed to bed rest and $+1 \mathrm{G}_{\mathrm{z}}$ acceleration. J. Appl. Physiol. 40: 911-914, 1976.

184. Khokhar, A. M., J. D. H. Slater, M. L. Forsling, and N. M. PAYNE. Effect of vasopressin on plasma volume and renin release in man. Clin. Sci. Mol. Med. 50: 415-424, 1976.

185. KIDD, B. S. L., AND S. M. Lyons. The distensibility of the blood vessels of the human calf determined by graded venous congestion. J. Physiol. London 140: 122-128, 1958.

186. Kirsch, K., L. Röcker, AND H. J. Wicke. Methodological aspects of future cardiovascular research in space. Physiologist 22(6): S11-S14, 1979.

187. Klein, K. E., H. M. Wegmann, and P. Kuklinski. Athletic endurance training-advantage for spaceflight?: the significance of physical fitness for selection and training of spacelab crews. Aviat. Space Environ. Med. 48: 215-222, 1977.

188. Korner, P. I. Central nervous control of autonomic cardiovascular function. In: Handbook of Physiology. The Cardiovascular System. The Heart, edited by R. M. Berne and N. Sperelakis. Bethesda, MD: Am. Physiol. Soc., 1979, sect. 2, vol. I, chapt. 20, p. 691-739.

189. Koubenec, H. J., W. D. Risch, and O. H. Gauer. Effective compliance of the circulation in the upright sitting posture. Pfluegers Arch. 374: 121-124, 1978.

190. Lamb, L. E., R. L. Johnson, and P. M. Stevens. Cardiovascular deconditioning during chair rest. Aerosp. Med. 35: 646$649,1964$.

191. LAmb, L. E., AND P. M. Stevens. Influence of lower body negative pressure on the level of hydration during bed rest. Aerosp. Med. 36: 1145-1151, 1965.

192. Lamb, L. E., P. M. Stevens, and R. L. Johnson. Hypokinesia secondary to chair rest from 4 to 10 days. Aerosp. Med. 36: $755-763,1965$.

193. Lambert, E. H., And E. H. Wood. The problem of blackout and unconsciousness in aviators. Med. Clin. N. Am. 30: 833$844,1946$.

194. Lancaster, M. C., and J. H. Triebwasser. The effect of total body exercise on metabolic, hematologic, and cardiovascular consequences of prolonged bed rest. In: Hypogravic and Hypodynamic Environments, edited by R. H. Murray and M. McCally. Washington, DC: Natl. Aeronaut. Space Admin., 1971 , SP-269, p. 225-248.

195. Lange, L., S. Lange, M. Echt, and O. H. Gauer. Heart volume in relation to body posture and immersion in a thermoneutral bath. Pfluegers Arch. 353: 219-226, 1974.

196. Langou, R. A., S. O. Wolfson, E. G. Olson, and L. S. Cohen. Effects of orthostatic postural changes on myocardial oxygen demands. Am. J. Cardiol. 39: 418-421, 1977.

197. LASSEN, N. A. Cerebral blood flow and oxygen consumption in man. Physiol. Rev. 39: 183-238, 1959.

198. Laughlin, M. H., W. M. Witt, R. N. Whittaker, and E. F. JONES. Coronary blood flow in conscious miniature swine during $+\mathrm{G}_{\mathrm{z}}$ acceleration stress. J. Appl. Physiol.: Respirat. Environ. Exercise Physiol. 49: 462-470, 1980.

199. Leach, C. S., J. I. Leonard, and P. C. Rambaut. Dynamics of weight loss during prolonged space flight. Physiologist 22(6): S61-S62, 1979.

200. Leach, C. S., and P. C. Rambaut. Biochemical responses of the Skylab crewmen. In: Biomedical Results From Skylab, edited by R. S. Johnston and L. F. Dietlein. Washington, DC: Natl. Aeronaut. Space Admin., 1977, SP-377, p. 204-216.

201. LECEROF, H. Influence of body position on exercise tolerance, heart rate, blood pressure, and respiration rate in coronary insufficiency. Br. Heart J. 33: 78-83, 1971.

202. Leonard, J. I., C. S. Leach, and J. A. Rummel. Computer simulation of postural change, water immersion and bed rest: an integrative approach for understanding the space flight response. Physiologist 22(6): S31-S32, 1979.

203. Levine, S. A. Some harmful effects of recumbency in the treatment of heart disease. J. Am. Med. Assoc. 126: 80-84, 1944.

204. Levine, S. A., AND B. Lown. The "chair" treatment of acute coronary thrombosis. Trans. Assoc. Am. Physicians 64: 316$327,1951$.

205. Life, J. S., And B. W. Pince. Role of the autonomic nervous system in the control of heart rate in acceleratively stressed monkeys. Aerosp. Med. 40: 44-48, 1969.

206. Lind, A. R., R. Burse, R. H. Rochelle, J. S. Rinehart, and J. S. Petrofsky. Influence of posture on isometric fatigue. $J$. Appl. Physiol.: Respirat. Environ. Exercise Physiol. 45: 270$274,1978$.

207. Lindberg, E. F., H. W. Marshall, W. F. Sutterer, T. F. MCGuire, AND E. H. Wood. Studies on cardiac output and circulatory pressures in human beings during forward acceleration. Aerosp. Med. 33: 81 91, 1962.

208. Lindberg, E. F., W. F. Sutterer, H. W. Marshall, R. W HEADLEY, AND E. H. Wood. Measurement of cardiac output during headward acceleration using the dye-dilution technique. Aerosp. Med. 31: 817-834, 1960.

209. Linden, R. J. Atrial reflexes and renal function. Am. J. Cardiol. 44: 879-883, 1979.

210. Lindsey, J. N., R. T. Dowell, L. A. Sordahl, H. H. ErickSON, AND H. L. STONE. Ultrastructural effects of $+\mathrm{G}_{\mathrm{z}}$ stress on swine cardiac muscle. Aviat. Space Environ. Med. 47: 505-511, 1976.

211. LoEPPKY, J. A. Cardiorespiratory responses to orthostasis and the effects of propranolol. Aviat. Space Environ. Med. 46: $1164-1169,1975$.

212. Love, D. R., J. Brown, R. H. Chinn, R. H. Johnson, A. F. LEVER, D. M. PARK, AND J. I. S. ROBERTSON. Plasma renin in idiopathic orthostatic hypotension: differential response in subjects with probable afferent and efferent autonomic failure. Clin. Sci. 41: 289-299, 1971.

213. LudBrook, J. Aspects of Venous Function in the Lower Legs. Springfield, IL: Thomas, 1966.

214. Ludbrook, J. The Analysis of the Venous System. Bern: Huber, 1972.

215. MacKenzie, W. F., R. R. Burton, and W. I. Butcher. Cardiac pathology associated with high sustained $+\mathrm{G}_{\mathrm{z}}$. II Stress cardiomyopathy. Aviat. Space Environ. Med. 47: 718725, 1976.

216. MagnaEs, B. Body position and cerebrospinal fluid pressure. I. Clinical studies on the effect of rapid postural changes. $J$. Neurosurg. 44: 687-697, 1976.

217. Magnaes, B. Body position and cerebrospinal fluid pressure. 
II. Clinical studies on orthostatic pressure and the hydrostatic indifferent point. J. Neurosurg. 44: 698-705, 1976.

218. Mancia, G., And D. E. Donald. Demonstration that atria, ventricles, and lungs each are responsible for a tonic inhibition of the vasomotor center in the dog. Circ. Res. 36: 310-318, 1975 .

219. Mancia, G., R. R. Lorenz, and J. T. Shepherd. Reflex control of circulation by heart and lungs. In: Cardiovascular Physiology II, edited by A. C. Guyton and A. W. Cowley. Baltimore, MD: University Park, 1976, vol. 9, p. 111-144. (Int. Rev. Physiol. Ser.)

220. MaréEs, H. DE. Veränderungen des Rumpfblutvolumens bei orthostatischer Kreislaufsofortregulation. I. Eine methode zur Bestimmung der Veränderungen des Rumpfblutvolumens. Aerztl. Forsch. 24: 221-227, 1970.

221. Marées, H. De, and H. Pixberg. Veränderungen des Rumpfblutvolumens bei orthostatischer Kreislaufsofortregulation. II. Beziehung zwischen Rumpfblutvolumenveränderung, Rumpfblutvolumen und Totalblutvolumen. Aerztl. Forsch. 24: 228$233,1970$.

222. Mark, A. L., F. M. Abboud, P. G. Schmid, and D. D. HeisTAD. Reflex vascular responses to left ventricular outflow obstruction and activation of ventricular baroreceptors in dogs. J. Clin. Invest. 52: 1147-1153, 1973.

223. Marshall, R. J., and J. T. Shepherd. Interpretation of changes in "central" blood volume and slope volume during exercise in man. J. Clin. Invest. 40: 375-385, 1961.

224. Matalon, S. V., AND L. E. Farhi. Cardiopulmonary readjustments in passive tilt. J. Appl. Physiol.: Respirat. Environ. Exercise Physiol. 47: 503-507, 1979.

225. MAyerson, H. S. Effect of gravity on the blood pressure of the dog. Am. J. Physiol. 135: 411-418, 1942.

226. MCCALly, M. Plasma volume response to water immersion: implications for space flight. Aerosp. Med. 38: 551-563, 1967.

227. McCally, M., S. A. Pohl, and P. A. Samson, JR. Relative effectiveness of selected space flight deconditioning countermeasures. Aerosp. Med. 39: 722-734, 1968.

228. McCally, M., and C. C. Wunder. Immersion techniques and the evaluation of spaceflight deconditioning countermeasures. In: Hypogravic and Hypodynamic Environments, edited by R. H. Murray and M. McCally. Washington, DC: Natl. Aeronaut. Space Admin., 1971, SP-269, p. 323-344.

229. MCDonald, D. A. Blood Flow in Arteries (2nd ed.). Baltimore, MD: Williams \& Wilkins, 1974.

230. MCMichael, J., AND E. P. Sharpey-Schafer. Cardiac output in man by a direct Fick method: effects of posture, venous pressure change, atropine and adrenaline. Br. Heart J. 6: 3340, 1944.

231. McNamara, H. I., J. M. Sikorski, and H. Clavin. The effects of lower body negative pressure on hand blood flow. Cardiovasc. Res. 3: 284-291, 1969.

232. MEAD, J., AND E. Agostoni. Dynamics of breathing. In: Handbook of Physiology. Respiration, edited by W. O. Fenn and H. Rahn. Washington, DC: Am. Physiol. Soc., 1964, sect. 3., vol. I, chapt. 14, p. 411-427.

233. Melada, G. A., R. H. Goldman, J. A. Luetscher, and P. G. ZAGER. Hemodynamics, renal function, plasma renin, and aldosterone in man after 5 to 14 days of bed rest. Aviat. Space Environ. Med. 46: 1049-1055, 1975.

234. Mellander, S. Interaction of local and nervous factors in vascular control. Angiologica 8: 187-201, 1971.

235. Mellander, S. On the control of capillary fluid transfer by precapillary and postcapillary vascular adjustments. Microvasc. Res. 15: 319-330, 1978.

236. Michel, E. L., J. A. Rummel, C. G. Sawin, M. C. Buderer, AND J. D. LEM. Results from Skylab medical experiment M 171-metabolic activity. In: Biomedical Results From Skylab, edited by R. S. Johnston and L. F. Dietlein. Washington, DC: Natl. Aeronaut. Space Admin., 1977, SP-377, p. 284-312.

237. Miller, P. B., R. L. Johnson, and L. E. Lamb. Effects of moderate physical exercise during four weeks of bed rest on circulatory functions in man. Aerosp. Med. 36: 1077-82, 1965.
238. Mitchell, J. H., L. L. Hefner, and R. G. Monroe. Performance of the left ventricle. Am. J. Med. 53: 481-494, 1972.

239. Moore-EdE, M. C., AND D. A. KAss. Chronic central vascular expansion induces hypokalemia in conscious primates. Physiologist 23(6): S123-S124, 1980.

240. Moskalenko, Y. E., G. B. Weinstein, B. B. Zelikson, T. I. Ivanova, AND Y. Kislyakov. Stability of the intracranial circulation in an altered gravitational field. Aerosp. Med. 45: 860-863, 1974.

241. Murray, R. H., J. Krog, L. D. Carlson, and J. A. Bowers. Cumulative effects of venesection and lower body negative pressure. Aerosp. Med. 38: 243-247, 1967.

242. Murray, R. H., and S. Shropshire. Effect of atropine on circulatory responses to lower body negative pressure and vasodepressor syncope. Aerosp. Med. 41: 717-722, 1970.

243. Murray, R. H., L. J. Thompson, J. A. Bowers, and C. P. AlbRight. Hemodynamic effects of graded hypovolemia and vasodepression syncope induced by lower body negative pressure. Am. Heart J. 76: 799-811, 1968.

244. Murray, R. H., L. J. Thompson, J. A. Bowers, E. F. SteinMETZ, AND C. D. Albright. Hemodynamic effects of hypovolemia in normal subjects and patients with congestive heart failure. Circulation 39: 55-63, 1969.

245. Musshoff, K., And H. Reindell. Zur Röntgenuntersuchung des Herzens in horizontaler und vertikaler Körperstellung. I. Der Einfluss der Körperstellung auf das Herzvolumen. Dtsch. Med. Wochenschr. 81: 1001-1008, 1956.

246. Myrhe, L., U. C. Luft, and M. D. Venters. Responses of athletes and nonathletes to lower body negative pressure and dehydration (Abstract). Med. Sci. Sports Exerc. 8: 53-54, 1976.

247. Newsom, B. D., W. L. Goldenrath, W. R. Winter, and H. SANDLER. Tolerance of females to $+\mathrm{G}_{\mathrm{Z}}$ centrifugation before and after bed rest. Aviat. Space Environ. Med. 48: 327-331, 1977.

248. Nicogossian, A. E., G. W. Hoffler, R. L. Johnson, and R. J. Gowen. Determination of cardiac size from chest roentgenograms following Skylab missions. In: Biomedical Results From Skylab, edited by R. S. Johnson and L. F. Dietlein. Washington, DC: Natl. Aeronaut. Space Admin., 1977, SP-377, p. $400-405$.

249. Nicogossian, A. E., H. Sandler, A. A. Whyte, C. S. Leach, and P. C. Rambaut. Chronological Summaries of United States, European, and Soviet Bed Rest Studies. Washington, DC: Natl. Aeronaut. Space Admin., Biotechnol. Off. Life Sci., 1979.

250. Nixon, J. V., R. G. Murray, C. Bryant, R. L. Johnson, JR., J. H. Mitchell, O. B. Holland, C. Gomez-Sanchez, P. VERGNE-MARINI, AND C. G. BlomQVist. Early cardiovascular adaptation to simulated zero gravity. J. Appl. Physiol: Respirat. Environ. Exercise Physiol. 46: 541-548, 1979.

251. Nixon, J. V., R. G. Murray, P. P. Leonard, J. H. Mitchell, AND C. G. BLOMQVIST. Effects of large variations in preload on left ventricular performance characteristics in normal subjects. Circulation 65: 698-703, 1982.

252. Nolan, A. C., H. W. Marshall, L. Cronin, W. F. Sutterer, AND E. H. WooD. Decreases in arterial oxygen saturation and associated changes in pressures and roentgenographic appearances of the thorax during forward $\left(+\mathrm{G}_{2}\right)$ acceleration. Aerosp. Med. 34: 797-813, 1963.

253. Nylin, G., AND M. Levander. Studies on the circulation with the aid of tagged erythrocytis in a case of orthostatic hypotension (asympathicotonic hypotension). Ann. Intern. Med. 28: 723-746, 1948.

254. ÖBERG, B. The relationship between active constriction and passive recoil of the veins at various distending pressures. Acta Physiol. Scand. 71: 233-247, 1967.

255. ÖBerg, B., AND P. Thorén. Studies on left ventricular receptors signalling in nonmedullated vagal afferents. Acta Physiol. Scand. 85: 145-163, 1972.

256. Oganov, V. S., A. N. Potapov, S. A. Skuratova, and M. A. SHIRVINSKAYA. Variability of physiological properties of rat skeletal muscles at different gravity levels. Physiologist 23(6): 
S71-S75, 1980

257. Paintal, A. S. Vagal sensory receptors and their reflex effects. Physiol. Rev. 53: 159-227, 1973.

258. PaK, Z. P., G. I. Kozyrevskaya, Yu. S. Koloskova, A. I. Grigor'yev, Yu. Ye. Bezumova, and Ye. N. Biryukov. Peculiarities of water-salt metabolism during 120-day hypokinesia (transl. from Russian). Space Biol. Med. 7: 86-91, 1973.

259. Parker, J. O., AND R. B. CASE. Normal left ventricular function. Circulation 60: 4-12, 1979.

260. Pentecost, B. L., D. W. Irving, and J. P. Shillingford. The effects of posture on the blood flow in the inferior vena cava. Clin. Sci. 24: 149-158, 1963.

261. Pestov, I. D., and S. J. Geratewohl. Weightlessness. In: Foundations of Space Biology and Medicine. Ecological and Physiological Bases of Space Biology and Medicine, edited by $\mathrm{M}$. Calvin and O. G. Gazenko. Washington, DC: Natl. Aeronaut. Space Admin., 1975, vol. 2, book 1, p. 305-354.

262. Poliner, L. R., G. J. Dehmer, S. E. Lewis, R. W. Parkey, C. G. Blomgvist, AND J. T. WILlerson. Left ventricular performance in normal subjects: a comparison of the responses to exercise in the upright and supine positions. Circulation 62 : 528-534, 1980.

263. Polinsky, R. J., I. J. Kopin, M. H. Ebert, and V. Weise. Pharmacologic distinction of different orthostatic hypotension syndromes. Neurology 31: 1-7, 1981.

264. Pollack, A., AND E. H. Wood. Venous pressure in the saphenous vein at the ankle in man during exercise and changes in posture. J. Appl. Physiol. 1: 649-662, 1948.

265. Rambaut, P. C., and R. S. Johnston. Prolonged weightlessness and calcium loss in man. Acta Astronautica 6: 1113-1122, 1979.

266. Raven, P. B., G. Pape, W. F. Taylor, F. A. Gaffney, and C. G. Blomqvist. Hemodynamic changes during whole body surface cooling and lower body negative pressure. Aviat. Space Environ. Med. 52: 387-391, 1981

267. Raven, P. B., M. Saito, F. A. Gaffney, J. Schutte, and C G. BLOMQvist. Interactions between surface cooling and LBNP-induced central hypovolemia. Aviat. Space Environ. Med. 51: 497-503, 1980.

268. Reed, J. H., JR., B. F. Burgess, and H. Sandler. Effects on arterial oxygen saturation of positive pressure breathing during acceleration. Aerosp. Med. 35: 238-243, 1964.

269. Risch, W. D., H. J. Koubenec, U. Beckmann, S. LANGe, and O. H. GAUER. The effect of graded immersion on heart volume, central venous pressure, pulmonary blood distribution, and heart rate in man. Pfluegers Arch. 374: 115-118, 1978.

270. Robinson, B. F., S. E. Epstein, G. D. Beiser, and E. BraunWALD. Control of heart rate by the autonomic nervous system. Studies in man on the interrelation between baroreceptor mechanisms and exercise. Circ. Res. 19: 400-411, 1966.

271. Roddie, I. C., J. T. Shepherd, and R. F. Whelan. Reflex changes in vasoconstriction tone in human skeletal muscle in response to stimulation of receptors in a low pressure area of the intrathoracic vascular bed. J. Physiol. London 139: 369376, 1957.

272. Rogge, J. D., A. F. Fasola, and B. L. Martz. Peripheral venous renin levels during $+\mathrm{G}_{\mathrm{z}}$ acceleration. Aerosp. Med. 38: 1024-1028, 1967.

273. Rogge, J. D., W. W. Moore, W. E. Segar, and A. F. Fasola. Effect of $+\mathrm{G}_{\mathrm{z}}$ and $+\mathrm{G}_{\mathrm{x}}$ acceleration on peripheral venous $\mathrm{ADH}$ levels in humans. J. Appl. Physiol. 23: 870-874, 1967.

274. RoKhlenKo, K. D., AND P. YA. MUL'DiYaRov. Ultrastructure of the myocardium of rats flown aboard the Cosmos-936 biosatellite. Space Biol. Aerosp. Med. 1: 112-118, 1981.

275. RosenHAMER, G. Influence of increased gravitational stress on the adaptation of cardiovascular and pulmonary function to exercise. Acta Physiol. Scand. Suppl. 276: 1-61, 1967.

276. Ross, J, JR., J. H. Gault, D. T. Mason, J. W. Linhart, and E. BRAUNWALD. Left ventricular performance during muscular exercise in patients with and without cardiac dysfunction Circulation 34: 597-608, 1966.

277. Rothe, C. F. Reflex control of the veins in cardiovascular function. Physiologist 22(2): 28-35, 1979.

278. Rowell, L. B. The splanchnic circulation. In: Peripheral Circulations, edited by R. Zelis. New York: Grune \& Stratton, 1975, p. 163-192.

279. Rowell, L. B. Reflex control of the cutaneous vasculature. $J$ Invest. Dermatol. 69: 154-166, 1977.

280. Rowell, L. B., J. R. Detry, J. R. Blackmon, and C. Wyss. Importance of the splanchnic vascular bed in human blood pressure regulation. J. Appl. Physiol. 32: 213-220, 1972.

281. Rowell, L. B., L. Hermansen, and J. R. Blackmon. Human cardiovascular and respiratory responses to graded muscle ischemia. J. Appl. Physiol. 41: 693-701, 1976.

282. Rowell, L. B., C. R. Wyss, and G. L. Brengelmann. Sustained human skin and muscle vasoconstriction with reduced baroceptor activity. J. Appl. Physiol. 34: 639-643, 1973.

283. Rummel, J. A., C. F. Sawin, and E. L. Michel. Exercise response. In: Biomedical Results of Apollo, edited by R. S. Johnston, L. F. Dietlein, and C. A. Berry. Washington, DC: Natl. Aeronaut. Space Admin., 1975, SP-368, p. 265-275.

284. RUSHMER, R. F. The nature of intraperitoneal and intrarectal pressures. Am. J. Physiol. 147: 242-249, 1946.

285. Rushmer, R. F. Postural effects on the baselines of ventricular performance. Circulation 20: 897-905, 1959.

286. SAGAWA, K. The ventricular pressure-volume diagram revisited. Circ. Res. 43: 677-694, 1978.

287. Saltin, B., G. Blomqvist, J. H. Mitchell, R. L. Johnson, JR., K. Wildenthal, and C. B. Chapman. Response to exercise after bed rest and after training. A longitudinal study of adaptive changes in oxygen transport and body composition. Circulation Suppl. 7: 1-78, 1968.

288. Saltin, B., J. Henriksson, E. NygaARd, ANd P. Andersen Fiber types and metabolic potentials of skeletal muscles in sedentary man and endurance runners. Ann. NY Acad. Sci. 301: 3-29, 1977.

289. Samueloff, S. L., N. L. Browse, and J. T. Shepherd. Response of capacity vessels in human limbs to head-up tilt and suction on lower body. J. Appl. Physiol. 21: 47-54, 1966.

290. SANDLER, H. Angiographic and hemodynamic study of transverse $\left(\mathrm{G}_{\mathrm{x}}\right)$ acceleration. Aerosp. Med. 37: 901-910, 1966.

291. SANDLER, H. Low-G simulation in mammalian research. Physiologist 22(6): S19-S24, 1979.

292. Sandler, H., R. Popp, and E. P. McCutcheon. Echocardiographic studies of bed rest induced changes during LBNP (Preprint). Annu. Sci. Meet. Aerosp. Med. Assoc., p. 242-243, 1977.

293. Sannerstedt, R., S. Julius, and J. Conway. Hemodynamic responses to tilt and $\beta$-adrenergic blockade in young patients with borderline hypotension. Circulation 42: 1057-1064, 1970.

294. Schmid, P. G., M. McCally, T. E. Piemme, and J. A. Shaver. Effects of bed rest on forearm vascular responses to tyranine and norepinephrine. In: Hypogravic and Hypodynamic Environments, edited by $\mathrm{R}$. H. Murray and M. McCally. Washington, DC: Natl. Aeronaut. Space Admin., 1971, SP-269, p. 211223.

295. Selkurt, E. E. The renal circulation. In: Handbook of Phys iology. Circulation, edited by W. F. Hamilton. Washington, DC: Am. Physiol. Soc., 1963, sect. 2, vol. II, chapt. 43, p. 14571516

296. Sharma, B., J. F. Goodwin, M. J. Raphael, R. E. Steiner, R. G. RAINBOW, AND S. H. TAYLOR. Left ventricular angiography on exercise. A new method of assessing left ventricular function in ischaemic heart disease. Br. Heart J. 38: 59-70, 1976 .

297. Shepherd, J. T., And P. M. Vanhoutte. Veins and Their Control. Philadelphia, PA: Saunders, 1975, 269 p.

298. Shepherd, J. T., and P. M. Vanhoutte. The Human Cardiovascular System. Facts and Concepts. New York: Raven, 1979, $351 \mathrm{p}$.

299. Shoukas, A. A., And K. Sagawa. Total systemic vascular compliance measured as incremental volume-pressure ratio. Circ. Res. 28: 277-289, 1971.

300. Shubrooks, S. J., Jr. Changes in cardiac rhythm during 
sustained high levels of positive $\left(+\mathrm{G}_{z}\right)$ acceleration. Aerosp. Med. 43: 1200-1206, 1972.

301. Shubrooks, S. J., Jr., J. W. Burns, and H. H. Erickson. Coronary hemodynamics during positive $\left(+\mathrm{G}_{\mathrm{z}}\right)$ acceleration. Aviat. Space Environ. Med. 46: 413-418, 1975.

302. Shulzhenko, E. B., V. E. Panfilov, K. I. Gogolev, and E. A. Aleksandrova. Comparison of physiological effects of head-down tilting and immersion of the human body. Aviat. Space Environ. Med. 50: 1020-1022, 1979.

303. Shulzhenko, E. B., I. F. Vil-Vilyans, A. I. Gregor'yev, K. I. Gololev, And M. A. Khudyakov. Prevention of human deconditioning during prolonged immersion in water. In: Life Sciences and Space Research XV, edited by P. H. A. Sneath. Oxford, UK: Pergamon, 1977, p. 219-224.

304. Shy, G. M., AND G. A. Drager. A neurological syndrome associated with orthostatic hypotension. Arch. Neurol. 2: $511-$ $527,1960$.

305. Sjöstrand, T. Volume and distribution of blood and their significance in regulating the circulation. Physiol. Rev. 33: 202$228,1953$.

306. SJöstrand, T. Blood volume. In: Handbook of Physiology. Circulation, edited by W. F. Hamilton. Washington, DC: Am. Physiol. Soc., 1962, sect. 2, vol. I, chapt. 4, p. 51-62.

307. SJöstrand, T. The regulation of the blood volume distribution in man. Acta Physiol. Scand. 26: 312-327, 1962.

308. Smith, E. E., AND A. C. GUYton. Center of arterial pressure regulation during rotation of normal and abnormal dogs. Am. J. Physiol. 204: 979-982, 1963.

309. Stead, E. A., J. V. Warren, A. J. Merril, and E. S. BranNON. Cardiac output in male subjects as measured by the technique of right heart catheterization. Normal values with observations on the effects of anxiety and tilting. J. Clin. Invest. 24: 326-331, 1945.

310. Stegemann, J., A. Busert, and D. Brock. Influence of fitness in the blood pressure control system in man. Aerosp. Med. 45: $45-48,1974$.

311. Stein, R. A., D. Michielli, E. L. Fox, and N. Krasnow. Continuous ventricular dimensions in man during supine exercise and recovery. Am. J. Cardiol. 41: 655-660, 1978.

312. Steiner, S. H., ANd G. C. E. Mueller. Pulmonary arterial shunting in man during forward acceleration. J. Appl. Physiol. 16: 1081-1086, 1961.

313. Stevens, P. M., And T. N. Lynch. Effects of 9-alphafluorohydrocortisone on dehydration due to prolonged bed rest. Aerosp. Med. 36: 1151-1156, 1965.

314. Stevens, P. M., T. N. Lynch, C. A. Gilbert, R. L. Johnson, AND L. E. LAMB. Potential uses of lower body negative pressure as an anti-deconditioning measure during weightlessness (Preprint). Annu. Sci. Meet. Aerosp. Med. Assoc., p. 160-161, 1966.

315. Stevens, P. M., T. N. Lynch, R. L. Johnson, And L. E. LAMB. Effects of 9-alphafluorohydrocortisone and venous occlusive cuffs on orthostatic deconditioning of prolonged bed rest. Aerosp. Med. 37: 1049-1056, 1966.

316. Stevens, P. M., P. B. Miller, C. A. Gilbert, T. N. Lynch, R. L. Johnson, AND L. E. LAMB. Influence of long-term lower body negative pressure on the circulatory function of man during prolonged bed rest. Aerosp. Med. 37: 357-367, 1966.

317. Stevens, P. M., P. B. Miller, and T. N. Lynch. Effects of lower body negative pressure on physiologic changes due to four weeks of hypoxic bed rest. Aerosp. Med. 37: 466-474, 1966.

318. Stone, H. L. Cardiac response to acceleration stress. II. Results in human volunteers and experimental animals. Aerosp. Med. 6: 313-324, 1967.

319. Stone, H. L., AND W. C. Alexander. Abdominal blood flow changes during acceleration stress in anesthetized dogs. Aerosp. Med. 39: 115-119, 1968.

320. Stone, H. L., L. A. Sordahl, R. T. Dowell, J. N. Lindsey, AND H. H. ERICKSON. Coronary flow and myocardial biochemical responses to high sustained $+\mathrm{G}_{\mathrm{z}}$ acceleration. AGARD Conf. Proc. 189: A5-1-A5-8, 1976.

321. Stone, H. L., H. F. Stegall, M. B. Kardon, H. SandleR, AND R. M. PAYNe. Changes in aortic, coronary, and carotid flows during $+\mathrm{G}_{\mathrm{x}}$ acceleration. J. Appl. Physiol. 30: 21-26, 1971.

322. Stone, H. L., B. H. Warren, and H. Wagner, Jr. The distribution of pulmonary blood flow in human subjects during zero-G. AGARD Conf. Proc. 2: 129-148, 1965.

323. Stremel, R. W., V. A. Convertino, E. M. Bernauer, and J. E. Greenleaf. Cardiorespiratory deconditioning with static and dynamic leg exercise during bed rest. J. Appl. Physiol. 41: 905-909, 1976.

324. Suga, H., AND K. Sagawa. Instantaneous pressure-volume relationships and their ratio in the excised, supported canine left ventricle. Circ. Res. 35: 117-126, 1974.

325. Szilágyi, T., Á. Szöör, Ö Takács, M. Rapcsák, V. S. Oganov, S. A. Skuratova, S. S. Oganesyan, L. M. Murashro, and M. A. Eloyan. Study of contractile properties and composition of myofibrillar proteins of skeletal muscles in the Cosmos-1129 experiment. Physiologist 23(6): S67-S70, 1980.

326. Taylor, H. L., L. Erickson, A. Henschel, and A. Keys. The effect of bed rest on the blood volume of normal young men. Am. J. Physiol. 144: 227-232, 1945.

327. Taylor, H. L., A. Henschel, J. BrožEK, and A. Keys. Effects of bed rest on cardiovascular function and work performance. J. Appl. Physiol. 2: 223-239, 1949.

328. Thadani, U., and J. O. Parker. Hemodynamics at rest and during supine and sitting bicycle exercise in normal subjects. Am. J. Cardiol. 41: 52-59, 1978.

329. Thadani, U., R. O. West, T. M. Mathew, and J. O. Parker. Hemodynamics at rest and during supine and sitting bicycle exercise in patients with coronary artery disease. Am. J. Cardiol. 39: 776-783, 1977.

330. Thompson, F. K., And C. B. Barnes. Projection of low venous afferent fibers to the spinal cord. Brain Res. 177: 561-565, 1979.

331. Thompson, F. K., K. A. Fields, and D. N. Lerner. Projection of limb venous afferents to the motor sensory cortex. J. Auton. Nerv. Syst. 2: 39-45, 1980.

332. Thompson, W. O., P. K. Thompson, and M. E. Dailey. The effect of posture upon the composition and volume of the blood in man. J. Clin. Invest. 5: 573-604, 1928.

333. ThorÉn, P. Role of cardiac vagal C-fibers in cardiovascular control. Rev. Physiol. Biochem. Pharmacol. 86: 1-94, 1979.

334. Thorén, P., and S. E. Ricksten. Cardiac C-fiber endings in cardiovascular control under normal and pathophysiological conditions. In: Disturbances in Neurogenic Control of the Circulation, edited by F. M. Abboud, H. A. Fozzard, J. P. Gilmore, and D. J. Reis. Bethesda, MD: Am. Physiol. Soc., 1981 , p. $17-31$.

335. Thornton, W. E., G. W. Hoffler, and J. A. Rummel. Anthropometric changes and fluid shifts. In: Biomedical Results From Skylab, edited by R. S. Johnston and L. F. Dietlein. Washington, DC: Natl. Aeronaut. Space Admin., 1977, SP-377, p. $330-338$.

336. Thornton, W. E., And J. ORD. Physiological mass measurements in Skylab. In: Biomedical Results From Skylab, edited by R. S. Johnston and L. F. Dietlein. Washington, DC: Natl. Aeronaut. Space Admin., 1977, SP-377, p. 175-182.

337. TobIas, C. A., AND Y. G. GRIGor'Yev. Ionizing radiation. In: Foundations of Space Biology and Medicine. Ecological and Physiological Bases of Space Biology and Medicine, edited by M. Calvin and O. G. Gazenko. Washington, DC: Natl. Aeronaut. Space Admin., 1975, SP-374, vol. II, book 2, p. 473531.

338. TORPHy, D. E. Effects of short-term bed rest and water immersion of plasma volume and catecholamine response to tilting. Aerosp. Med. 37: 383-387, 1966.

339. Vandenberg, R. A., A. C. Nolan, J. H. Reed, Jr., and E. H. WooD. Regional pulmonary arterial-venous shunting caused by gravitational and inertial forces. J. Appl. Physiol. 25: 516$527,1968$.

340. Vogt, F. B. Tilt table and plasma volume changes with short term deconditioning experiments. Aerosp. Med. 38: 564-568, 1967. 
341. Vogt, F. B., P. B. Mack, AND P. C. Johnson. Tilt table response and blood volume changes associated with 30 days of recumbency. Aerosp. Med. 37: 771-777, 1966.

342. Vogt, F. B., P. B. Mack, P. C. Johnson, and L. Wade, JR. Tilt table response and blood volume changes associated with fourteen days of recumbency. Aerosp. Med. 38: 43-48, 1967.

343. Volicer, L., R. Jean-Charles, and A. V. Chobanian. Effect of head-down tilt on fluid and electrolyte balance. Aviat. Space Environ. Med. 47: 1065-1068, 1976.

344. Wagner, H. N. Orthostatic hypotension. Bull. Johns Hopkins Hosp. 105: 322-359, 1959

345. Wang, Y. R., R. J. Marshall, and J. T. Shepherd. The effect of changes in posture and of graded exercise on stroke volume in man. J. Clin. Invest. 39: 1051-1061, 1960.

346. WATSON, J. F., AND R. M. RAPP. Effect of forward acceleration on renal function. J. Appl. Physiol. 17: 413-416, 1962.

347. Weber, K. T., J. S. Janicki, S. Shroff, and A. P. Fishman. Contractile mechanics and interactions of the right and left ventricles. Am. J. Cardiol. 47: 686-695, 1981.

348. Weiss, J. L., M. L. Weisfeldt, S. J. Mason, J. B. Garrison, S. V. Livengood, AND N. J. Fortuin. Evidence of FrankStarling effect in man during severe semisupine exercise. Circulation 59: 655-661, 1979.

349. Weissler, A. M., J. J. Leonard, and J. V. Warren. Effects of posture and atropine on the cardiac output. J. Clin. Invest. 36: 1656-1662, 1957.

350. Wennergren, G. Aspects of central integrative and efferent mechanisms in cardiovascular reflex control. Acta Physiol. Scand. Suppl. 428: 1-53, 1975.

351. Werkö, L., H. Bucht, AND B. Josephson. The renal extraction of PAH and oxygen in man during functional changes of the circulation. Scand. J. Clin. Lab. Invest. 1: 321-327, 1949.

352. WEST, J. B. Influence of hydrostatic pressure on the pulmonary circulation. Jpn. Heart J. 7: 350-368, 1966.

353. Whittle, M. W., R. Herron, and J. Cuzzi. Biostercometric analysis of body form. In: Biomedical Results From Skylab, edited by R. S. Johnston and L. F. Dietlein. Washington, DC: Natl. Aeronaut. Space Admin., 1977, SP-377, p. 198-203.

354. Wilkins, R. W., J. W. Culbertson, ANd F. J. Ingelfinger.
The effect of splanchnic sympathectomy in hypertensive patients upon estimated hepatic blood flow in the upright as contrasted with the horizontal position. J. Clin. Invest. 30: 312-317, 1951.

355. Wolthuis, R. A., S. A. Bergman, and A. E. Nicogossian. Physiological effects of locally applied reduced pressure in man. Physiol. Rev. 54: 566-595, 1974.

356. Wood, E. H., A. C. Nolan, D. E. Donald, and L. Cronin. Influence of acceleration on pulmonary physiology. Federation Proc. 22: 1024-1034, 1963.

357. Wood, E. H., W. F. Sutterer, H. W. Marshall, F. F. LiNDBERG, AND R. N. HEADly. Effect of Headward and Footward Accelerations on the Cardiovascular System. Dayton, OH: Wright-Patterson AFB, 1961, p. 1-48. (WADD Tech. Rep. 60-634.)

358. Wyss, C. R. Systemic Pressure-Volume Relationships in the Dog: Linearity, Low Frequency Dynamic Behavior, Effect of Capillary Filtration, and Effect of Active Changes in Splenic Volume. Seattle, WA: Univ. of Washington, 1977. Dissertation.

359. Yegorov, A. D. Results of Medical Studies During LongTerm Manned Flights on the Orbital Salyut-6 and Soyuz Complex (transl. from Russian). Moscow: Acad. Sci., Minist. Public Health, Inst. Med. Biol. Probl., 1979. (NASA TM76014.)

360. Yu, P. N. Pulmonary Blood Volume in Health and Disease. Philadelphia, PA: Lea \& Febiger, 1969.

361. Ziegler, M. G., C. R. Lake, and I. J. Kopin. The sympathetic nervous system defect in primary orthostatic hypotension. $N$. Engl. J. Med. 296: 293-297, 1977.

362. Zoller, R. P., A. L. Mark, F. M. Abboud, P. G. Schmidt, AND D. D. HEISTAD. Role of low pressure baroceptors in reflex vasoconstrictor responses in man. J. Clin. Invest. 51: 29672972,1972

363. ZsOTÉr, T., AND R. F. P. CRONIN. Venous distensibility in patients with varicose veins. Can. Med. Assoc. J. 94: 1293$1297,1966$.

364. Zuidema, G. D., S. I. Cohen, A. J. Silverman, and M. D. RILEY. Human tolerance to prolonged acceleration. J. Aviat. Med. 27: 469-481, 1956. 